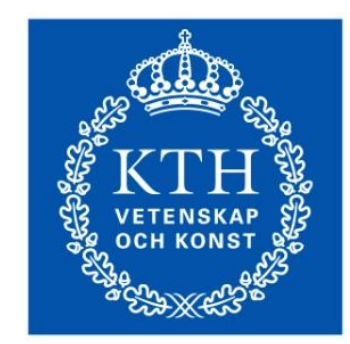

KTH Industrial Engineering

and Management

\title{
ASSESSMENT OF POLLUTION LEVELS RESULTING FROM BIOMASS GASIFICATION
}

\author{
Emmanuel Menya \\ 821123A231 \\ Supervisors: \\ Dr. Peter Hagström \\ Assoc. Prof. Mackay Okure \\ Mr. Joseph Olwa
}

Submitted in partial fulfillment of the requirements for the award of the degree of Master of Science in Mechanical Engineering with specialization in Sustainable Energy Engineering

\section{M.Sc. Thesis Report} 2012

Master of Science Thesis Energy Technology EGI-2012-044MSC EKV893

KTH School of Industrial Engineering and Management

Department of Energy Technology

Division of Heat and Power Technology

SE-100 44 STOCKHOLM 


\section{ACKNOWLEDGEMENT}

I extend my sincere appreciation to SIDA for the scholarship support awarded to me for the academic period 2008/2010 that enabled me to pursue the Master of Science in Mechanical Engineering with specialization in Sustainable Energy Engineering at the Royal Institute of Technology, KTH.

To my supervisors; Dr. Peter Hagström of KTH, Assoc. Prof. Mackay Okure and Mr. Joseph Olwa of Makerere University, I am indeed very grateful for all your technical guidance you always rendered to me while pursuing the research.

Special thanks also go to Mr. Andrew Wabwire of Mechanical Engineering Department, Makerere University for the technical assistance rendered to me regarding the project.

To the management of SGS Ltd in Mombasa particularly Ms. Sarah Wakesho and Mr. Edwin Senengo, your technical assistance rendered to me while using the GC/MSD machine to analyze the condensates was indeed a turning point to the accomplishment of this research.

Lastly I convey my sincere appreciation to my dear parents (i.e. Mr. and Mrs. Semugabi Semei) and colleagues of DSEE, Makerere University for the encouragement they always gave me while pursuing the Masters degree program.

God bless you all. 


\begin{tabular}{|c|c|c|}
\hline 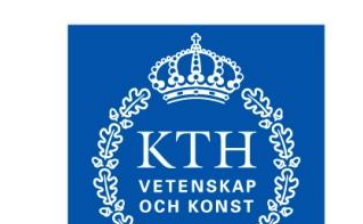 & \multicolumn{2}{|c|}{$\begin{array}{c}\text { Master of Science Thesis EGI-2012-044MSC EKV893 } \\
\text { Assessment of Pollution Levels } \\
\text { resulting from Biomass Gasification }\end{array}$} \\
\hline \multicolumn{3}{|c|}{ Emmanuel Menya (821123A231) } \\
\hline $\begin{array}{l}\text { Approved } \\
24^{\text {th }} \text { August, } 2012\end{array}$ & $\begin{array}{l}\text { Examiner } \\
\text { Assoc. Prof. Andrew Martin }\end{array}$ & $\begin{array}{l}\text { Supervisor } \\
\text { Dr. Peter Hagström } \\
\text { Assoc. Prof. Mackay Okure } \\
\text { Mr. Joseph Olwa }\end{array}$ \\
\hline & $\begin{array}{l}\text { Commissioner } \\
\text { Dr. Adam Sebbit }\end{array}$ & $\begin{array}{l}\text { Contact person } \\
\text { Mr. Emmanuel Menya }\end{array}$ \\
\hline
\end{tabular}

\section{ABSTRACT}

Today the large scale introduction of biomass gasification is hampered by health, and environmental issues which present a major barrier in the deployment of this technology. The condensate in particular resulting from producer gas cooling before use in gas engines is highly toxic and carcinogenic which, if not adequately controlled, can lead to detrimental impacts on human health and the environment. The study was therefore aimed at assessment of pollution levels resulting from biomass gasification organic condensates. The study involved assessing the concentration of polycyclic aromatic hydrocarbons (PAHs) and BTEX (i.e. benzene, toluene, ethylbenzene and xylene) in the condensate deemed toxic and carcinogenic, mention their impact on human health and the environment as well as recommend measures aimed at minimizing pollution levels resulting from biomass gasification.

The gasifier installation at Makerere University was run in downdraft mode using maize cobs as biomass fuel. The producer gas was cooled using a water cooled condenser connected to the exhaust pipe of the gasifier. The condensate was then transferred into sampling bottles made of opaque glass to minimize photochemical reactions in water samples and preserved in a cooler at $2^{\circ} \mathrm{C}$ to $6^{\circ} \mathrm{C}$ until the time for analysis to minimize volatilization and bacterial degradation of the hydrocarbons. The capillary gas chromatography with mass spectrometric detector (CGCMSD) was used to analyze the condensate for the selected hydrocarbons.

The procedures involved preparation of PAHs and BTEX standard solutions using standard mixtures and internal standards, calibration of the CGCMSD, extraction of the aromatic hydrocarbons using hexane, performing a surrogate analysis to 
assess percent recoveries and injecting a $2 \mu \mathrm{l}$ aliquot of the final solution of each test sample in a CGCMSD for analysis. Identification of targeted hydrocarbons was based on the retention time match and mass spectra match against the calibration standards while quantitation was done by use of internal standards.

The average concentration of naphthalene was $204.3 \mathrm{mg} / \mathrm{m}^{3}$, benzene- 16.8 $\mathrm{mg} / \mathrm{m}^{3}$, toluene- $105.5 \mathrm{mg} / \mathrm{m}^{3}$, ethylbenzene- $200.9 \mathrm{mg} / \mathrm{m}^{3}$, 1,2-dimethyl benzene$209.5 \mathrm{mg} / \mathrm{m}^{3}$ and 1,3+1,4-dimethyl benzene-790.4 $\mathrm{mg} / \mathrm{m}^{3}$. Acenaphthylene, acenaphthene, fluorene, phenanthrene and anthracene were not detected in the condensate by the CGCMSD due to their concentration levels being below the detection limit of the CGCMSD. The concentrations of naphthalene and xylene were considerably high compared to the recommended permissible exposure limits thus posing risks on both human health and the environment. It is therefore important to treat the condensate before disposal to the environment. On the other hand, the concentrations of benzene, toluene and ethylbenzene were below the permissible exposure limit and therefore for this study, the liquid effluent was considered to meet the regulatory standards. The recommendations aimed at minimizing pollution levels during biomass gasification were also discussed.

Keywords: producer gas cooling, condensate, PAHs, BTEX, CGCMSD, carcinogenic, toxic 


\section{Table of Contents}

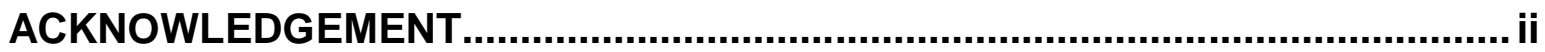

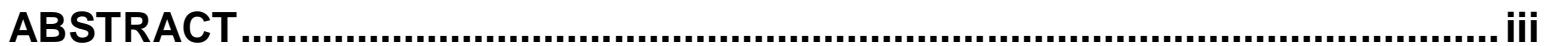

LIST OF ACRONYMS AND ABBREVIATIONS............................................. viii

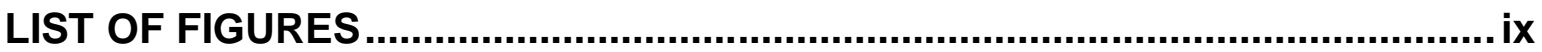

LIST OF TABLES

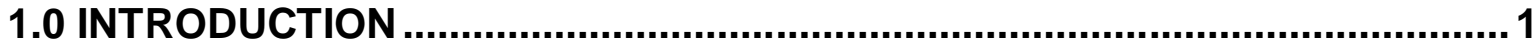

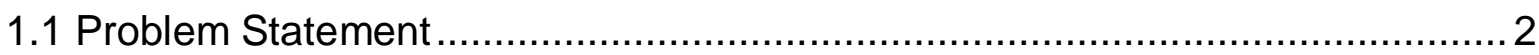

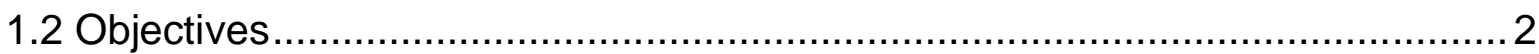

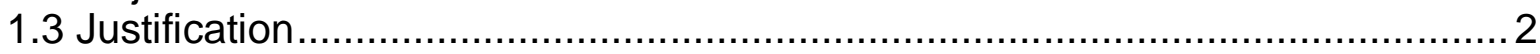

1.4 Scope

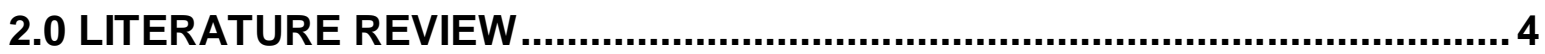

2.1 Condensate accumulation points in biomass gasification plants .................... 4

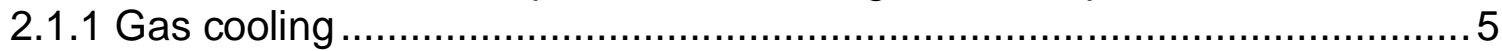

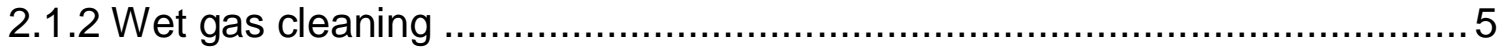

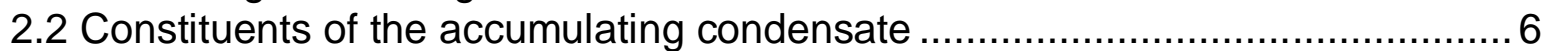

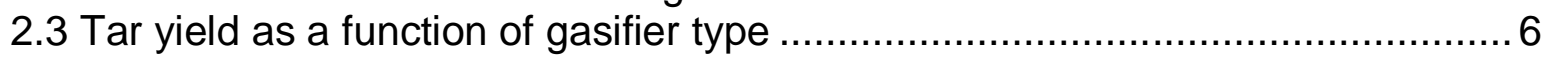

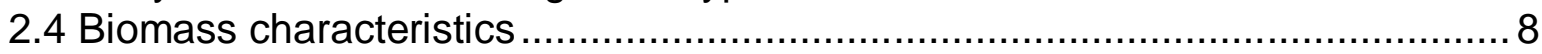

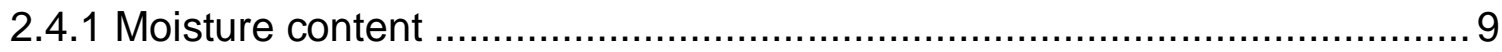

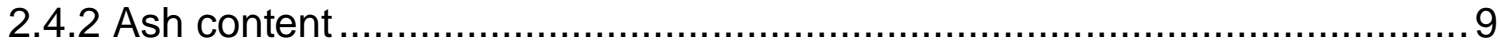

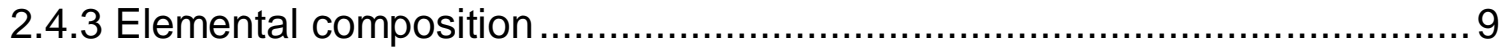

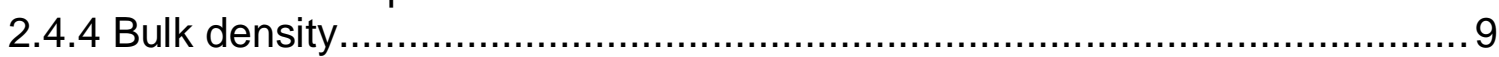

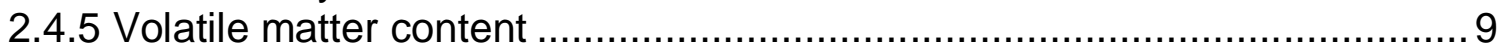

2.5 Gasification Operating Parameters....................................................... 10

2.5.1 Superficial velocity, $V_{\mathrm{s}}$ or specific gas production rate, SGPR …............ 10

2.5.2 Fuel consumption and gas production rate ....................................... 10

2.6 Analysis of aromatic hydrocarbons using CGCMSD ..................................11

2.7 Health and environmental effects associated with selected aromatic

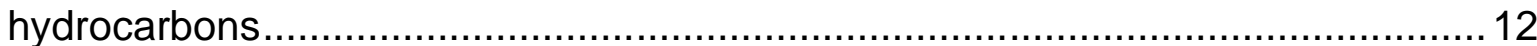

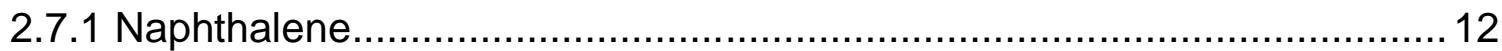

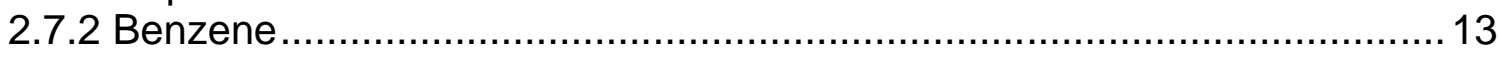

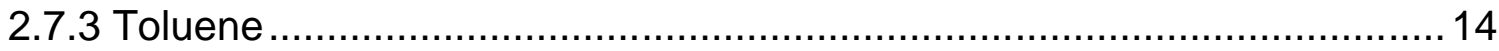

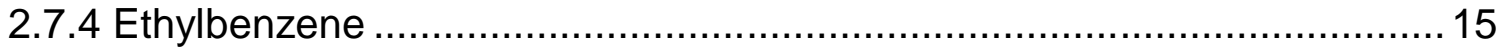

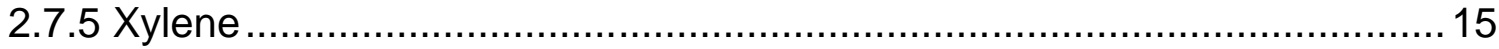

3.0 MEASUREMENT METHODS AND ANALYZES.......................................17

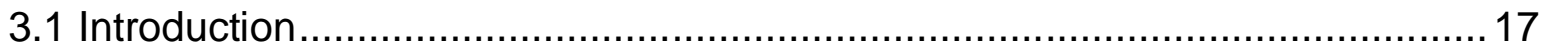

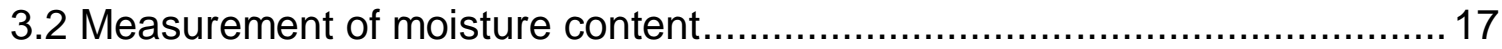

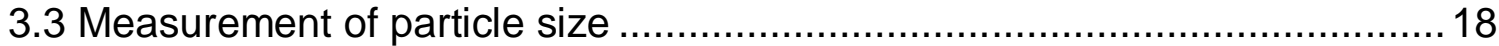

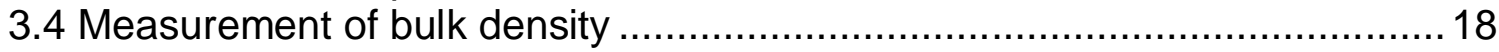

3.5 Determination of the ash content .................................................... 18

3.6 Fuel consumption rate and specific load of reactor ................................... 19

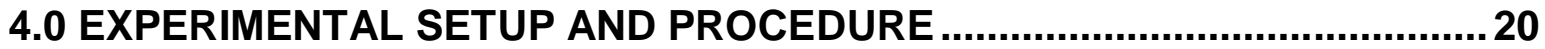

4.1 Description of gasifier setup and operation...............................................20 


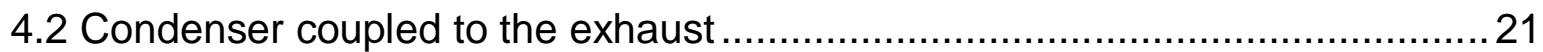

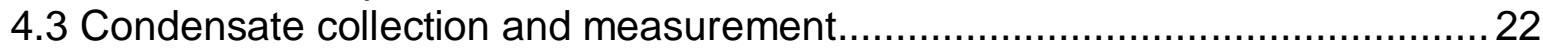

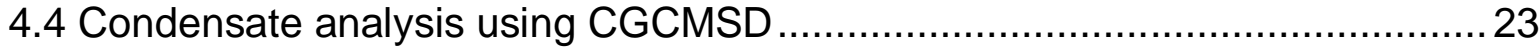

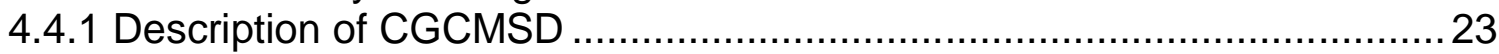

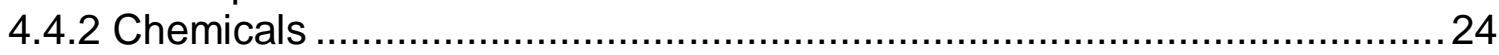

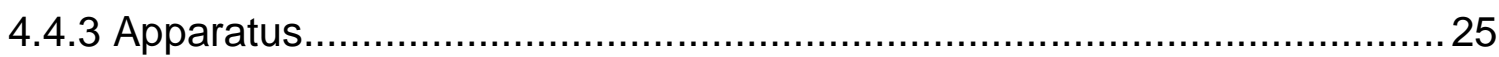

4.4.4 Preparation of standard solutions for PAH determination ......................2. 25

4.4.5 Preparation of standard solutions for BTEX determination .....................26

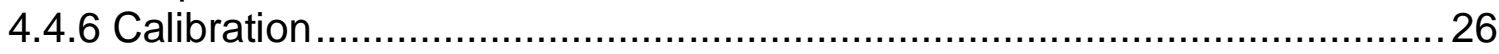

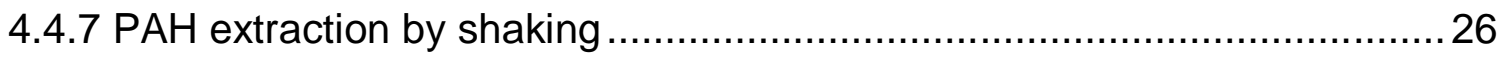

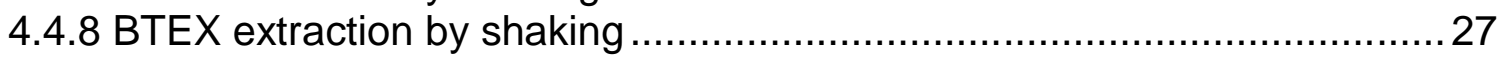

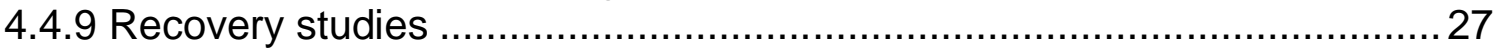

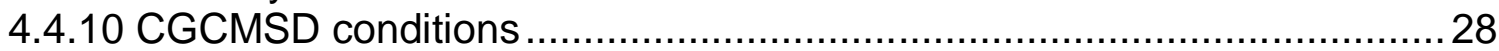

4.4.11 Identification and quantitation of the hydrocarbons ............................28

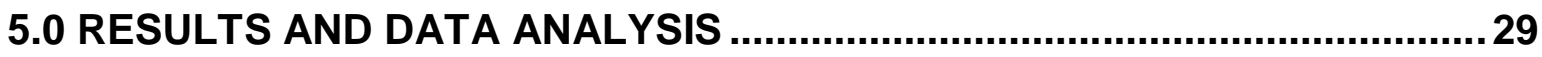

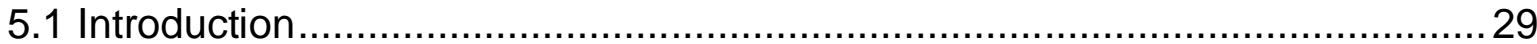

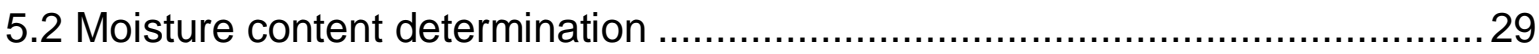

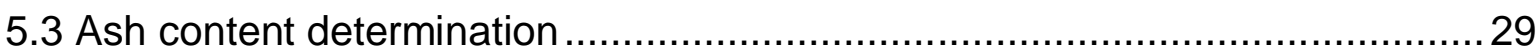

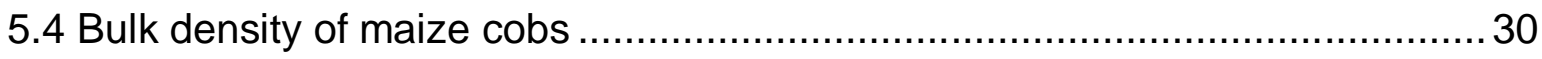

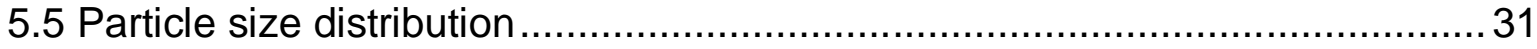

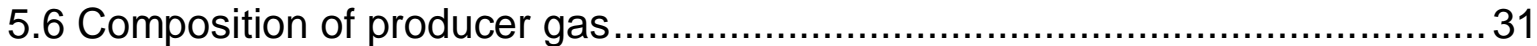

5.7 Fuel flow rate (FFR) and specific load of reactor (SLR) ................................ 33

5.8 Amount of condensate collected per kg fuel per hour.................................... 33

5.9 Superficial velocity or specific gas production rate ......................................34

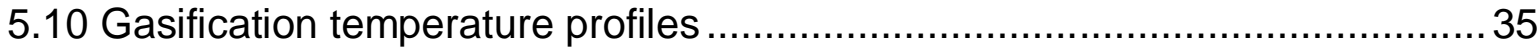

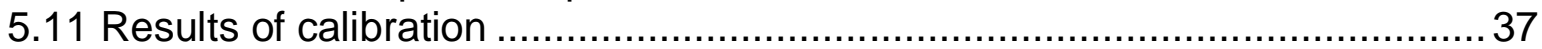

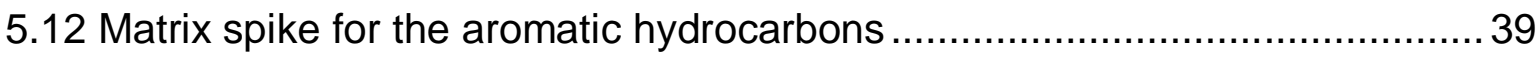

5.13 Analysis of selected aromatic hydrocarbons in condensate ....................... 40

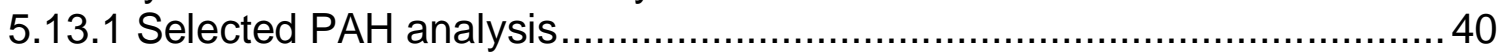

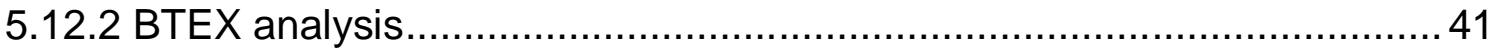

5.14 Measures to minimize health, environmental effects and pollution levels, resulting from biomass gasification................................................................43

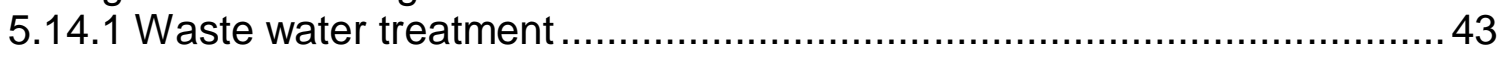

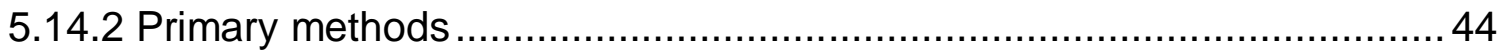

6.0 CONCLUSIONS AND RECOMMENDATIONS ............................................46

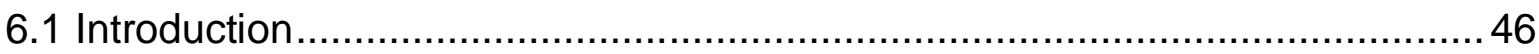

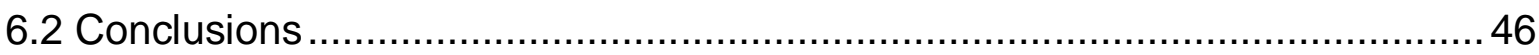

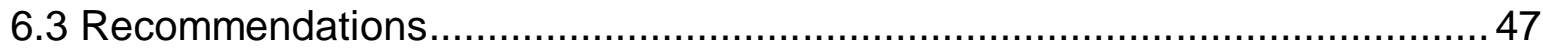

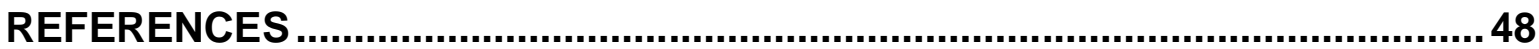

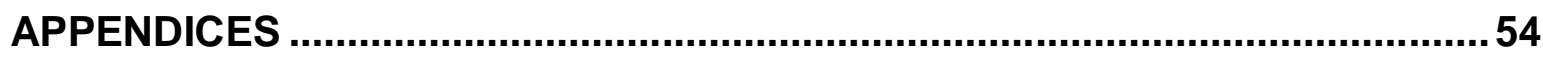

Appendix A: CGCMSD Conditions for PAH Analysis ......................................54

Appendix B: CGCMSD Conditions for BTEX Analysis ...................................5 57

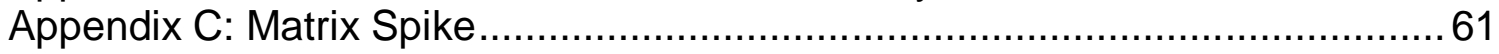


Appendix E: Total Ion Chromatograms

Appendix F: Calibration curves of selected aromatic hydrocarbons...................64 


\section{LIST OF ACRONYMS AND ABBREVIATIONS}

$\begin{array}{ll}\text { AFR } & \text { Air Flow Rate } \\ \text { ACGIH } & \text { American Conference of Governmental Industrial Hygienists } \\ \text { BOD } & \text { Biological Oxygen Demand } \\ \text { BTEX } & \text { Benzene, Toluene, Ethylbenzene, Xylene } \\ \text { CDC } & \text { Centers for Disease Control and Prevention } \\ \text { CGC } & \text { Capillary Gas Chromatograph } \\ \text { CGCMSD } & \text { Capillary Gas Chromatograph with Mass Spectrometric Detection } \\ \text { Conc } & \text { Concentration } \\ \text { DSEE } & \text { Distant masters program in Sustainable Energy Engineering } \\ \text { EPA } & \text { Environmental Protection Agency } \\ \text { FAO } & \text { Food of Agricultural Organization } \\ \text { FFR } & \text { Fuel flow rate } \\ \text { GPR } & \text { Gas Production Rate } \\ \text { HPLC } & \text { High Performance Liquid Chromatography } \\ \text { HSE } & \text { Health Safety and Environment } \\ \text { ISTD } & \text { Internal Standard } \\ \text { IUPAC } & \text { International Union of Pure and Applied Chemistry } \\ \text { KTH } & \text { Kungliga Tekniska Högskolan } \\ \text { LOD } & \text { Limit of Detection } \\ \text { LOQ } & \text { Limit of Quantitation } \\ \text { MSD } & \text { Mass Spectrometric Detector } \\ \text { m/z } & \text { mass to charge ratio } \\ \text { ND } & \text { Not Detected } \\ \text { Nm } & \text { Normal cubic meter } \\ \text { NTP } & \text { Normal Temperature and Pressure } \\ \text { PAH } & \text { Polycyclic Aromatic Hydrocarbons } \\ \text { ppm } & \text { parts per million } \\ \text { RSD } & \text { Relative Standard Deviation } \\ \text { RT } & \text { Retention Time } \\ \text { S.D } & \text { Standard Deviation } \\ \text { SIM } & \text { Selective lon Monitoring } \\ \text { STEL } & \text { Short Term Exposure Limits } \\ \text { TLV } & \text { Threshold Limit Value } \\ \text { TWA } & \text { Total Weighted Average } \\ \text { UV } & \text { Ultra Violet } \\ \text { Vs } & \text { Superficial Velocity } \\ \text { SGPR } & \text { Specific Gas Production Rate } \\ \text { SLR } & \text { Specific load of the reactor } \\ & \\ & \end{array}$




\section{LIST OF FIGURES}

Figure 2- 1: Possible condensate accumulation points in a biomass gasification plant [Lettner et al., 2007] ......................................................................

Figure 4- 1: Sectional siew of a downdraft fixed bed gasifier at Makerere University

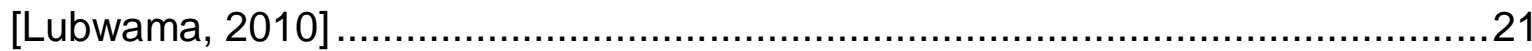

Figure 4- 2: Water cooled condenser connected to the exhaust pipe ...................22

Figure 4- 3: Condensate in sampling bottles .................................................23

Figure 4- 4: Agilent GC/MSD (6890) used in the analysis at SGS Ltd, Mombasa,

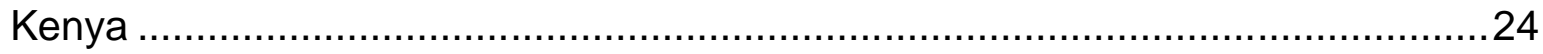

Figure 5- 1: Percentage composition of producer gas from maize cobs...............32

Figure 5- 2: Temperature profiles in the gasifier reactor....................................37 


\section{LIST OF TABLES}

Table 2- 1: Classification of quantitatively analyzed compounds 7

Table 2- 2: Tar Classification $\quad 8$

Table 2- 3: Occupational exposure limits $\quad 12$

Table 2- 4: Effects of Naphthalene Exposure 13

Table 4- 1: Surrogate standards and the corresponding PAH they represent 25

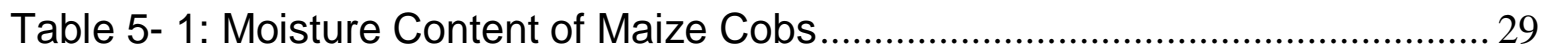

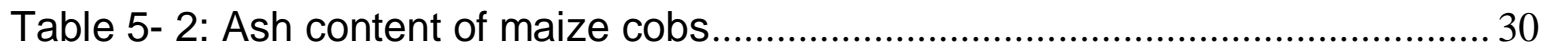

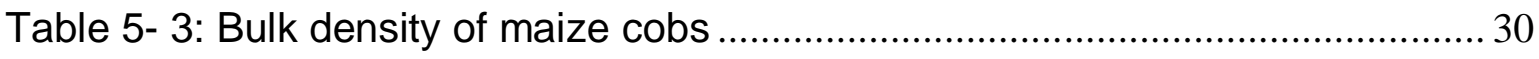

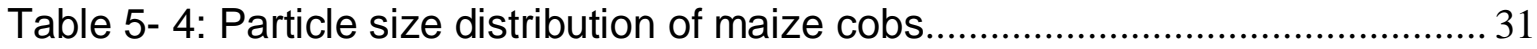

Table 5- 5: Percentage composition of producer gas from maize cobs .................. 32

Table 5- 6: Fuel flow rate (FFR) and specific load of reactor (SLR) …..................... 33

Table 5- 7: Amount of condensate collected per $\mathrm{kg}$ fuel per hour............................. 34

Table 5- 8: Specific gas production rate and superficial velocity................................35

Table 5- 9: Correlation coefficient, \%RSD, LOD and LOQ for selected $\mathrm{PAH}$.......... 38

Table 5- 10: Correlation coefficient, \%RSD, LOD and LOQ for BTEX ..................... 38

Table 5- 11: Matrix spike and percentage recoveries.................................................4 40

Table 5- 12: Concentration of targeted light PAH in the condensate..........................40

Table 5- 13: Concentration of targeted light aromatic hydrocarbons ........................ 42 


\subsection{INTRODUCTION}

Biomass gasification is a thermo-chemical conversion process that converts biomass and other solid fuels into gases [Bridgewater, 1993]. According to Larsen et al., [2003], the finished gas consists of $18-20 \%$ hydrogen, $18-20 \%$ carbon monoxide, $2-3 \%$ methane, $8-10 \%$ carbon dioxide and the rest nitrogen. In most cases, some char and tars are also formed, along with methane, water, and other constituents. In practice, gasification can convert $60 \%$ to $90 \%$ of the energy in the biomass into energy in the gas depending on the type of gasifier and the operating conditions [Reed, 1988]. The biomass can be gasified by different kinds of gasifying medium, i.e. oxygen, air, steam, mixture of oxygen and steam or mixture of air and steam. Pure oxygen is more preferable than air but most of the time pure oxygen is much more expensive than air, hence for economical reasons air is often used in the gasification process [Anisa, 2005]. Industries with large amounts of biomass residues and in need of both thermal and electrical energy have good potentials for biomass gasification technology.

In Uganda, most of the gasification work is being carried out in research institutions and a few prototypes have been developed and tested. These include installations at Makerere University and Kyambogo University in the Kampala district, Kings College Budo in the Wakiso district and Nyabyeya Forestry College in the Masindi district [Kasedde, 2010]. Other gasifier installations have been commercially operated for power generation and thermal applications. These include installations at the Muzizi Tea Estate in the Kibale district and the Ankole Tea Estate in the Bushenyi district respectively.

As biomass gasification gains popularity as a renewable energy technology, it is necessary to ensure that health, safety and environmental issues do not become hurdles to its unconditional acceptance in the market. However, today the large scale introduction is hampered by health, safety and environmental issues which present a major barrier in the deployment of this technology [Fürnsinn, 2005]. The liquid effluent in particular resulting from producer gas cooling and cleaning is highly toxic and carcinogenic which, if not adequately controlled, can lead to detrimental impacts on human health and the environment.

The application of producer gas from biomass gasification for power generation through engines requires cooling and cleaning. Wet scrubbing is often chosen because it is a cheaper option to remove organic components, particulate matter and to cool the gas, resulting in the production of contaminated water. On the other hand, even for dry gas cleaning technologies, cooling still produces contaminated 
liquids because of the considerable amounts of water vapor contained in the producer gas. Similar studies have been conducted to evaluate hazards and safety issues of gasifiers in Uganda [Kasedde, 2010] in which carbonmonoxide due to leakages was measured around the gasifier reactor, gaseous contaminants, temperature, and pressure among others were assessed for their associated health, safety and environment effects.

\subsection{Problem Statement}

Biomass gasification producer gas is often cooled before use in gas engines to increase the energy density of the gas. A $10 \%$ temperature reduction of the gas increases the maximum output of the engine by almost $2 \%$ [FAO, 1986]. However, during the cooling process some hydrocarbons are condensed with the water vapor out of the gas resulting in a condensate contaminated with organic compounds. The polycyclic aromatic hydrocarbons (PAH) and BTEX (benzene, toluene, ethylbenzene and xylene) from this condensate are carcinogenic and highly toxic leading to a risk of water pollution, adverse health and environmental effects. It was therefore important to determine the quantities of some of these organic compounds in the generated condensate resulting from gas cooling, relate their concentrations to known recommended values, mention their impact on human health and the environment and propose measures aimed at minimizing pollution levels resulting from biomass gasification.

\subsection{Objectives}

The main objective of this research was to assess pollution levels resulting from biomass gasification organic condensates with specific objectives including:

- Assessment of concentration of selected polycyclic aromatic hydrocarbons (PAHs) in condensate

- Assessment of concentration of BTEX in condensate

- Propose measures aimed at minimizing pollution levels resulting from biomass gasification

\subsection{Justification}

The study will raise awareness on the health, safety and environmental aspects that may arise due to waste water generated during biomass gasification by providing vital information to operators of gasifiers, engineers, policy makers, investors and other stakeholders who are the market actors of the technology. The information is vital especially as the upcoming industries draw more interest in taking up the gasification technology for their power and thermal applications. In 
addition, the research will promote good environmental practices at the installations by proposing measures aimed at minimizing pollution levels resulting from biomass gasification.

\subsection{Scope}

The study was conducted on the gasifier facility at Makerere University and run in the downdraft mode using maize cobs as gasifier fuel. The downdraft mode was chosen because it is used for gas engine applications due to the low tar levels it generates compared to the others. However, since the producer gas requires cooling before use in gas engines, a contaminated condensate is generated due to gas cooling. The liquid effluent problem does not arise in updraft gasifiers commonly used for heat applications, since such systems usually combust the dirty hot producer gas completely, including the tar components, which are gaseous at higher temperatures [Stassen, 1995].

The aromatic hydrocarbons measured were limited to mono aromatic hydrocarbons and light polycyclic aromatic hydrocarbons that are detected by the gas chromatograph. Light aromatics are hydrocarbons with detectable single ring and do not pose a problem regarding condensability and solubility. Light poly aromatic hydrocarbons are two and three ring compounds which condense at low temperature even at very low concentration [Sousa, 2001; Podgorska, 2006]. 


\subsection{LITERATURE REVIEW}

The essence of a gasification process is the conversion of solid carbon fuels into carbon monoxide and hydrogen by a complex thermal chemical process [Turare, 1998], as shown in the general formula below.

$$
\text { Biomass } \begin{aligned}
\mathrm{O}_{2}\left(\text { or } \mathrm{H}_{2} \mathrm{O}\right) & \rightarrow \mathrm{CO}, \mathrm{CO}_{2}, \mathrm{H}_{2} \mathrm{O}, \mathrm{H}_{2}, \mathrm{CH}_{4}+\text { other hydrocarbons } \\
& \rightarrow \mathrm{Tar}+\text { char }+ \text { ash } \\
& \rightarrow \mathrm{HCN}+\mathrm{NH}_{3}+\mathrm{HCl}+\mathrm{H}_{2} \mathrm{~S}+\text { other sulphur gases }
\end{aligned}
$$

According to Turare, [1998], the resulting gas is called producer gas which is a mixture of combustible gases (i.e. $\mathrm{H}_{2}, \mathrm{CO}, \mathrm{CH}_{4}$ ) and incombustible gases (i.e. $\mathrm{CO}_{2}$ and $\mathrm{N}_{2}$ ). Rauch, [2005] reports that gasification is a water consuming process which is opposite to combustion processes where water is formed.

\subsection{Condensate accumulation points in biomass gasification plants}

Depending on the type of gasifier and the operation conditions, about 0.01 to $0.1 \mathrm{~kg}$ water per $\mathrm{kg}$ of dry fuel is consumed [Rauch, 2005]. The excess of water, which is transported into the gasification system by the water content of the biomass, leaves the gasifier together with the product gas. Water is therefore also a constituent of producer gas, although it is normally removed by cooling and cleaning, the basis for an accumulation of condensate [Lettner et al., 2007]. Figure 2-1 shows possible condensate accumulation points in a biomass gasification plant depending on the gasifier operation conditions such as temperature, pressure, equivalence ratio, gasifying medium, biomass properties and plant configuration among others. 


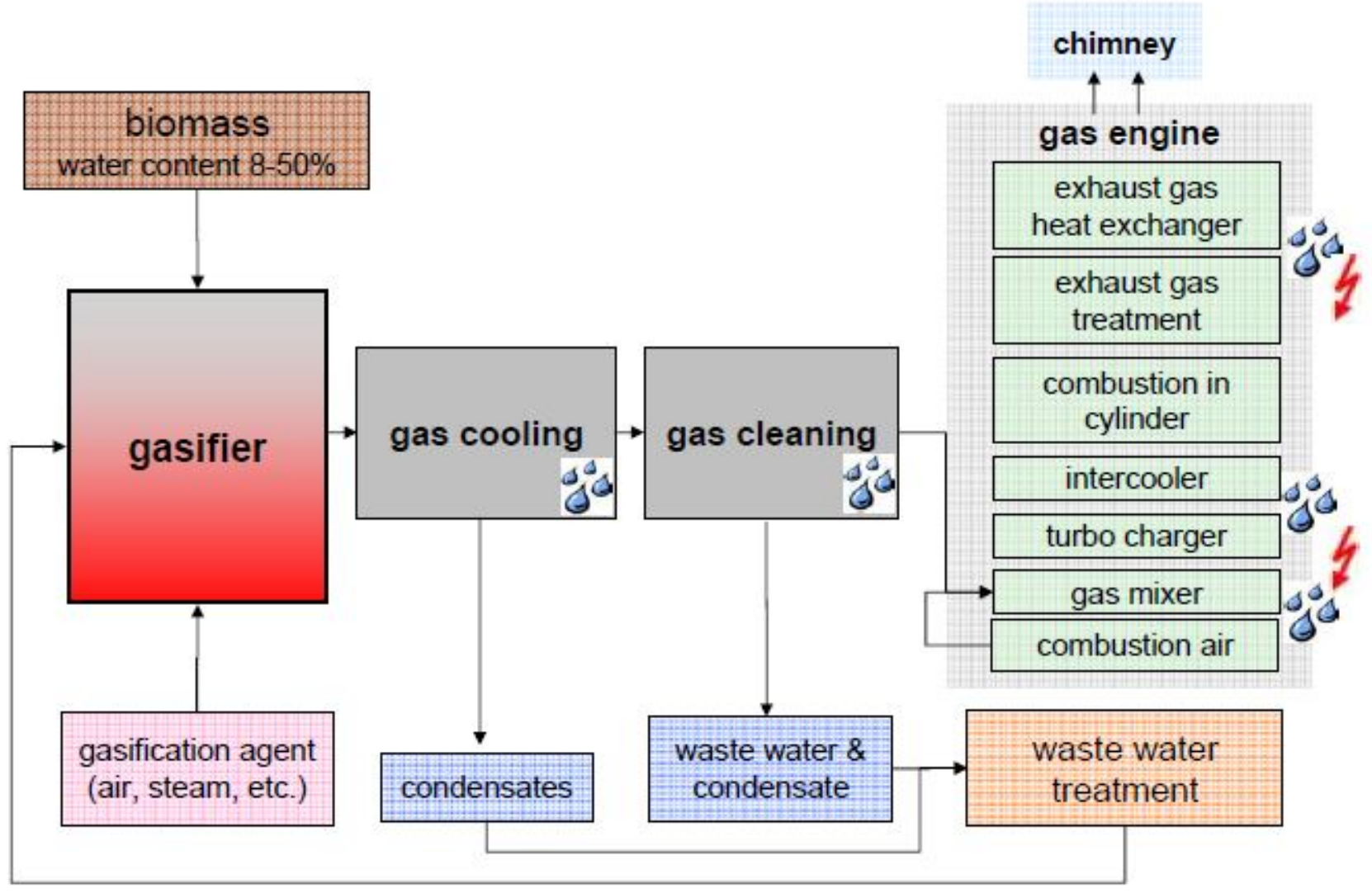

Figure 2- 1: Possible condensate accumulation points in a biomass gasification plant [Rauch, 2005]

\subsubsection{Gas cooling}

Gas cooling mainly serves the purpose of increasing the density of producer gas in order to maximize the amount of combustible gas entering the cylinder of the engine at each stroke. Highest power output is realized at lowest gas temperature. Thus, in power applications, it is advantageous to cool the gas as far as is practical. A $10 \%$ temperature reduction of the gas increases the maximum output of the engine by almost $2 \%$ [FAO, 1986]. Cooling, however, allows vaporized tars in the gas to condense on engine parts such as inlet manifolds and valve stems. Also, soot and ash particles in the gas may form deposits in the engine. These phenomena will result in excessive engine wear, so in power applications, it is absolutely necessary to filter and clean the gas from soot, ash, and tar [Stassen, 1995].

\subsubsection{Wet gas cleaning}

Wet gas cleaning is purification of the producer gas by means of liquid scrubbing agents in a suitable scrubber system. The cleaning effect is brought about the dissolving of the contaminants by washing agents [Lettner, 2007]. This kind of gas 
cleaning additionally fulfils the function of gas cooling because of the heat exchange between the producer gas and the washing agent due to the intensive contact and the heat removal through heat extraction via suitable heat exchangers. Washing agents that may be used include water, water/oil emulsions and various hydrocarbons.

\subsection{Constituents of the accumulating condensate}

Depending on the selected combination of gasification and gas cleaning technology and the set operating parameters, the aqueous condensates of biomass gasification plants contain a varying amount of inorganic and organic load. The content and composition of organic hydrocarbons depend on the type of reactor, the residence time of producer gas in the reactor, feed particle size distribution, method of tar extraction and analysis and the temperature in the reactor [Rauch, 2005].

\subsection{Tar yield as a function of gasifier type}

Generally, biomass tar is referred to as condensable organics in the syngas produced in the gasification process of biomass, and it is assumed to be largely aromatic [Milne \& Evans, 1998]. Each type of gasifier has its unique operation and reaction conditions, which results in different tar composition and yield. As a general conclusion, it has been proven and explained scientifically and technically that updraft gasifiers produce more organic hydrocarbons (tars) than fluidized beds and the latter more than downdrafts [Milne \& Evans, 1998]. Tar loading in raw syngas from updraft gasifiers has an average value of about $100 \mathrm{~g} / \mathrm{Nm}^{3}$, fluidized bed and CFBs have an average tar loading of about $10 \mathrm{~g} / \mathrm{Nm}^{3}$, downdraft gasifiers produce the cleanest syngas with tar loading typically less than $1 \mathrm{~g} / \mathrm{Nm}^{3}$ [Milne \& Evans, 1998].

It is also established that well-functioning updraft gasifiers produce largely primary tar, with some degree of secondary character; downdraft gasfiers produce mostly tertiary tar, and fluidized beds produce a mixture of secondary and tertiary tars. Primary tars are fragments originating directly from the cellulose, hemicelluloses and lignin structures in the biomass. Secondary tars consist mainly of phenolics and olefins and are products from the conversion of primary tars. Alkyl tertially products are characterized by methyl derivatives of aromatics and finally, the tertially tars are polycyclic aromatic hydrocarbons (PAH). Based on gasification temperatures, primary tars are formed in temperature ranges $200-500^{\circ} \mathrm{C}$, secondary tars $500-800^{\circ} \mathrm{C}$ while tertiary tars at temperatures greater than $800^{\circ} \mathrm{C}$ 
[Milne \& Evans, 1998]. Table 2-1 shows classification of quantitatively analyzed tar compounds.

Table 2-1: Classification of quantitatively analyzed compounds

[Milne \& Evans, 1998]

\begin{tabular}{|c|c|c|}
\hline Tar compound class & Compound Type & Compound Name \\
\hline \multirow[t]{5}{*}{$\begin{array}{l}\text { Primary tar } \\
\text { compounds }\end{array}$} & Acids & $\begin{array}{l}\text { Acetic acid, Propioninc acid, } \\
\text { Butyric acid }\end{array}$ \\
\hline & Ketones & Acetol (1-hydroxy-2-propanone \\
\hline & Phenols & $\begin{array}{l}\text { Phenol, 2,3-Dimethyl phenol, } \\
\text { 2,4/2,5-dimethyl phenol, 2,6- } \\
\text { Dimethyl phenol, 3,4-Dimethyl } \\
\text { phenol, 3,5-Dimethyl phenol }\end{array}$ \\
\hline & Guaiacols & Guaiacol, 4-methyl guaiacols \\
\hline & Furans & $\begin{array}{l}\text { Furfural, Furfural alcohol, 5- } \\
\text { methyl furfural }\end{array}$ \\
\hline \multirow[t]{2}{*}{$\begin{array}{l}\text { Secondary tar } \\
\text { compounds }\end{array}$} & Phenols & $\begin{array}{l}\text { Phenol, o-cresol, } p \text {-cresol, } m \text { - } \\
\text { cresol }\end{array}$ \\
\hline & Monoaromatic hydrocarbons & $p / m$-xylene, $o$-xylene \\
\hline \multirow[t]{3}{*}{ Secondary/tertiary tar } & Monoaromatic hydrocarbons & $\begin{array}{l}\text { Benzene, Ethylbenzene, a- } \\
\text { methylstyrene } \\
3 \& 2-\quad \text { methylstyrene, } \\
\text { methylstyrene, 3-ethyltoluene, } 4- \\
\text { ethyltoluene, 2-ethyltoluene }\end{array}$ \\
\hline & Miscellaneous hydrocarbons & $\begin{array}{l}\text { 2,3-benzofuran, Dibenzofuran, } \\
\text { Biphenyl, Indene }\end{array}$ \\
\hline & $\begin{array}{lll}\text { Methyl derivatives of } \\
\text { aromatics }\end{array}$ & $\begin{array}{l}\text { 2-methyl naphthalene, 1-methyl } \\
\text { naphthalene, Toluene }\end{array}$ \\
\hline \multirow[t]{5}{*}{$\begin{array}{l}\text { Tertiary tar } \\
\text { compounds }\end{array}$} & PAH: 2 ring & $\begin{array}{l}\text { Acenaphthylene, Acenaphthene, } \\
\text { Fluorene, Naphthalene }\end{array}$ \\
\hline & 3 ring & $\begin{array}{l}\text { Phenanthrene, Anthrancene, } \\
\text { Fluoranthene, Pyrene }\end{array}$ \\
\hline & 4 ring & $\begin{array}{l}\text { Benz [a]anthracene, Chrysene, } \\
\text { Benz [e] acephenanthrylene, } \\
\text { Benzo [k] fluoranthene }\end{array}$ \\
\hline & 5 ring & $\begin{array}{l}\text { Benzo [a] pyrene, perylene, } \\
\text { Dibenzo [ah] anthrance, Indeno } \\
{[1,2,3-c d] \text { pyrene }}\end{array}$ \\
\hline & 6 ring & Benzo [ghi] perylene \\
\hline
\end{tabular}

Based on molecular weight of tar compounds, a popular classification of tar is shown in Table 2-2. Sousa [2001] and Podgorska [2006] divided tar components into five groups, and each group has its specific property and representative compounds. 
Table 2- 2: Tar Classification [Sousa, 2001; Podgorska, 2006]

\begin{tabular}{|c|c|c|c|}
\hline Class & Class Name & Property & Representative Compounds \\
\hline 1 & GC-undetectable & $\begin{array}{l}\text { Very heavy tars, cannot } \\
\text { be detected by GC }\end{array}$ & None \\
\hline 2 & Heterocyclic & $\begin{array}{l}\text { Tars containing hetero } \\
\text { atoms; highly water } \\
\text { soluble compounds }\end{array}$ & $\begin{array}{l}\text { Pyridine, phenol, cresols, } \\
\text { benzonitril, quinoline, isoquinoline, } \\
\text { dibenzophenol }\end{array}$ \\
\hline 3 & Light aromatic & 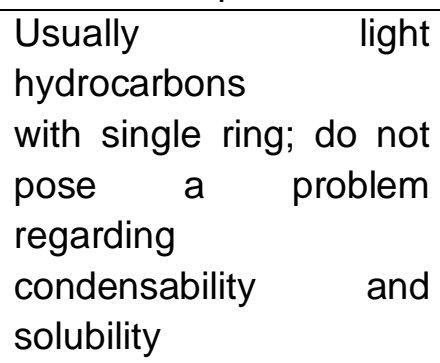 & $\begin{array}{l}\text { Toluene, ethylbenzene, xylenes, } \\
\text { styrene }\end{array}$ \\
\hline 4 & $\begin{array}{l}\text { Light } \\
\text { polyaromatic }\end{array}$ & $\begin{array}{l}\text { Two and three ring } \\
\text { compounds; condense } \\
\text { at } \\
\text { low temperature even at } \\
\text { very low concentration }\end{array}$ & $\begin{array}{l}\text { Indene, naphthalene, } \\
\text { methylnaphthalene, } \\
\text { biphenyl, acenaphtylene, } \\
\text { fluorene, phenanthrene, } \\
\text { anthracene }\end{array}$ \\
\hline 5 & $\begin{array}{l}\text { Heavy } \\
\text { polyaromatic }\end{array}$ & $\begin{array}{l}\text { Larger than three-rings. } \\
\text { These components } \\
\text { condense at high } \\
\text { temperatures at low } \\
\text { concentrations }\end{array}$ & $\begin{array}{l}\text { fluoranthene, pyrene, chrysene, } \\
\text { perylene, coronene, triphenylene, } \\
\text { benzo(a)anthracene, } \\
\text { benzo(c)phenanthrene, } \\
\text { benzo(e)pyrene, } \\
\text { benzo(j)fluoranthene, } \\
\text { benzo(k)fluoranthene }\end{array}$ \\
\hline
\end{tabular}

Light tar is all tar that is measurable with a gas chromatograph; heavy tar is all the rest (Neeft, 2000). Light tars are considered to have at most 4 to 7 aromatic rings, other tars with more aromatic rings are considered to be heavy tars (gravimetric tar) [Neeft, 2000]. According to Brown [2011], soluble tars include: phenols, acetone, naphthalene, BTEX while insoluble tars include: acenaphthylene, fluorene, phenanthrene, pyrene, chrysene.

\subsection{Biomass characteristics}

All carbon containing biomass fuels can be gasified, provided the fuel meets requirements of the particular equipment. Physical and chemical properties of feed stocks should be carefully considered since different kinds of gasifiers have different requirements regarding the physical and chemical properties of biomass. Below is a description of some of the physical and chemical characteristics of the feedstock. 


\subsubsection{Moisture content}

The moisture content of biomass is defined as the quantity of water in the material expressed as a percentage of the material's weight. Dry biomass feed stock with low moisture content is needed in gasification processes in order to produce a higher quality gas i.e. higher heating value, higher efficiency and lower tar levels. The moisture content of feed material affects reaction temperature due to the energy required to evaporate water in the fuel. Therefore, the gasification process takes place at a lower temperature. Downdraft fixed bed gasifiers cannot tolerate moisture contents above 20\%. Updraft fixed bed gasifiers and fluidized bed gasifiers can tolerate higher moisture contents of $50 \%$ and $65 \%$, respectively [Roos, 2010].

\subsubsection{Ash content}

Ash is the inorganic content of the biomass, which remains after complete combustion. The amount of ash in different feed stock varies widely i.e. $0.1 \%$ in wood up to $15 \%$ for some agricultural products [Hariie, 2005] and influences the design of the reactor, particularly the ash removal system. The chemical composition of the ash also affects the melting behavior of the ash and ash melting causes slagging and in the reactor.

\subsubsection{Elemental composition}

The generic formula for biomass is $\mathrm{CH}_{1.4} \mathrm{O}_{0.6}$ [Reed \& Das, 1988] on dry and ashfree basis. The elemental composition of the fuel is important with respect to the heating value and the emission levels in almost all applications. The heating value is determined by the elemental composition, the ash content of the biomass and in particular on the fuel moisture content.

\subsubsection{Bulk density}

Bulk density is defined as the weight per unit volume of loosely tipped fuel (FAO, 1986). Biomass fuels with high bulk density are advantageous because they represent a high energy-for-volume value while low bulk density fuels sometimes give rise to insufficient flow under gravity, resulting in low gas heating values and ultimately in burning of the char in the reduction zone.

\subsubsection{Volatile matter content}

The amount of volatiles has an impact on the tar production levels in gasifiers. Depending on the gasifier design, the volatiles leave the reactor at low temperatures (updraft gasifiers), at moderate temperatures (fluid bed gasifiers) or 
pass through a hot incandescent oxidation zone (downdraft gasifiers) were they are thermally cracked. For biomass materials the volatile matter content varies between 50 and $80 \%$ [Hariie, 2005].

\subsection{Gasification Operating Parameters}

\subsubsection{Superficial velocity, $V_{s}$ or specific gas production rate, SGPR}

The superficial velocity of a gasifier is the most important measure of its performance, controlling gas production rate, gas energy content, fuel consumption rate, power output and char and tar production rate. According to Hariie [2005], superficial velocity is expressed as follows:

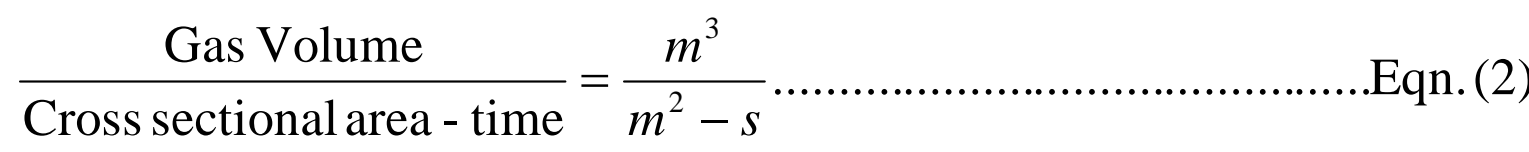

According to Jain [2006] specific gas production rate is expressed as:

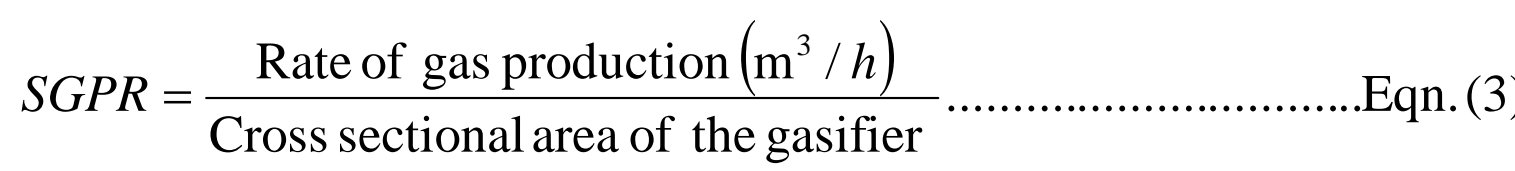

Where, the cross-sectional area of the reactor is taken at the throat (constriction). A low superficial velocity causes slow pyrolysis conditions; a high superficial velocity causes very fast pyrolysis conditions.

\subsubsection{Fuel consumption and gas production rate}

The fuel consumption is needed to determine the gasifier overall efficiency. The fuel consumption can be measured by a weighing balance and expressed on a unit mass per unit time $(\mathrm{kg} / \mathrm{hr})$, or unit mass per energy produced $(\mathrm{kg} / \mathrm{kW}$ e) or unit mass per cross sectional diameter and time $\left(\mathrm{kg} / \mathrm{m}^{2} \times \mathrm{hr}\right)$.

The gas flow rate can be calculated from the primary air flow if the nitrogen content in the producer gas is known, or measured by orifice plates, venturies, pitot tubes or rota-meters. The rate of gas production $\left(\mathrm{Nm}^{3} / \mathrm{hr}\right)$ is obtained from the expression below:

$$
\text { Rate of gas production, } \mathrm{Nm}^{3} / \mathrm{h}=\frac{\text { Air flow rate } \times 3.76 / 4.76}{\text { Nitrogen mole fraction of dry producer gas }\left(\mathrm{yN}_{2}\right)}
$$


To calculate the gas flow on a normal cubic meter basis, also the temperature and pressure need to be measured. The normal gas flow rates are determined using Equation (5) below:

$$
\frac{\dot{\mathrm{V}}_{1}}{\mathrm{~T}_{1}}=\frac{\dot{\mathrm{V}}_{2}}{\mathrm{~T}_{2}}
$$

\subsection{Analysis of aromatic hydrocarbons using CGCMSD}

Aromatic hydrocarbons in water samples may be extracted by either liquid-liquid or solid phase extraction and cleaned up using silica column chromatography. The extract may be analyzed by capillary gas chromatography (CGC) with mass spectrometric detection or by a high performance liquid chromatography (HPLC).

Aromatic hydrocarbons in water samples are quantified using an internal standard method. For each compound, integration is performed on the ion chromatogram of the quantitation ion using the internal standard eluting closest to the compound being quantified [Soniassy et al., 1994].

Calibration mixtures are analyzed and the calibration curve calculated. The response factor is defined by the slope of the curve Area $x$ / Area ISTD versus Concentration $\mathrm{x}$ /Concentration ISTD:

i.e. $\mathrm{RF}=\frac{\text { Area ISTD }}{\text { Area } \mathrm{x}} \times \frac{\text { Concentration } \mathrm{x}}{\text { Concentration ISTD }}$

Where:

Area ISTD: peak area of the internal standard (ISTD) in calibration mixture Area $\mathrm{x}$ : peak area of PAH standard in calibration mixture

Concentration ISTD: Concentration of the ISTD in calibration mixture Concentration $\mathrm{x}$ : concentration of $\mathrm{PAH}$ standard in calibration mixture

The concentration in $\mu \mathrm{g} / \mathrm{l}$ of the PAH in the unknown sample is finally calculated by:

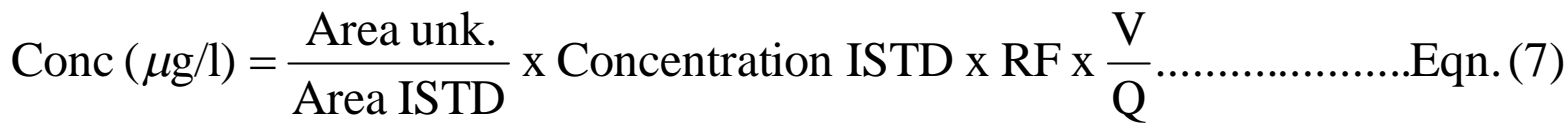
Where:

Area ISTD: peak area of the ISTD in the sample analysis

Area unk: peak area of the PAH unknown in the sample analysis

Concentration ISTD: concentration of the ISTD in the sample 
RF: response factor calculated from calibration analysis

$\mathrm{V}$ : volume $(\mu \mathrm{l})$ in which the sample has been dissolved before injection

$\mathrm{Q}$ : sample volume in $\mathrm{ml}$

\section{Quality Control}

Method performance is monitored using laboratory control check samples, method blanks and internal quality control samples. The United States Environmental Protection Agency (EPA) recommends the use of in-house laboratory control limits for surrogate standards recoveries for all organic compound analyses [US EPA, 1996a].

\subsection{Health and environmental effects associated with selected aromatic hydrocarbons}

\subsubsection{Naphthalene}

Naphthalene is an organic compound with formula $\mathrm{C}_{10} \mathrm{H}_{8}$. It is the simplest polycyclic aromatic hydrocarbon with a characteristic odor that is detectable at concentrations as low as $0.08 \mathrm{ppm}$ (or $0.42 \mathrm{mg} / \mathrm{m}^{3}$ ) [Amoore et al., 1983]. As an aromatic hydrocarbon, naphthalene's structure consists of a fused pair of benzene rings. Table 2-3 shows the occupational exposure limits of naphthalene.

Table 2- 3: Occupational exposure limits [ACGIH, 1986]

\begin{tabular}{|l|l|}
\hline Occupational Exposure Parameter & Limit \\
\hline Total weighted average (TWA) & $10 \mathrm{ppm}\left(\right.$ or $\left.52.35 \mathrm{mg} / \mathrm{m}^{3}\right)$ \\
\hline Short term exposure limit (STEL) & $15 \mathrm{ppm}\left(\right.$ or $78.53 \mathrm{mg} / \mathrm{m}^{3}$ ) \\
\hline
\end{tabular}

\section{Health effects due to naphthalene exposure}

Hemolytic anemia (a condition involving the breakdown of red blood cells) is the primary health concern for humans exposed to naphthalene for either short or long periods of time. Ingestion of naphthalene results in the formation of an epoxide metabolite that is probably responsible for haemolysis [Haddon et al., 1998]. Haemolysis mostly occurs in individuals with a hereditary deficiency of glucose-6phosphate dehydrogenase due to instability of erythrocyte glutathion. Table 2-4 summarizes the probable health effects associated with exposure to naphthalene. 
Table 2- 4: Effects due to naphthalene exposure

[NIOSH, 2005]

\begin{tabular}{|l|l|}
\hline Type of Exposure & \multicolumn{1}{|c|}{ Acute Hazards/Symptoms } \\
\hline Inhalation & $\begin{array}{l}\text { Headache, weakness, nausea, vomiting, sweating, } \\
\text { confusion, jaundice and dark urine }\end{array}$ \\
\hline Skin & $\begin{array}{l}\text { Naphthalene may be absorbed into the skin and cause } \\
\text { yellowish skin }\end{array}$ \\
\hline Eyes & $\begin{array}{l}\text { The substance may have effects on the eyes, resulting in } \\
\text { the development of cataract and yellowish eyes (jaundice). }\end{array}$ \\
\hline Ingestion & $\begin{array}{l}\text { Abdominal pain, diarrhea, convulsions, unconsciousness, } \\
\text { may result in death }\end{array}$ \\
\hline $\begin{array}{l}\text { Effects of short } \\
\text { term exposure }\end{array}$ & $\begin{array}{l}\text { The substance may cause effects on the blood, resulting in } \\
\text { lesions of blood cells (haemolysis) }\end{array}$ \\
\hline $\begin{array}{l}\text { Effects of long- } \\
\text { term or repeated } \\
\text { exposure }\end{array}$ & $\begin{array}{l}\text { The substance may have effects on the blood, resulting in } \\
\text { chronic haemolytic anaemia. The substance may have } \\
\text { effects on the eyes, resulting in the development of } \\
\text { cataract. This substance is possibly carcinogenic to } \\
\text { humans. }\end{array}$ \\
\hline
\end{tabular}

Other effects include nausea, vomiting, diarrhea, kidney damage, jaundice (yellowish skin or eyes) and liver damage. These effects can occur from either breathing or eating naphthalene. However, the levels of naphthalene at which these effects can occur are not known. The effects of skin contact with naphthalene have not been carefully studied. Cancer has not been seen in humans or animals exposed to naphthalene [United States Public Health Service, 1990]

\section{Environmental effects due to naphthalene exposure}

According to Richieri et al., [1988] naphthalene is very toxic to aquatic organisms and may cause long-term effects in the aquatic environment. Animal studies have also reported depletion of pulmonary glutathione and dose-dependent bronchiolar epithelial cell necrosis

\subsubsection{Benzene}

Benzene is an organic chemical compound with the molecular formula $\mathrm{C}_{6} \mathrm{H}_{6}$.

According to ACGIH, [1987], the American Connference of Governmental Industrial Hygienists (ACGIH) designated benzene as a suspected human carcinogen having an assigned threshold limit value (TLV) of $10 \mathrm{ppm}$ (or 30 $\mathrm{mg} / \mathrm{m}^{3}$ ) as a total weighted average (TWA) for a normal 8-hour work day and a 40hour work week. 


\section{Health effects of benzene}

Benzene can cause bone marrow not to produce enough red blood cells, which can lead to anemia, damage the immune system by changing blood levels of antibodies and causing the loss of white blood cells. The seriousness of poisoning caused by benzene depends on the amount, route, and length of time of exposure, as well as the age and preexisting medical condition of the exposed person. Immediate signs and symptoms of exposure to benzene include: drowsiness, dizziness, rapid or irregular heartbeat, headaches, tremors, confusion, unconsciousness and death at very high levels [CDC, 2005].

\section{Environmental effects of benzene}

Australian water quality guidelines for fresh and marine waters reports maximum permissible pollution level of $300 \mathrm{mg} / \mathrm{m}^{3}$ [ANZECC,1992]. Benzene in soil or water decomposes with the presence of oxygen. It can be mobile in soil and may contaminate groundwater. Benzene has a high acute toxic effect on aquatic life. Long term effects on marine life can mean shortened lifespan and reproductive problems.

\subsubsection{Toluene}

Toluene, also known as methylbenzene is an aromatic hydrocarbon with formula $\mathrm{C}_{7} \mathrm{H}_{8}$. The occupational safety and health administration (OSHA) reports that the permissible exposure limit (PEL) of $200 \mathrm{ppm}$ (or $753.70 \mathrm{mg} / \mathrm{m}^{3}$ ) is considered an acceptable level of exposure as a time-weighted average for an 8-hour workday while toluene levels of $500 \mathrm{ppm}$ (or $1884.25 \mathrm{mg} / \mathrm{m}^{3}$ ) are considered immediately dangerous to life and health [United States Department of Labor, 2004].

\section{Health effects of toluene}

In cases where the concentration of toluene exceeds $500 \mathrm{ppm}$ (or $1884.25 \mathrm{mg} / \mathrm{m}^{3}$ ), acute toxicity in humans and animals from exposure to intermediate to high levels of toluene for short periods of time is shown by nervous system effects ranging from headaches to intoxication, convulsions, narcosis, and death. In addition, repeated doses of toluene results in chronic effects in the central nervous system and can damage the upper respiratory system, the kidney, and the liver [US EPA, 1994].

\section{Environmental effects of toluene}

Generally, toxic effects of toluene on aquatic organisms are observed with concentrations ranging between 10 and $90 \mathrm{mg} / \mathrm{l}$ [Environment Canada, 1984]. High concentrations of toluene can be toxic to both fish and other small organisms in the aquatic food chain including bacteria and phytoplankton. Acute poisoning in fish 
depends on temperature and species of fish for a particular concentration of toluene.

\subsubsection{Ethylbenzene}

Ethylbenzene is an organic compound with the formula $\mathrm{C}_{6} \mathrm{H}_{5} \mathrm{CH}_{2} \mathrm{CH}_{3}$. The current Occupational Safety and Health Administration (OSHA) permissible exposure limit (PEL) for ethylbenzene is $100 \mathrm{ppm}$ (or $435 \mathrm{mg} / \mathrm{m}^{3}$ ) as an 8-hour time-weighted average (TWA) concentration while the National Institute for Occupational Safety and Health (NIOSH) has established recommended exposure limits (RELs) for ethyl benzene of $100 \mathrm{ppm}\left(435 \mathrm{mg} / \mathrm{m}^{3}\right)$ as a TWA for up to a 10-hour workday and a 40 -hour workweek and $125 \mathrm{ppm}\left(545 \mathrm{mg} / \mathrm{m}^{3}\right)$ as a short-term exposure limit [NIOSH, 1992].

\section{Health effects of ethylbenzene}

High levels of ethylbenzene can cause paralysis, trouble breathing, liver damage and death. Ethylbenzene in food or water can rapidly and almost completely enter the body through the digestive tract. It may enter through the skin when one comes into contact with liquids containing ethylbenzene. People living in areas near hazardous waste sites such as gasification plants may be exposed by breathing air or by drinking water contaminated with ethylbenzene [United States Public Health Service, 1990].

\section{Environmental effects of ethylbenzene}

Ethylbenzene has high acute toxicity to aquatic life causing death of animals, birds, or fish, and death or low growth rate in plants. Insufficient data are available to evaluate or predict the short-term effects of ethylbenzene to birds or land animals Chronic toxic effects may include shortened lifespan, reproductive problems, lower fertility, and changes in appearance or behavior. In surface water such as rivers, ethylbenzene breaks down by reacting with other compounds naturally present in the water. In soil, the major way ethylbenzene is broken down is by soil bacteria [ANZECC, 1992].

\subsubsection{Xylene}

Xylene consists of three isomers of dimethylbenzene which are distinguished by the designations ortho- (o-), meta- $(m-)$, and para- $(p-)$, which specify to which carbon atoms of the benzene ring the two methyl groups are attached. The 0 isomer has the IUPAC name of 1,2-dimethylbenzene, the $m$ - isomer has the IUPAC name of 1,3-dimethylbenzene, and the $p$-isomer has the IUPAC name of 1,4-dimethylbenzene [ATSDR, 2007]. 
Xylene is most likely to enter the body when one breathes xylene vapors. It may also enter the body through eating or drinking xylene-contaminated food or water. Less often, xylene enters the body through the skin following direct contact. Xylene is rapidly absorbed by the lungs after breathing air containing it. The amount of xylene retained ranges from 50 to $75 \%$ of the amount of xylene inhaled [ATSDR, 2007].

\section{Health effects of xylene}

According to ACGIH, [1988], the permissible exposure limit for xylene must not exceed $100 \mathrm{ppm}$ or $435 \mathrm{mg} / \mathrm{m}^{3}$ as a total weighted average, $200 \mathrm{ppm}$ (or 870 $\mathrm{mg} / \mathrm{m}^{3}$ ) as a short term exposure limit and $300 \mathrm{ppm}$ (or $1305 \mathrm{mg} / \mathrm{m}^{3}$ ) as a "ceiling" limit which must never be exceeded for any period of time.

Short-term exposure of people to high levels of xylene can cause irritation of the skin, eyes, nose, and throat, difficulty in breathing, impaired function of the lungs, delayed response to a visual stimulus, impaired memory, stomach discomfort and possible changes in the liver and kidneys. Both short- and long-term exposure to high concentrations of xylene can also cause a number of effects on the nervous system such as: headache, lack of muscle coordination, dizziness, confusion, and changes in one's sense of balance [United States Public Health Service, 1995].

United States Public Health Service, [1995] reports that both the International Agency for Research on Cancer (IARC) and EPA have found that there is insufficient information to determine whether or not xylene is carcinogenic and consider xylene not classifiable as to its human carcinogenicity [United States Public Health Service, 1995].

\section{Environmental effects of xylene}

Xylene has high acute toxicity to aquatic life. It causes injury to various agricultural and ornamental crops. It also has high chronic (long-term) toxicity to aquatic life. There are not sufficient data to predict the acute or chronic toxicity of xylene to birds or land animals. Xylene is expected to moderately bioaccumulate, in fish [Environment Australia, 2001]

Since xylene evaporates easily, most xylene that gets into soil and water (if not trapped underground) is expected to go into the air where it is broken down by sunlight into other less harmful chemicals within a couple of days. For this reason, xylene is rarely found in high concentrations in topsoil or surface water unless there is a continuing source of contamination. Any xylene that does not evaporate quickly from soil or water is broken down by small organisms. Only very small amounts are taken up by plants, fish, and birds [ATSDR, 2007]. 


\subsection{MEASUREMENT METHODS AND ANALYZES}

\subsection{Introduction}

In this chapter the steps that were undertaken to achieve the specific objectives of the study are described.

\subsection{Measurement of moisture content}

The apparatus that was used included: vacuum oven, weighing balance, metal dishes with fitting covers and desiccators. The following procedure was used to determine the moisture content:

i. The metal dish plus cover were dried by placing them in a drying oven at $105 \pm 3{ }^{\circ} \mathrm{C}$ for four hours and weighed to obtain weight $\mathrm{W}_{1}$

ii. A 5-10 g sample of maize cobs was spread evenly over the bottom of the metal dish and cover fitted to give $\mathrm{W}_{2}$

iii. A metal dish was placed in an oven at $105^{\circ} \mathrm{C}$ and dried to constant weight. Constant weight is defined as \pm 0.1 percent change in weight percent solids upon one hour of re-heating the sample.

iv. The metal dish was then placed in a desiccator to cool and later weighed to obtain $\mathrm{W}_{3}$

Calculations that were involved included:

$\%$ Moisture content dry basis $(\mathrm{db})=\frac{W_{2}-W_{3}}{W_{3}-W_{1}} \times 100$

The following calculations were used to obtain the mean and standard deviation (S. D) of the samples.

$\operatorname{Mean}\left(\mathrm{X}_{\mathrm{m}}\right)=\sqrt{\left(\frac{\sum_{i=1}^{n} X_{i}}{n}\right)^{2}}$

Where:

$X_{m}$ is the root mean square of all $x$-values in the set

$\mathrm{n}$ is the number of samples in the set 


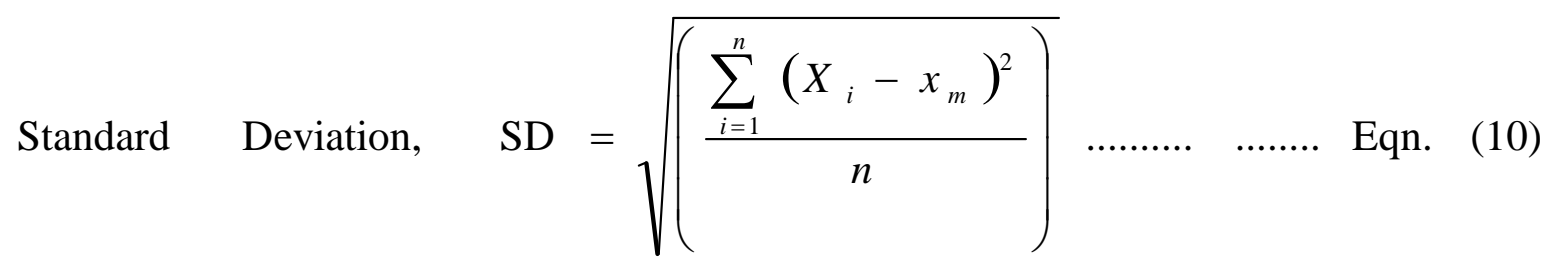

\subsection{Measurement of particle size}

A digital vernier caliper was used to measure the lengths of the samples at three different points and their averages obtained. The average length of each sample was then recorded as shown in Table 4-4. The root mean square deviation and the average lengths for the samples considered for the maize cobs were calculated using Equation (9) and Equation (10) above.

\subsection{Measurement of bulk density}

Bulk density is defined as the weight per unit volume of loosely tipped fuel (FAO, 1986). The bulk density of maize cobs was determined as follows:

i. A cylindrical steel container of volume $0.0679 \mathrm{~m}^{3}$ (obtained from $V=\pi r^{2} h$ ) was used to measure the mass of the biomass waste in kilograms.

ii. The mass of container was measured using a weighing scale.

iii. The biomass was filled to the brim of the container. The total mass of the container and the biomass waste was measured and recorded.

iv. The mass of the maize cobs was obtained by subtracting the mass of empty container from the mass of container when filled with the maize cobs.

v. The bulk density was obtained by dividing the mass of the biomass with the volume of container as shown below.

Bulk Density $=\frac{\text { Weight of Fuel }}{\text { Volume of Container }}$

\subsection{Determination of the ash content}

The following procedure according to Sluiter et al., [2005] was used to determine the ash content of maize cobs.

i. The biomass samples were ashed using a muffle furnace equipped with a ramping program as shown below.

- Ramped from room temperature to $105^{\circ} \mathrm{C}$ and kept at this temperature for 12 minutes

- Ramped to $250^{\circ} \mathrm{C}$ at $10^{\circ} \mathrm{C} /$ minute and held at $250{ }^{\circ} \mathrm{C}$ for 30 minutes 
- Ramped to $575{ }^{\circ} \mathrm{C}$ at $20^{\circ} \mathrm{C} /$ minute and held at this temperature for 180 minutes and allowed to drop to $105^{\circ} \mathrm{C}$ and later held at this temperature until samples were removed

ii. The steel containers were removed from the furnace and allowed to cool. The steel containers and ash were weighed.

iii. The samples were placed back into the furnace at $575 \pm 25^{\circ} \mathrm{C}$ and ashed to constant weight. Constant weight is defined as less than $\pm 0.3 \mathrm{mg}$ change in the weight upon one hour of re-heating the crucible

iv. The percentage ash on oven dry weight (ODW) basis was determined from:

$\%$ Ash $=\frac{\text { Weight of Container and Ash }- \text { Weight of Container alone }}{\text { Oven Dry Weight of Sample }}$. Eqn.

\subsection{Fuel consumption rate and specific load of reactor}

The fuel consumption was obtained by measuring the total amount of biomass feedstock fed into the gasifier while recording the time taken for its gasification. The fuel flow rate was determined using Equation (13).

Fuel flow rate $=\frac{\text { Mass of biomass gasified }(\mathrm{kg})}{\text { Gasification time }(\text { hours })}$

The specific load of the reactor is the amount of biomass that is consumed per cross section of the reactor in an hour. It was determined using Equation (14).

Specific Load of the Reactor $=\frac{\text { Mass of biomass gasified }}{\text { Gasificati on time } \times \text { Area }} \mathrm{kg} / \mathrm{hr} \times \mathrm{m}^{2} .$. Eqn. 


\subsection{EXPERIMENTAL SETUP AND PROCEDURE}

\subsection{Description of gasifier setup and operation}

The gasifier system comprises of a reactor, fuel feeding system, air blower connected to a three phase motor, ash collecting system, a gas sampling unit and a condenser coupled to the exhaust pipe. The reactor consists of a cylindrical shape with an internal diameter of $58 \mathrm{~cm}$, height of $121 \mathrm{~cm}$ and $4 \mathrm{~mm}$ thick reactor wall made of mild steel. At the bottom half of the reactor is an internal ceramic cylinder of dimensions $28 \mathrm{~cm}$ internal diameter and $37 \mathrm{~cm}$ external diameter. The ash collection point has an internal diameter of $38 \mathrm{~cm}$ and a height of $43.5 \mathrm{~cm}$ from the grate to the bottom of the ash collection point. The feeding point has a diameter of $29 \mathrm{~cm}$. The internal diameter of the air inlet point on the gasifier is $10 \mathrm{~cm}$. Figure 4-1 shows a sectional view of the downdraft fixed bed gasifier that was used to perform the experiments at Makerere University.

The gasifier was cleaned of tars from previous experiments that had clogged the gasifier system before it was used to run the experiments in the downdraft mode. Charcoal amounting to an average weight of $7 \mathrm{~kg}$ was fed into the gasifier to provide a char bed during gasification. Maize cobs as biomass was then weighed and fed into the reactor until the feedstock completely covered the thermocouple in the drying zone.

Temperature was measured using K-type thermocouples and recorded continuously using a data acquisition system (87623 SRP-6-1.5M data logger). The temperature profiles in the drying, pyrolysis zone and gas exit after cyclone were recorded and monitored from the computer.

Air flow speed was measured at the air inlet of the gasifier using an air flow meter at intervals of 5 minutes and the average obtained. The air speeds were then used to determine the airflow rates and gas production rates according to Equation (4).

The gas was tested by flaring and once the flare was obtained, the gas sampling unit was turned on and gas samples collected for analysis. In addition the producer gas was cooled and condensate collected in a condenser. 


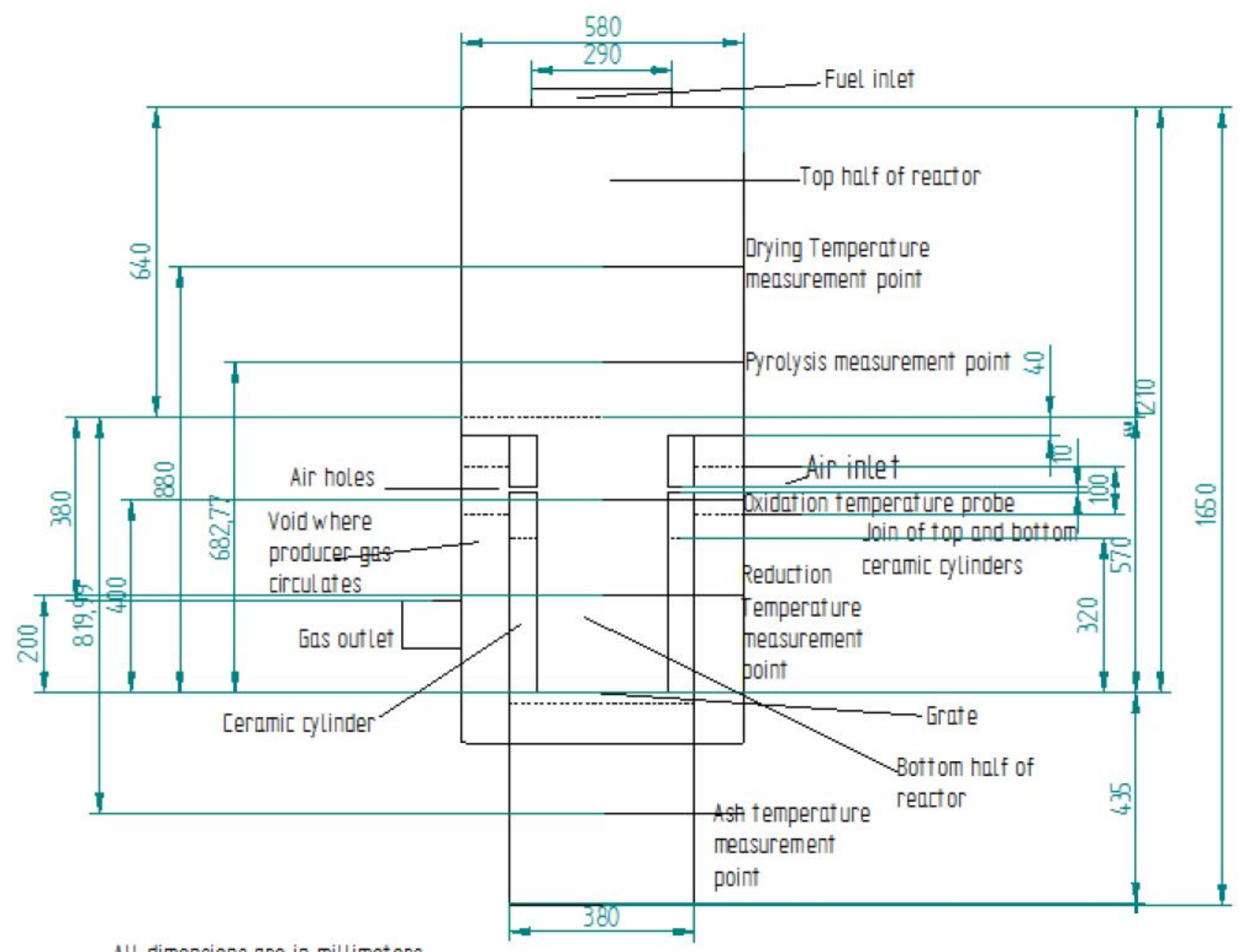

All dimensions are in millimeters

Top part of ceramic cylinder has seven holes

Figure 4- 1: Sectional siew of a downdraft fixed bed gasifier at Makerere University [Lubwama, 2010]

The operation of the gasifier was stopped once the maize cobs were exhausted from the gasifier bed. This was determined when a distinct sound was produced by the gasifier signaling no more feedstock in the reactor. The ash and unburned residues from the gasifier operation was allowed to cool for three to five hours after which they were weighed using a weighing scale.

\subsection{Condenser coupled to the exhaust}

The condenser system consisted of a water bath filled with iced water, collection chamber for the tarry condensate after condensation of vapor in producer gas, an inlet pipe into the collection chamber and exhaust pipe out of the collection chamber. The condenser was fabricated and coupled to the exhaust pipe. The 
aromatic hydrocarbons were collected in a water cooled condenser as shown in Figure 4-2.

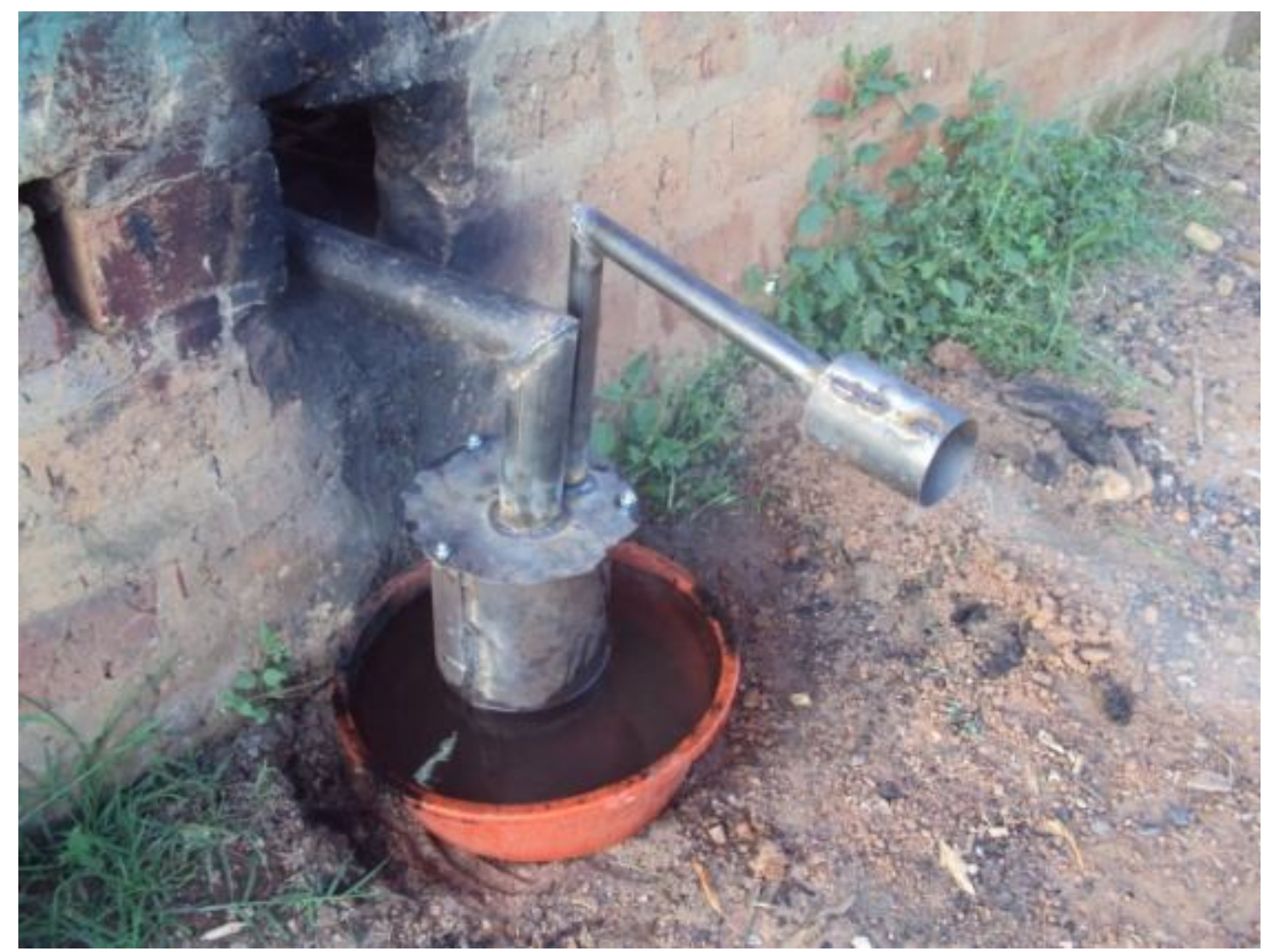

Figure 4- 2: Water cooled condenser connected to the exhaust pipe

"Tars" present in producer gas are able to condense at less than $370^{\circ} \mathrm{C}$ [Miller, 1983]. The tar will condense if the temperature of the process equipment is lower than the tar dew point temperature. The producer gas exiting the exhaust was flared to avoid emissions into the atmosphere.

\subsection{Condensate collection and measurement}

The condensate was collected after the producer gas was cooled, and immediately transferred from the condenser to graduated $250 \mathrm{ml}$ water sampling bottles made of opaque glass to avoid photochemical reactions in water samples. See Figure 43. 


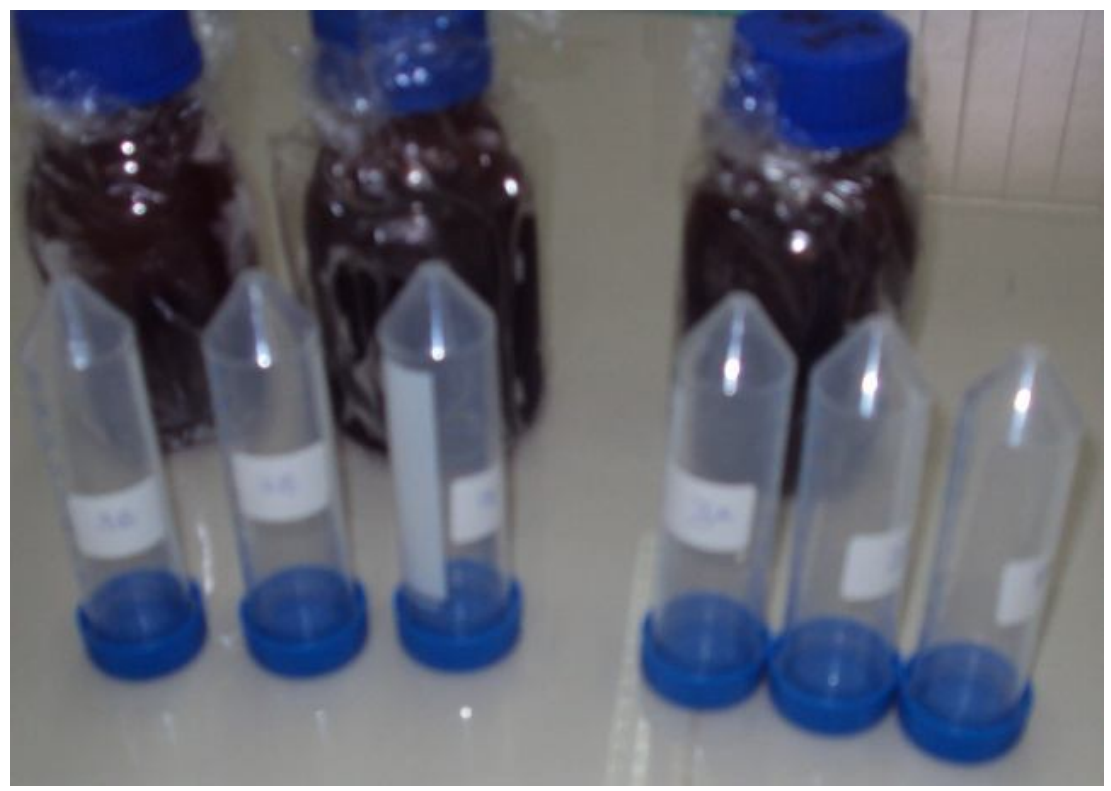

Figure 4- 3: Condensate in sampling bottles

The condensate samples were preserved in a cooler at $2-6{ }^{\circ} \mathrm{C}$ until the time of analysis purposely to minimize the volatilization of the organic compounds with low boiling points and bacterial degradation of the organic compounds.

\subsection{Condensate analysis using CGCMSD}

\subsubsection{Description of CGCMSD}

The Capillary Gas Chromatograph/Mass Spectrometric Detector (model: Agilent GC-MSD 6890) was used to analyze the condensate generated from cooling of biomass producer gas. Figure 4-4 shows the capillary gas chromatography with mass spectrometric detector (CGCMSD) used in the analysis at SGS Ltd located in Mombasa, Kenya.

CGCMSD consists of an injector port where the sample to be analyzed is initially injected into the gas chromatography (GC) and the mixture vaporized in a heated chamber. The gas mixture travels through a GC column, where the compounds become separated as they interact with the column. A mass spectrometer using the ionizer creates charged particles (ions) from molecules. It then analyzes the ions using an ion analyzer to provide information about the molecular weight of the compound and its chemical structure. 


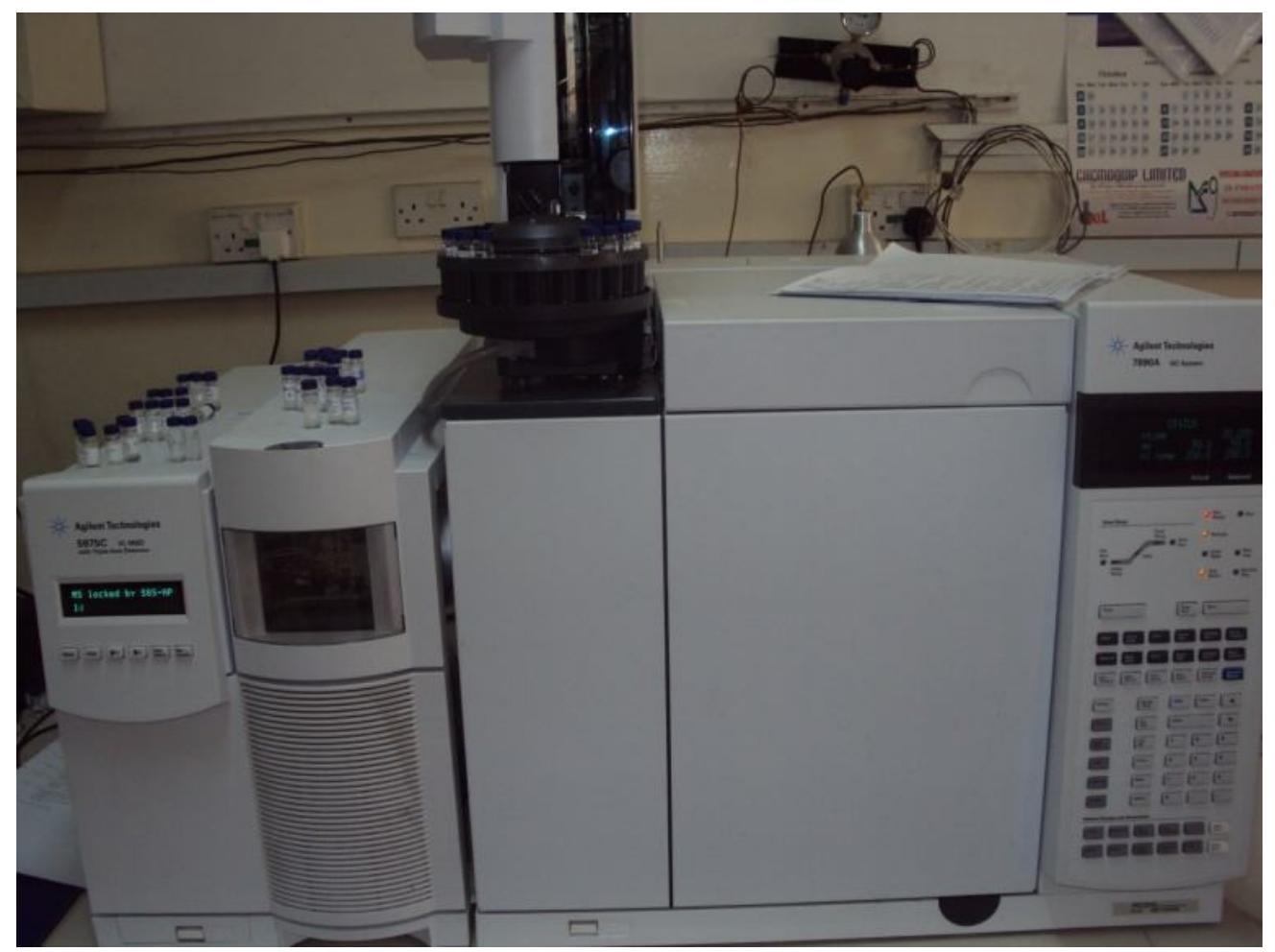

Figure 4- 4: Agilent CGCMSD (6890) used in the analysis at SGS Ltd, Mombasa, Kenya

The mass spectrometer also consists of a detector which works by producing an electronic signal when struck by an ion. The size of the signal is recorded by a data system and is plotted against elapsed time to produce a chromatogram. Timing mechanisms which integrate those signals with the scanning voltages allow the instrument to report which mass to charge ratio $(\mathrm{m} / \mathrm{z})$ strikes the detector. The mass analyzer sorts the ions according to $\mathrm{m} / \mathrm{z}$ and the detector records the abundance of each $\mathrm{m} / \mathrm{z}$.

\subsubsection{Chemicals}

All chemicals and reagents were of analytical grade and of highest possible purity. The use of high purity reagents and solvents helped to minimize interference problems. Due to the non-polar nature of the GC column, hexane (CGCMSD grade) was used as an organic solvent for extractions.

A PAH reference standard mixture containing the target light polycyclic aromatic hydrocarbons (i.e. naphthalene, acenaphthylene, acenaphthene, fluorene, phenanthrene and anthracene) was used in the study. The mixture contained the two isotopically labeled PAHs namely acenaphthalene- $d_{10}$ and phenanthrene- $d_{10}$ as internal standards. Table $4-1$ shows the list of the surrogate standards and the 
corresponding PAHs they present. For BTEX analysis in the condensate, fluorobenzene (4000 $\mathrm{mg} / \mathrm{l}$ in methanol) was used as an internal standard while BTEX-GC standard solution containing benzene, toluene, ethylbenzene and xylene was used as a reference standard mixture.

Table 4- 1: Surrogate standards and the corresponding PAH they represent

\begin{tabular}{|l|l|}
\hline Acenaphthene $\mathbf{d}_{\mathbf{1 0}}$ & Phenanthrene-d $_{\mathbf{1 0}}$ \\
\hline Naphthalene & phenanthrene \\
\hline Acenaphthene & Anthracene \\
\hline Acenaphthylene & Fluoranthene \\
\hline Fluorene & Pyrene \\
\hline
\end{tabular}

\subsubsection{Apparatus}

The apparatus used in sample preparation included: measuring cylinders, pipettes, vials, centrifugal tubes, mechanical shaker, centrifuge machine, analytical balance, Agilent GC-MSD (6890) in electron ionization mode with splitless injector and capillary column of size $30 \mu \times 250 \mu \mathrm{m} \times 0.25 \mu \mathrm{m}$. Measuring cylinders, vials, pipettes and centrifugal tubes used were cleaned with hexane and dried in an oven at $105{ }^{\circ} \mathrm{C}$. This was done to avoid method interferences due to contaminants in solvents, reagents, glassware, and other sample processing hardware.

\subsubsection{Preparation of standard solutions for PAH determination}

Five standard solutions each containing the target compounds were prepared by diluting to $1.0,0.75,0.50,0.25$ and $0.1 \mathrm{ppm}$ of $10 \mathrm{ppm}$ of each PAH standard mixture with $20 \mathrm{ml}$ of hexane. A pipette was used to measure the respective volumes calculated according to Equation (15):

$\mathrm{C}_{1} * \mathrm{~V}_{1}=\mathrm{C}_{2} * \mathrm{~V}_{2}$

Where:

$$
\begin{aligned}
& \mathrm{C}=\text { Concentration }(\mathrm{ppm}) \\
& \mathrm{V}=\text { Volume }(\mathrm{ml})
\end{aligned}
$$

To all of the solutions $0.5 \mu \mathrm{g}$ each of the internal standards was added. The solutions were transferred into capped and sealed vials ready for analysis. The standard solutions obtained were used for creating calibration curves for evaluation of method linearity and spiking the samples for quantitative determination of the $\mathrm{PAH}$. 


\subsubsection{Preparation of standard solutions for BTEX determination}

Five standard solutions containing the target aromatics (i.e. benzene, toluene, ethylbenzene and xylene) in varying concentrations were prepared by diluting to $1.0,0.75,0.50,0.25$ and $0.1 \mathrm{ppm}$ of each BTEX GC standard with $20 \mathrm{ml}$ of hexane. A pipette was used to measure the respective volumes calculated according to Equation (15).

To all the standard solutions, $5 \%$ of fluorobenzene $(4000 \mathrm{mg} / \mathrm{l}$ in methanol) as an internal standard was added. The standard solutions obtained were used for creating calibration curves for evaluation of method linearity and spiking the samples for quantitative determination of BTEX.

\subsubsection{Calibration}

Calibration curves were obtained using a series of varying concentrations (i.e. 1.0, $0.75 .0 .50,0.25$, and $0.1 \mathrm{ppm}$ ) of a standard mixture containing each of the target aromatic hydrocarbon. The several dilutions of the standard PAH mixture and BTEX GC standard mixture made were analyzed to determine the limit of detection (LOD), limit of quantitation (LOQ), relative standard deviation (RSD) and coefficient of correlation ( $r$ ). The LOD and LOQ were determined from the plot of response factor versus concentration. The LOD was determined using Equation (16) while the limit of quantitation was determined using Equation (17) [Miller et al., 1993].

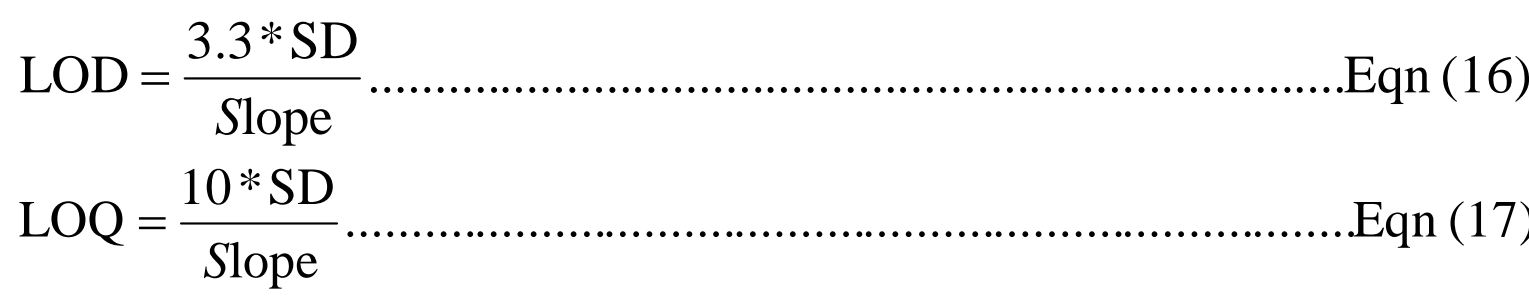

\subsubsection{PAH extraction by shaking}

In a $50 \mathrm{ml}$ glass vial, $20 \mathrm{ml}$ of sample was measured using measuring cylinders and mixed with $10 \mathrm{~g}$ of anhydrous sodium sulphate. The purpose of the anhydrous sodium sulphate was to remove any water that would otherwise mix with the solvent prior to injection of the prepared sample in the GC. $20 \mathrm{ml}$ of the organic solvent (i.e. hexane) and $100 \mu \mathrm{l}$ of the internal standards were added to the mixture and the solutions mixed by mechanical shaking at $200 \mathrm{rpm}$ for $20 \mathrm{~min}$ at room temperature. The two phases formed were separated by centrifugation at $1,500 \mathrm{rpm}$ for a period of $30 \mathrm{~min}$. See Figure 4-5 and Figure 4-6 showing a mechanical shaker and a centrifuge respectively. The extracted samples were purified by passing them through a silica gel column prepared by loading $10 \mathrm{~g}$ of 
activated silica gel onto a chromatographic column. The organic phase was then transferred into $20 \mathrm{ml}$ glass test tube after which a $2 \mu \mathrm{l}$ aliquot of the final solution of each test sample was then injected in a GCMSD for analysis.

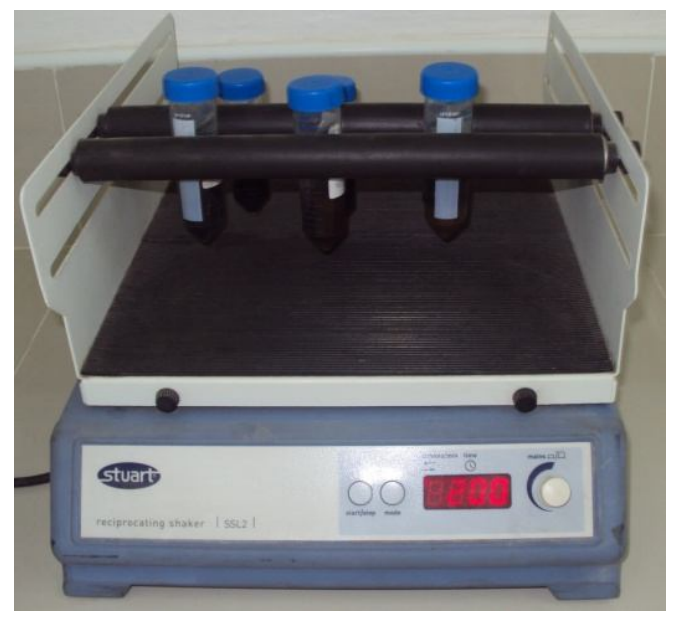

Figure 4- 5: Mechanical Shaker

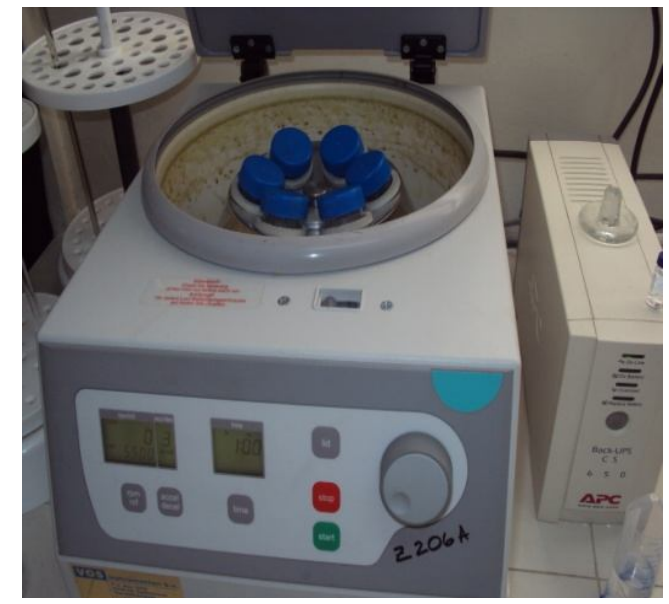

Figure 4- 6: Samples Placed in a centrifuge

\subsubsection{BTEX extraction by shaking}

In a $50 \mathrm{ml}$ glass vial, was placed $20 \mathrm{~g}$ of sample and $10 \mathrm{~g}$ of anhydrous sodium sulphate. $20 \mathrm{ml}$ of hexane and $100 \mu \mathrm{l}$ of flourobenzene $(4000 \mathrm{mg} / \mathrm{L}$ in methanol) were added to the solution and mixed by mechanical shaking for $20 \mathrm{~min}$ at room temperature. The two phases were separated by centrifugation at $1,500 \mathrm{rpm}$ for a period of $30 \mathrm{~min}$ and the organic phase transferred into a $20 \mathrm{ml}$ glass test tube. A 2 $\mu \mathrm{l}$ aliquot of the final solution was injected in a GC.

\subsubsection{Recovery studies}

Prior to extraction, two surrogate standards were added to the sample to monitor the recovery of different target compounds. The surrogate standards used included: acenaphthene $d_{10}$, and phenanthrene- $d_{10}$ for PAH analysis. BTEX-GC surrogate standard was used for BTEX analysis. A surrogate is a chemical compound not expected to occur in the sample under study. This was used to monitor method performance. The samples were subjected to the same extraction procedures as described above. The surrogate percent recovery was calculated using Equation 18:

$$
\% \text { surrogate recovery }=\frac{\mathrm{Q}_{\mathrm{d}}}{\mathrm{Q}_{\mathrm{a}}} x 100
$$

Where:

$Q_{d}$ is the quantity determined by analysis 
$Q_{a}$ is the quantity added.

For surrogate percent recovery to be acceptable it must fall between 60 and $120 \%$ (US EPA, 1999).

\subsubsection{CGCMSD conditions}

Agilent GC/MSD (6890) in electron ionization mode with splitless injector coupled to a capillary column HP-5MS (5\% Methyl Phenyl Silox) of size $30 \mathrm{~m} \times 250 \mu \mathrm{m} \times$ $0.25 \mu \mathrm{m}$ was used to detect and quantify the target aromatic hydrocarbons in the condensate. Helium (>99.999\% pure) was used as the carrier gas and the column head pressure was maintained at $25.83 \mathrm{kPa}$ to give an approximate flow rate of $1 \mathrm{ml} / \mathrm{min}$ with an injection port configured in the splitless mode. The injection port and detector temperatures were maintained at $250^{\circ} \mathrm{C}$ and $300^{\circ} \mathrm{C}$, respectively. All injection volumes were $2 \mu \mathrm{l}$ in the splitless mode. See Appendix A and B for CGCMSD conditions during PAH and BTEX analysis respectively. The initial column oven temperature was held at $50^{\circ} \mathrm{C}$ for 0.4 min and was programmed to $195{ }^{\circ} \mathrm{C}$ at a $25{ }^{\circ} \mathrm{C} \mathrm{min}{ }^{-1}$ rate for $1.5 \mathrm{~min}$, and finally to $315^{\circ} \mathrm{C}$ at $20{ }^{\circ} \mathrm{C} \mathrm{min}{ }^{-1}$ rate where it was held for $1.25 \mathrm{~min}$. The overall GC program time was $20.2 \mathrm{~min}$. The mass spectrometer was used in electron ionization mode by electron impact (70 $\mathrm{eV})$.

\subsubsection{Identification and quantitation of the hydrocarbons}

Identification of the target compounds was based on the retention time match and mass spectra match against the calibration standards. Quantitation was performed by the method of internal standardization using acenaphthene- $d_{10}$ and phenanthrene- $d_{10}$ for PAH and fluorobenzene for BTEX. The quantitation was based on the ratio of the peak height of the quantitation ion to that of the corresponding internal standard. However, the integrated programs of the CGCMSD were used to quantify the concentration of the individual target compounds.

Overall quantification was based on the following target ions $(\mathrm{m} / \mathrm{z})$ : naphthalene, 128; acenaphthylene, 152; acenaphthene, 154; fluorene, 166; phenanthrene, 178; anthracene, 178. For BTEX analysis, the detector was operated in the SIM mode, selecting the following specific ions $(\mathrm{m} / \mathrm{z})$ : benzene, 78.11, toluene, 92.14; ethylbenzene, 106.17; 1,2-dimethylbenzene, 106.16; 1,3-dimethylbenzene, 106.16 and 1,4-dimethylbenzene, 106.16. The limit of detection for each target aromatic hydrocarbon was established from calibration. 


\subsection{RESULTS AND DATA ANALYSIS}

\subsection{Introduction}

This chapter documents the results of: the moisture content measurements, ash content determination, bulk density determination, particle size determination, producer gas analysis, fuel flow rate and specific load of reactor, amount of condensate collected, specific gasification rate, superficial velocity, specific gas production rate and the test runs on the gasifier in which temperature profiles were recorded and the experiments performed on the condensate using a CGCMSD. The analysis of the results is shown as well as the discussion of the results.

\subsection{Moisture content determination}

The moisture content of maize cobs was calculated from six selected samples. The moisture content of maize cobs ranged from $12.57 \%$ dry basis to $15.48 \%$ dry basis. The average moisture content was $13.55 \%$ dry basis with a variability of $0.99 \%$. Table $5-1$ shows results obtained from the oven dry method.

Table 5- 1: Moisture Content of Maize Cobs

\begin{tabular}{|c|c|c|c|c|}
\hline Sample & Wet $\mathbf{W t} / \mathbf{g}$ & Dry $\mathbf{W t} / \mathbf{g}$ & $\mathbf{M C}(\mathbf{W t} / \mathbf{g})$ & \% $\mathbf{M C} \mathbf{~ d b}$ \\
\hline 1 & 20.37 & 17.99 & 2.38 & 13.23 \\
\hline 2 & 17.31 & 14.99 & 2.32 & 15.48 \\
\hline 3 & 29.67 & 26.32 & 3.35 & 12.73 \\
\hline 4 & 18.14 & 15.90 & 2.24 & 14.09 \\
\hline 5 & 18.05 & 15.95 & 2.10 & 13.17 \\
\hline 6 & 19.70 & 17.50 & 2.20 & 12.57 \\
\hline Mean & 20.54 & 18.11 & 2.43 & 13.55 \\
\hline S. D & 4.21 & 3.81 & 0.42 & 0.99 \\
\hline
\end{tabular}

The moisture content of the agricultural residues favored downdraft gasification. FAO [1986] reports that downdraft gasifiers need reasonably dry fuels (less than $25 \%$ moisture dry basis) to reduce on the tar entrainment problem.

\subsection{Ash content determination}

Six samples of maize cobs were used in the determination of ash content. Table 52 shows the ash contents of the six samples. The ash content of the six samples ranged from $2.50 \%$ to $3.97 \%$ with the mean of $3.39 \%$ and variability of $0.51 \%$. 
The ash content of the agricultural residue was considerably low therefore no slagging problems in the reactor were encountered.

Table 5- 2: Ash content of maize cobs

\begin{tabular}{|c|c|c|c|}
\hline Run & Oven dry weight (g) & Dry Matter (g) & \% Ash content \\
\hline 1 & 18.03 & 17.34 & 3.83 \\
\hline 2 & 15.33 & 14.87 & 3.00 \\
\hline 3 & 24.35 & 23.54 & 3.33 \\
\hline 4 & 15.97 & 15.57 & 2.50 \\
\hline 5 & 17.57 & 16.92 & 3.70 \\
\hline 6 & 16.61 & 15.95 & 3.97 \\
\hline Mean & 17.98 & 17.37 & 3.39 \\
\hline S.D & 2.99 & 2.88 & 0.51 \\
\hline
\end{tabular}

According to FAO [1986], slagging can lead to excessive tar formation and/or complete blocking of the reactor thus affecting smooth operation of the gasifier. In general, no slagging is observed with fuels having ash contents below 5-6 percent [FAO, 1986].

\subsection{Bulk density of maize cobs}

Nine samples were used to determine the bulk density of maize cobs as shown in Table $5-3$. The bulk density ranged from $304.20 \mathrm{~kg} / \mathrm{m}^{3}$ to $422.24 \mathrm{~kg} / \mathrm{m}^{3}$ with a mean of $358.99 \mathrm{~kg} / \mathrm{m}^{3}$ and variability of $40.42 \mathrm{~kg} / \mathrm{m}^{3}$. The high variability of bulk densities may be attributed to collection of the agricultural residue from different fields with different grain quality.

Table 5- 3: Bulk density of maize cobs

\begin{tabular}{|r|c|}
\hline Sample & Bulk density $\mathbf{( k g} / \mathbf{m}^{\mathbf{3}} \mathbf{~}$ \\
\hline 1 & 313.78 \\
\hline 2 & 383.13 \\
\hline 3 & 304.20 \\
\hline 4 & 384.67 \\
\hline 5 & 354.32 \\
\hline 6 & 422.24 \\
\hline 7 & 310.78 \\
\hline 8 & 353.58 \\
\hline 9 & 404.20 \\
\hline Mean & 358.99 \\
\hline S.D & 40.42 \\
\hline
\end{tabular}


The bulk density of the agricultural residue was high and therefore advantageous because it represents a high energy-for-volume value. Low bulk density fuels sometimes give rise to insufficient flow under gravity, resulting in low gas heating values and ultimately in burning of the char in the reduction zone.

\subsection{Particle size distribution}

The particle sizes of the maize cobs that were used in the gasifier were determined as shown in Table 5-4. The average length of the agricultural waste was obtained from 9 samples. The length of the maize cobs sampled varied from a maximum length of $127.04 \mathrm{~mm}$ to a minimum of $69.46 \mathrm{~mm}$. The mean particle size was 91.20 $\mathrm{mm}$ with a standard deviation of $18.05 \mathrm{~mm}$.

Table 5- 4: Particle size distribution of maize cobs

\begin{tabular}{|c|c|}
\hline Sample & Length $(\mathbf{m m})$ \\
\hline 1 & 70.65 \\
\hline 2 & 109.55 \\
\hline 3 & 72.52 \\
\hline 4 & 96.65 \\
\hline 5 & 90.00 \\
\hline 6 & 69.46 \\
\hline 7 & 127.04 \\
\hline 8 & 88.36 \\
\hline 9 & 96.58 \\
\hline Mean & 91.20 \\
\hline S.D & 18.05 \\
\hline
\end{tabular}

According to Ming [2005], particles sized between 10 and $300 \mathrm{~mm}$ are suitable for small downdraft gasifiers. This implies that since the mean particle size obtained was within the acceptable range, then the biomass was suitable for use in the down draft gasifiers.

\subsection{Composition of producer gas}

Three gas samples were analyzed using the GC to determine the percentage composition of the gas. The results of the analysis are shown in Figure 5-1. 
Table 5- 5: Percentage composition of producer gas from maize cobs

\begin{tabular}{|l|c|c|c|c|c|c|c|c|}
\hline & $\% \mathrm{H}_{2}$ & $\% \mathbf{O}_{2}$ & $\% \mathbf{N}_{2}$ & $\% \mathbf{C O}$ & $\% \mathbf{C H}_{4}$ & $\% \mathbf{C O}_{2}$ & $\% \mathbf{C}_{2} \mathrm{H}_{4}$ & $\%$ Total \\
\hline Calibration Gas 1 & 8.05 & 0.35 & 58.97 & 9.93 & 5.09 & 17.96 & 0.00 & 100.35 \\
\hline Normal Air & 0.00 & 20.90 & 78.00 & 0.00 & 0.00 & 0.00 & 0.00 & 98.90 \\
\hline Producer Gas 1 & 8.05 & 5.57 & 57.24 & 12.14 & 2.08 & 11.86 & 0.00 & 96.94 \\
\hline Producer Gas 2 & 8.05 & 5.57 & 57.53 & 12.14 & 1.87 & 12.03 & 0.00 & 97.19 \\
\hline Producer Gas 3 & 8.05 & 5.81 & 58.11 & 13.24 & 1.66 & 10.76 & 0.00 & 97.62 \\
\hline Mean & 8.05 & 5.65 & 57.63 & 12.50 & 1.87 & 11.55 & 0.00 & 97.25 \\
\hline SD & 0.00 & 0.11 & 0.36 & 0.52 & 0.17 & 0.56 & 0.00 & 0.28 \\
\hline
\end{tabular}

The composition of the three gas samples was close to those reported by FAO [1986] for a typical downdraft gasifier. According to FAO [1986], gas composition of a typical downdraft gasifier include: $\mathrm{N}_{2}(50-54 \%), \mathrm{CO}(17-22 \%), \mathrm{CO}_{2}(9-15 \%), \mathrm{H}_{2}$ $(12-20 \%)$ and $\mathrm{CH}_{4}(2-3 \%)$.

The results obtained above show that the mean total composition of producer gas analyzed was $97.25 \%$ with a standard deviation of $0.28 \%$. The mean total measured concentration of the gases was not $100 \%$ due to the impossibility to measure water vapor, and tar in the producer gas with the gas chromatography. Figure 5-1 is a graphical representation of the percentage composition of producer gas obtained from the three experimental runs.

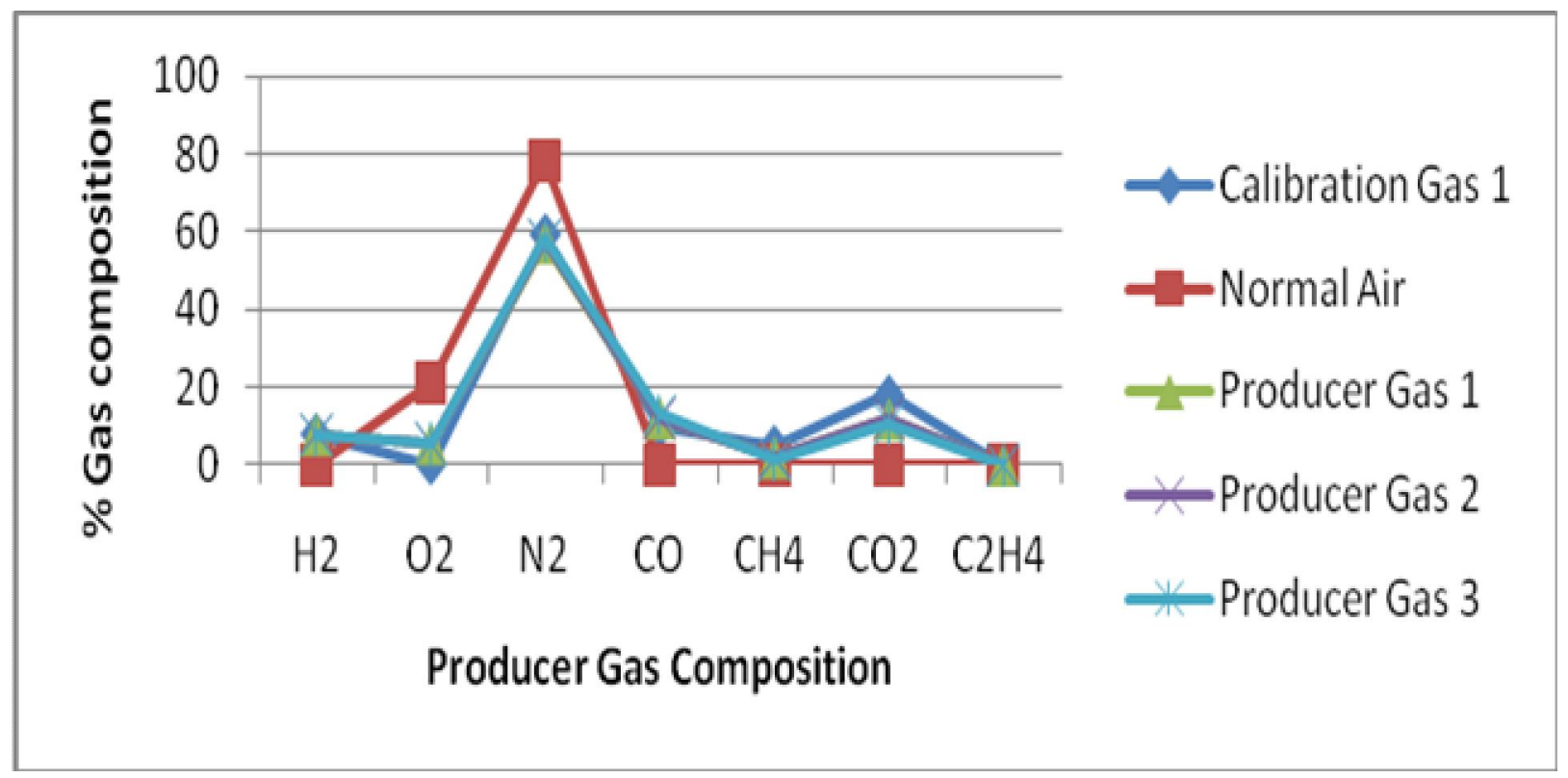

Figure 5-1: Percentage composition of producer gas from maize cobs 
The producer gas was diluted due to presence of nitrogen. An average of $57.63 \%$ of gas was composed of noncombustible nitrogen thus reducing the thermal efficiency of the producer gas.

\subsection{Fuel flow rate (FFR) and specific load of reactor (SLR)}

The fuel flow rate was determined using Equation (13) as shown below:

$$
\text { Fuel flow rate }=\frac{\text { Mass of biomass gasified }(\mathrm{kg})}{\text { Gasification time (hours) }}
$$

The specific load of the reactor is the amount of biomass that is consumed per cross section of the reactor in an hour. It was determined using Equation (14) as shown below:

$$
\text { Specific Load of the Reactor }=\frac{\text { Mass of biomass gasified }}{\text { Gasification time } \mathrm{x} \text { Area }} \mathrm{kg} /\left(\mathrm{hr} \times \mathrm{m}^{2}\right)
$$

Since the diameter of the reactor used was measured as $280 \mathrm{~mm}$, then the cross sectional area of the reactor was $0.062 \mathrm{~m}^{2}$. Goorts, [2008] states that the characteristic value of specific loads of the reactor ranges between 500 and 2000 $\mathrm{kg} /\left(\mathrm{m}^{2} \times \mathrm{hr}\right)$. However, from results shown in Table 5-6, all experiments showed very low specific loads (average of $185.14 \mathrm{~kg} /\left(\mathrm{m}^{2} \times \mathrm{hr}\right.$ ). This may be explained by the high heat loss in the reactor resulting in lower overall efficiency.

Table 5- 6: Fuel flow rate (FFR) and specific load of reactor (SLR)

\begin{tabular}{|c|c|c|}
\hline Run & FFR (kg fuel/hr) & SLR $\left.\mathbf{( k g} / \mathbf{m}^{2} \mathbf{x} \mathbf{h r}\right)$ \\
\hline 1 & 12.00 & 194.88 \\
\hline 2 & 9.60 & 155.91 \\
\hline 3 & 11.38 & 184.81 \\
\hline 4 & 12.02 & 195.24 \\
\hline 5 & 12.00 & 194.88 \\
\hline Mean & 11.40 & 185.14 \\
\hline S.D & 0.93 & 15.14 \\
\hline
\end{tabular}

\subsection{Amount of condensate collected per $\mathrm{kg}$ fuel per hour}

The amount of condensate collected per kilogram fuel per hour is shown in Table 5-7. It was determined from the expression below: 
Condensate collected $\left(\mathrm{m}^{3} / \mathrm{kg}\right.$ fuel $\left.\times \mathrm{hr}\right)=\frac{\text { Total condensate collected }\left(\mathrm{m}^{3}\right)}{\text { Amount of biomass gasified }(\mathrm{kg}) * \text { No.of hours }}$

Table 5- 7: Amount of condensate collected per $\mathrm{kg}$ fuel per hour

\begin{tabular}{|c|c|c|c|}
\hline Run & $\begin{array}{l}\text { biomass gasified } \\
\text { (kg) }\end{array}$ & Condensate $\left(\times 10^{-5} \mathrm{~m}^{3}\right)$ & $\begin{array}{l}\text { Condensate } \\
\left(\times 10^{-6} \mathrm{~m}^{3} / \mathrm{kg} \text { fuel } \times \mathrm{hr}\right)\end{array}$ \\
\hline 1 & 15.00 & 22.0 & 11.7 \\
\hline 2 & 12.00 & 12.5 & 8.3 \\
\hline 3 & 19.00 & 24.5 & 7.7 \\
\hline 4 & 22.00 & 24.8 & 6.2 \\
\hline 5 & 18.00 & 23.5 & 8.7 \\
\hline Mean & 17.20 & 21.46 & 8.5 \\
\hline S.D & 3.43 & 4.59 & 1.8 \\
\hline
\end{tabular}

The amount of condensate collected per kilogram fuel per hour ranged between $6.2 \times 10^{-6} \mathrm{~m}^{3}$ and $11.7 \times 10^{-6} \mathrm{~m}^{3}$. The mean amount of condensate collected was $8.5 \times 10^{-6} \mathrm{~m}^{3} /(\mathrm{kg}$ fuel $\times \mathrm{hr})$ with a standard deviation of $1.82 \times 10^{-6} \mathrm{~m}^{3} /(\mathrm{kg}$ fuel $\times \mathrm{hr})$.

\subsection{Superficial velocity or specific gas production rate}

According to Reed and Das [1988], for imbert type gasifiers, the diameter is measured at the throat (upper value) or at the air entry level (lower value). However, since the gasifier used had no throat, the diameter at the air entry level was considered. Cross sectional area of the air inlet = $\frac{\prod D^{2}}{4}=\frac{\prod \times 0.1^{2}}{4}=0.007855 \mathrm{~m}^{2}$

The air flow rate was obtained by multiplying the air speeds $(\mathrm{m} / \mathrm{s})$ with the cross sectional area of the air inlet while the rate of gas production $\left(\mathrm{Nm}^{3} / \mathrm{hr}\right)$ was obtained from Equation (4) as shown below:

Rate of gas production, $\mathrm{m}^{3} / \mathrm{h}=\frac{\text { Air flow rate } \times 3.76 / 4.76}{\text { Nitrogen mole fraction of dry producer gas }\left(\mathrm{yN}_{2}\right)}$

From Table 5-5, the mean mole fraction of dry producer gas was 0.5763 . The U.S Metric Association (USMA) suggests an average room temperature lies between $20^{\circ} \mathrm{C}$ and $25^{\circ} \mathrm{C}$ [http://lamar.colostate.edu/ hillger/temps.htm]. Therefore average room temperature considered was $\frac{(20+25)}{2}=22.5^{\circ} \mathrm{C}$

Thus the air flow rates were measured at $22.5^{\circ} \mathrm{C}(295.5 \mathrm{~K})$ and a pressure of 1 atmosphere after which the air flow rates were converted to normal conditions i.e. 
$0^{\circ} \mathrm{C}(273 \mathrm{~K})$ and a pressure of 1 atmosphere. The normal air flow rates were determined using Equation (5) as shown below:

$$
\frac{\dot{V}_{1}}{T_{1}}=\frac{\dot{V}_{2}}{T_{2}}
$$

Using the gas production rate and the cross sectional area of the gasifier at the air inlet, the specific gas production rate (SGPR) and superficial velocity $\left(V_{s}\right)$ were calculated and the results tabulated in Table 5-8.

Table 5- 8: Specific gas production rate and superficial velocity

\begin{tabular}{|c|c|c|c|c|}
\hline Run & Normal AFR $\left(\mathrm{Nm}^{3} / \mathrm{hr}\right)$ & GPR $\left(\mathrm{Nm}^{3} / \mathrm{hr}\right)$ & $\operatorname{SGPR}\left(\mathrm{Nm}^{3} / \mathrm{hr} \cdot \mathrm{m}^{2}\right)$ & $V s(\mathrm{~m} / \mathrm{s})$ \\
\hline 1 & 54.86 & 75.19 & 9572.6 & 2.23 \\
\hline 2 & 45.98 & 63.02 & 8023.4 & 1.52 \\
\hline 3 & 83.6 & 114.59 & 14588 & 2.17 \\
\hline 4 & 44.68 & 61.24 & 7796.1 & 2.14 \\
\hline 5 & 44.15 & 60.52 & 7704.2 & 1.58 \\
\hline 6 & 75.24 & 103.13 & 13129 & 1.87 \\
\hline 7 & 38.66 & 52.99 & 6746.6 & 1.43 \\
\hline 8 & 63.75 & 87.37 & 11123 & 1.33 \\
\hline 9 & 27.43 & 37.6 & 4786.3 & 1.56 \\
\hline 10 & 32.13 & 44.04 & 5606.9 & 2.35 \\
\hline mean & 51.05 & 69.97 & 8907.6 & 1.82 \\
\hline SD & 17.33 & 23.75 & 3024.1 & 0.36 \\
\hline
\end{tabular}

From Table 5-8, the mean specific gas production rate was $8907.6 \mathrm{Nm}^{3} / \mathrm{hr}-\mathrm{m}^{2}$ while the mean superficial velocity was $1.82 \mathrm{~m} / \mathrm{s}$ with standard deviation of 0.36 . Hariie [2005] suggests an optimum value of superficial velocity of $2.5 \mathrm{~m} / \mathrm{s}$ or specific gas production rate of $9000 \mathrm{Nm} / \mathrm{hr}^{3} \mathrm{~m}^{2}$ calculated at NTP from the throat diameter. Reed [1998] reports that the practical range for superficial velocity is $0.8 \mathrm{~m} / \mathrm{s}$ where tars are quite high to $2.5 \mathrm{~m} / \mathrm{s}$. The superficial velocity of $1.82 \mathrm{~m} / \mathrm{s}$ was close to the optimum value of $2.5 \mathrm{~m} / \mathrm{s}$. The superficial velocity of a gasifier is the most important measure of its performance, controlling gas production rate, gas energy content, fuel consumption rate, power output, and char and tar production rate.

\subsection{Gasification temperature profiles}

In this section, the temperature variations are presented for the drying, pyrolysis and gas exit sections. Figures 5-2, 5-3 and 5-4 show the temperature profiles in selected zones of the gasifier reactor during three experimental runs. In Figure 5-2, 
the temperature in the pyrolysis zone (green line) ranged between $136.87^{\circ} \mathrm{C}$ and $676.83^{\circ} \mathrm{C}$ thus favoring formation of primary tars.

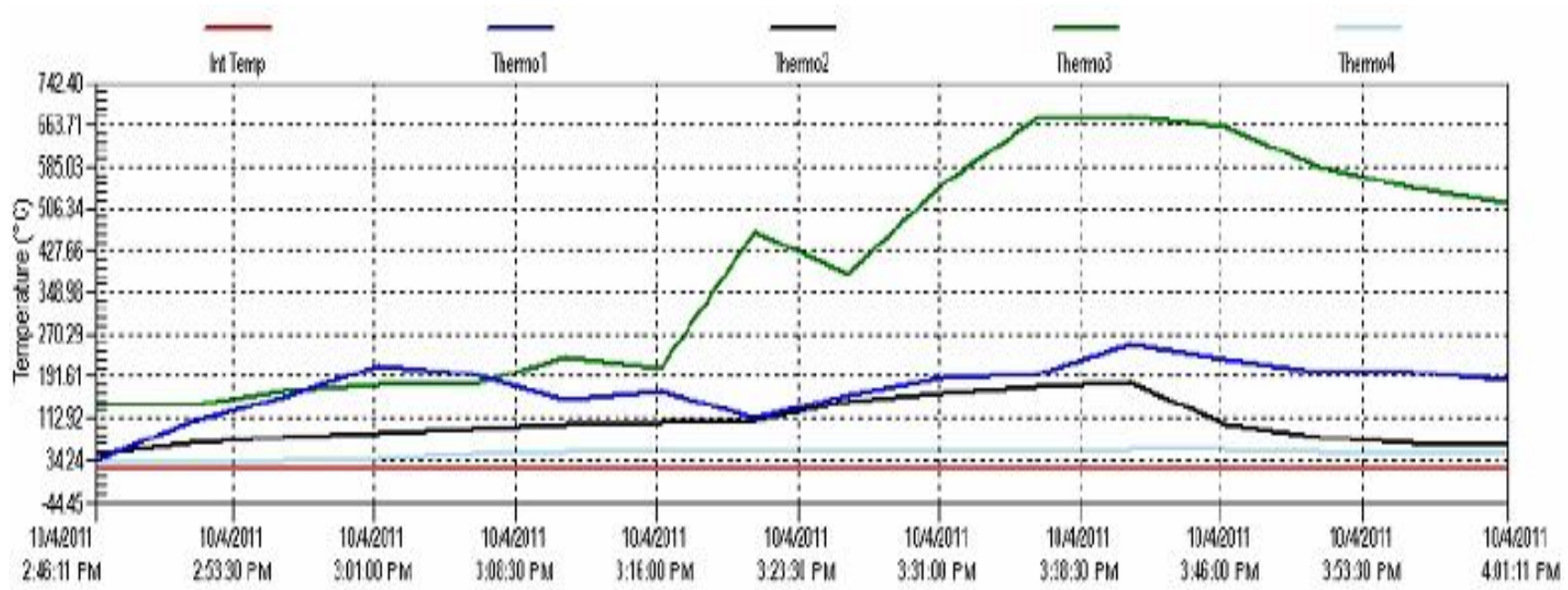

Figure 5- 2: Temperature profile in the reactor for experimental Run 1

According to Milne \& Evans [1998], primary tars are formed within a temperature range of $200{ }^{\circ} \mathrm{C}$ and $500{ }^{\circ} \mathrm{C}$. Therefore since the temperatures in the pyrolysis zone were below $800^{\circ} \mathrm{C}$ reported by Milne \& Evans [1998], there were fewer chances for formation of polycyclic aromatic hydrocarbons. The temperature of the gas exiting the gasifier (blue line) ranged between 37.14 to $252{ }^{\circ} \mathrm{C}$ while the drying temperature (black colour) ranged between 47.81 to $178.84{ }^{\circ} \mathrm{C}$.

Figure 5-3 shows the temperature profile of experimental run 2 with the temperature in the pyrolysis zone (green line) between $48.59{ }^{\circ} \mathrm{C}$ and $766.54{ }^{\circ} \mathrm{C}$ thus favoring formation of both primary tars and secondary tars.

MAILE KUBS-150n NOK-2011

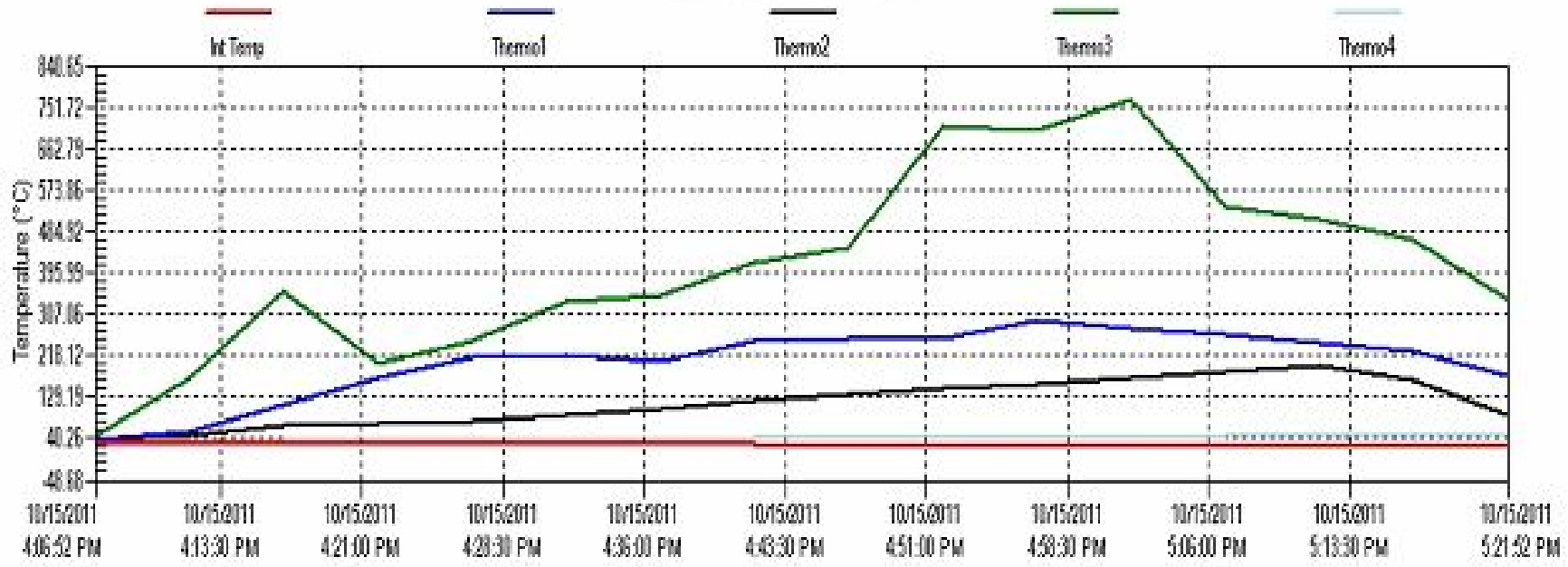

Figure 5- 3: Temperature profile in the reactor for experimental Run 2 
According to Milne \& Evans [1998], secondary tars are formed within a temperature range of $500{ }^{\circ} \mathrm{C}$ and $800{ }^{\circ} \mathrm{C}$. The temperature of the gas exiting the gasifier (blue line) ranged between $38.38{ }^{\circ} \mathrm{C}$ and $293.37{ }^{\circ} \mathrm{C}$ while the drying temperature (black colour) ranged between $36.86^{\circ} \mathrm{C}$ and $197.65^{\circ} \mathrm{C}$.

Figure 5-4 shows the temperature profile of experimental run 3 , with the temperature in the pyrolysis zone (green line) ranging between $172.06{ }^{\circ} \mathrm{C}$ and $807.77^{\circ} \mathrm{C}$.

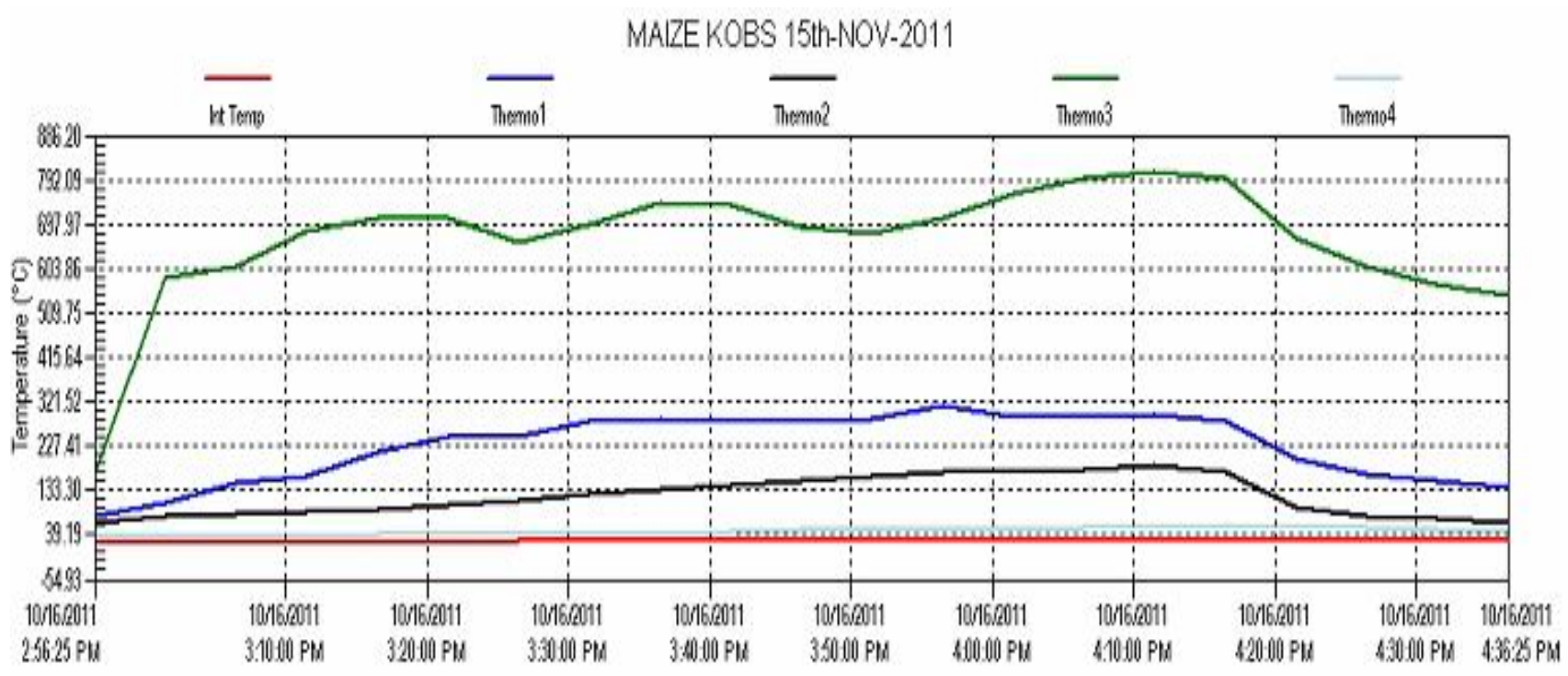

Figure 5- 4: Temperature profile in the reactor for experimental run 3

According to Milne \& Evans [1998], tertiary tars are formed at temperatures higher than $800^{\circ} \mathrm{C}$. As gasification took over at higher temperatures, the primary products were thermally decomposed to lesser amounts of secondary and tertiary products. Temperature of the gas exiting the gasifier (blue line) ranged between 77.33 and $311.03^{\circ} \mathrm{C}$ while the drying temperature (black colour) ranged between 63.16 to $184.98^{\circ} \mathrm{C}$.

\subsection{Results of calibration}

For the selected light polycyclic aromatic hydrocarbons, a linear relationship was obtained with correlation coefficients from the linear regression of 0.991 and above. The calibration graphs with corresponding equations of the regression lines are shown in Appendix E. Other analytical parameters for the chromatographic method such as percent relative standard deviations (\%RSD), limits of detection 
(LOD), limits of quantitation (LOQ) are provided in Table 5-9. The LOD and LOQ were determined from Equation (16) and Equation (17) as shown below:

$$
\mathrm{LOD}=\frac{3.3 * \mathrm{SD}}{\text { Slope }} \text { and } \mathrm{LOQ}=\frac{10 * \mathrm{SD}}{\text { Slope }}
$$

Table 5- 9: Correlation coefficient, \%RSD, LOD and LOQ for selected PAH

\begin{tabular}{|l|c|c|c|c|}
\hline Compound & $\begin{array}{l}\text { Correlation } \\
\text { coefficient, } \mathbf{r}\end{array}$ & \% RSD & LOD $(\boldsymbol{\mu g} / \mathbf{m l})$ & LOQ $(\boldsymbol{\mu g} / \mathbf{m l})$ \\
\hline Naphthalene & 0.991 & 3.72 & 0.11 & 0.33 \\
\hline Acenaphthylene & 0.992 & 5.27 & 0.11 & 0.33 \\
\hline Acenaphthene & 0.996 & 2.88 & 0.07 & 0.21 \\
\hline Fluorene & 0.998 & 2.96 & 0.06 & 0.17 \\
\hline Anthracene & 0.993 & 4.16 & 0.07 & 0.29 \\
\hline Phenanthrene & 0.995 & 3.92 & 0.08 & 0.24 \\
\hline
\end{tabular}

The LOD for the selected polycyclic aromatic hydrocarbons ranged between 0.06 $0.11 \mu \mathrm{g} / \mathrm{ml}$, with naphthalene having the highest and fluorene the lowest. This signifies that any of the selected polycyclic aromatic hydrocarbons that fell below the respective LOD values in the course of analysis could not be detected by the MSD and would therefore fall below the non -detectable limit. The LOQ, ranged between $0.17-0.33 \mu \mathrm{g} / \mathrm{ml}$ with naphthalene having the highest and fluorene with the lowest. The percent relative standard deviation (\%RSD) ranged between 2.96$5.27 \%$ with acenapthylene having the highest while acenapthene had the lowest. According to Driscoll et al., [1991], precision is acceptable if percent relative standard deviation (\%RSD) is less than $20 \%$. The calibration graphs with corresponding equations of the regression lines for the light aromatic hydrocarbons are shown in Appendix E. Other analytical parameters for the chromatographic method such as percent relative standard deviations (\%RSD), limits of detection (LOD), limits of quantitation (LOQ) are provided in Table 5-10.

Table 5- 10: Correlation coefficient, \%RSD, LOD and LOQ for BTEX

\begin{tabular}{|l|c|c|c|c|}
\hline Compound & Correlation coefficient, $\mathbf{r}$ & \% RSD & LOD $(\boldsymbol{\mu g} / \mathbf{m l})$ & LOQ $(\boldsymbol{\mu g} / \mathbf{m l})$ \\
\hline Benzene & 0.998 & 3.13 & 0.05 & 0.16 \\
\hline Toluene & 0.992 & 5.97 & 0.11 & 0.32 \\
\hline Ethylbenzene & 0.993 & 5.40 & 0.10 & 0.29 \\
\hline $\begin{array}{l}1,2 \\
\text { Dimethylbenzene }\end{array}$ & 0.998 & 3.14 & 0.05 & 0.16 \\
\hline $\begin{array}{l}1,3+1,4 \\
\text { Dimethylbenzene }\end{array}$ & 0.991 & 6.35 & 0.05 & 0.16 \\
\hline
\end{tabular}


The LOD for the selected light aromatic hydrocarbons ranged between $0.05-0.11$ $\mu \mathrm{g} / \mathrm{ml}$, with toluene having the highest while benzene, 1,2 dimethylbenzene and $1,3+1,4$ dimethylbenzene having the lowest. This signifies that any of the selected light aromatic hydrocarbons that fell below the respective LOD values in the course of analysis could not be detected by the GC and would therefore fall below the non -detectable limit. The $\mathrm{LOQ}$, ranged between $0.16-0.32 \mu \mathrm{g} / \mathrm{ml}$ with toluene having the highest while benzene, 1,2 dimethylbenzene and 1,3+1,4 dimethylbenzene having the lowest. The percent relative standard deviation (\%RSD) ranged between $3.13-6.35 \%$ with 1,3+1,4 dimethylbenzene having the highest while benzene having the lowest. According to Driscoll et al., [1991], precision is acceptable if percent relative standard deviation (\%RSD) is less than $20 \%$.

For both the selected light polycyclic aromatic hydrocarbons and the light aromatic hydrocarbons, a linear relationship was obtained with correlation coefficients from the linear regression of 0.991 and above. The correlation coefficient $(r)$ is evaluated as a measure of acceptability for which a value of 1.00 represents a perfect correlation although in practice, a value of $r$ greater than 0.990 is considered satisfactory [Edgerly, 1998].

\subsection{Matrix spike for the aromatic hydrocarbons}

The performance of the CGCMSD was determined by assessment of the surrogate standard compound recoveries. The samples were spiked with a known concentration of surrogate standard of $1 \mathrm{ppm}$ of each target compound and the spike was injected into the CGCMSD for analysis. The CGCMSD was run in selective ion mode (SIM) mode. The concentrations of the target compounds after analysis and the corresponding percentage recoveries are shown in Table 5-11. The percentage recoveries were determined using Equation (18).

From Table 5-11, the percentage recoveries ranged between $70 \%$ and $103 \%$. For surrogate percent recovery to be acceptable it must fall between 60 and $120 \%$ [US EPA, 1999]. 
Table 5- 11: Matrix spike and percentage recoveries

\begin{tabular}{|l|c|c|c|}
\hline Target Compounds & $\begin{array}{c}\text { Conc. added } \\
\left(\mathbf{m g} / \mathbf{m}^{\mathbf{3}}\right)\end{array}$ & $\begin{array}{c}\text { Conc. after analysis } \\
\left(\mathbf{m g} / \mathbf{m}^{\mathbf{3}} \mathbf{)}\right.\end{array}$ & \% recovery \\
\hline Naphthalene & 5.24 & 4.29 & 82 \\
\hline Acenaphthylene & 6.22 & 6.40 & 103 \\
\hline Acenaphthene & 6.22 & 5.78 & 93 \\
\hline Fluorene & 6.79 & 5.91 & 87 \\
\hline Phenanthrene & 7.28 & 5.10 & 70 \\
\hline Anthracene & 7.28 & 5.75 & 79 \\
\hline Benzene & 3.19 & 2.30 & 72 \\
\hline Toluene & 3.77 & 3.62 & 96 \\
\hline Ethylbenzene & 4.34 & 3.73 & 86 \\
\hline 1,2-Dimethyl benzene & 4.34 & 3.26 & 75 \\
\hline 1,3+1,4-Dimethyl benzene & 4.34 & 3.17 & 73 \\
\hline
\end{tabular}

\subsection{Analysis of selected aromatic hydrocarbons in condensate}

\subsubsection{Selected PAH analysis}

Out of the calibrated light polycyclic-aromatic components shown in Table 5-12, naphthalene was the only detected organic compound in the condensate. The average concentration of naphthalene was $204.25 \mathrm{mg} / \mathrm{m}^{3}$ with standard deviation of $16.84 \mathrm{mg} / \mathrm{m}^{3}$.

Table 5- 12: Concentration of targeted light PAH in the condensate

\begin{tabular}{|l|l|l|l|l|l|l|}
\hline \multirow{2}{*}{ Run } & \multicolumn{5}{|c|}{ Concentration $\left(\mathbf{m g} / \mathbf{m}^{\mathbf{3}}\right)$} \\
\cline { 2 - 7 } & Naphthalene & Acenaphthylene & Acenaphthene & Fluorene & Phenanthrene & Anthracene \\
\hline 1 & 176.01 & ND & ND & ND & ND & ND \\
\hline 2 & 212.02 & ND & ND & ND & ND & ND \\
\hline 3 & 220.30 & ND & ND & ND & ND & ND \\
\hline 4 & 208.67 & ND & ND & ND & ND & ND \\
\hline Mean & 204.25 & & & & & \\
\hline SD & 16.84 & & & & & \\
\hline
\end{tabular}

Note: $\mathrm{ND}=$ Not Detected 
Acenaphthylene, acenaphthene, fluorene, phenanthrene and anthracene were not detected in the condensate by the mass spectrometric detector (MSD). This may be attributed to concentration levels of the organic compounds being below the detection limits of the MSD and could therefore not be identified.

Comparing the total weighted average (TWA) and short term exposure limits (STEL) with the pollution levels of naphthalene obtained in the condensate, the concentration of naphthalene which ranged between $176.01 \mathrm{mg} / \mathrm{m}^{3}$ and 220.30 $\mathrm{mg} / \mathrm{m}^{3}$ was considerably high compared to the TWA of $52.35 \mathrm{mg} / \mathrm{m}^{3}$ and STEL of $78.53 \mathrm{mg} / \mathrm{m}^{3}$ reported by ACGIH, [1986]. This indicates that the condensate generated from producer gas cooling was associated with a high risk to cause both health and environmental effects. According to $\mathrm{NIOSH}$, [2005], the following are the probable health effects due to naphthalene exposure:

- When naphthalene vapors are inhaled for example when producer gas escapes to the environment, it can cause headache, weakness, nausea, vomiting, sweating, confusion, jaundice and dark urine

- In contact with the skin, naphthalene may be absorbed into the skin which results into a yellowish skin

- Naphthalene also has effects on the eyes which results into the development of cataract and yellowish eyes (jaundice)

- If ingested, naphthalene may cause abdominal pain, diarrhea, convulsions, unconsciousness and may result in death if ingested in high concentrations

- Short term exposure to naphthalene may cause effects on the blood, resulting in lesions of blood cells (haemolysis) while long term effects may have effects on the blood, resulting in chronic haemolytic anaemia.

Other effects include kidney and liver damage which may occur from either breathing or eating naphthalene. However, the levels of naphthalene at which each of the above mentioned effects can occur are not known.

According to Richieri et al., [1988], the probable environmental effects due to naphthalene exposure include: high toxicity to aquatic organisms and may cause long-term effects in the aquatic environment.

\subsubsection{BTEX analysis}

The light aromatic hydrocarbons analyzed in the condensate included: benzene, toluene, ethylbenzene, 1,2 dimethylbenzene and 1,3+1,4 dimethylbenzene. Table $5-13$ shows the average concentration of the targeted light aromatic hydrocarbons. 
Table 5- 13: Concentration of targeted light aromatic hydrocarbons

\begin{tabular}{|l|r|r|r|r|r|}
\hline \multicolumn{6}{|c|}{ Concentration $\mathbf{( m g / \mathbf { m } ^ { \mathbf { 3 } } )}$} \\
\hline \multicolumn{1}{|l|}{ Run } & Benzene & Toluene & Ethylbenzene & $\mathbf{1 , 2}$ Dimethylbenzene & $\mathbf{1 , 3 + 1 , 4}$ Dimethylbenzene \\
\hline 1 & 11.87 & 192.04 & 238.22 & 401.01 & 1097.42 \\
\hline 2 & 21.82 & 18.88 & 163.53 & 17.98 & 483.42 \\
\hline mean & 16.84 & 105.48 & 200.88 & 209.51 & 790.42 \\
\hline SD & 4.98 & 86.60 & 37.34 & 191.54 & 307.00 \\
\hline
\end{tabular}

The high variability in the concentrations of the respective light aromatic hydrocarbons may be attributed to the limited number of experiments conducted and the volatile nature of the compounds. It is therefore important to conduct several experiments in future on the condensate for analysis of light aromatic hydrocarbons so as to obtain conclusive results.

\section{Benzene}

The average concentration of benzene in the condensate (i.e. $16.84 \mathrm{mg} / \mathrm{m}^{3}$ ) was below the permissible exposure limit of $30 \mathrm{mg} / \mathrm{m}^{3}$ reported by ACGIH, [1987] therefore no adverse health and environmental effects would result from exposure due to benzene.

\section{Toluene}

The average concentration of toulene of $105.48 \mathrm{mg} / \mathrm{m}^{3}$ (or $0.105 \mathrm{mg} / \mathrm{l}$ ), was well below the permissible exposure range of 10 and $90 \mathrm{mg} / \mathrm{l}$ reported by Environment Canada, [1984]. Generally, toxic effects of toluene on aquatic organisms are observed with concentrations ranging between 10 and $90 \mathrm{mg} / \mathrm{l}$. It may therefore be concluded that toulene pollution levels resulting from the condensate could not cause significant toxicity in aquatic life [Environment Canada, 1984].

\section{Ethylbenzene}

The concentration of ethylbenzene (i.e. $46.26 \mathrm{ppm}$ or $200.88 \mathrm{mg} / \mathrm{m}^{3}$ ) in the condensate was well below the permissible exposure limit of $100 \mathrm{ppm}\left(435 \mathrm{mg} / \mathrm{m}^{3}\right)$ as a total weighted average (TWA) for up to a 10-hour workday and $125 \mathrm{ppm}$ (545 $\mathrm{mg} / \mathrm{m}^{3}$ ) as a short-term exposure limit reported by NIOSH, [1992]. It may also therefore be concluded that ethylbenzene pollution levels resulting from the condensate could not cause significant health effects on humans.

\section{Xylene}

The total concentration of xylene (i.e. 1,2 dimethylbenzene and 1,3+1,4 dimethylbenzene) in the condensate (i.e. $234.64 \mathrm{ppm}$ or $999.93 \mathrm{mg} / \mathrm{m}^{3}$ ) was considerably higher than the permissible exposure limit of $100 \mathrm{ppm}$ (or $435 \mathrm{mg} / \mathrm{m}^{3}$ ) 
and 150ppm (or $655 \mathrm{mg} / \mathrm{m}^{3}$ ) as a total weighted average and short term exposure limit respectively reported by $\mathrm{ACGIH}$, [1988] thus presenting a potential to cause both health and environmental effects. According to United States Public Health Service, [1995], the probable health effects due to xylene exposure include: irritation of the skin, eyes, nose, and throat, difficulty in breathing, impaired function of the lungs, delayed response to a visual stimulus, impaired memory, stomach discomfort and possible changes in the liver and kidneys. Both short- and longterm exposure to high concentrations of xylene can also cause effects on the nervous system such as headache, lack of muscle coordination, dizziness and confusion.

According to Environment Australia, [2001], the probable environmental effects due to xylene exposure include: high acute toxicity to aquatic life and can cause injury to various agricultural and ornamental crops. It also has high chronic (longterm) toxicity to aquatic life. However, there are not sufficient data to predict the acute or chronic toxicity of xylene to birds or land animals. According to ATSDR, [2007], only very small amounts are taken up by plants, fish, and birds since xylene evaporates easily.

\subsection{Measures to minimize health, environmental effects and pollution levels, resulting from biomass gasification}

\subsubsection{Waste water treatment}

The waste water generated from producer gas cooling is as a result of secondary methods used as treatments for the hot product gas from the gasifier. The condensate is highly toxic and carcinogenic due to the presence of some polycyclic aromatic hydrocarbons (PAHs) and BTEX and therefore the condensate should be treated before disposal to the environment. The waste water treatment systems may be based on physical, chemical and biological processes [Lettner et al., 2007]. However, according to Milne [1998], the choice of treatment system depends on the specific application and the results of techno-economic evaluation that must be carried out before a process is selected. Below is a brief discussion on each of the processes.

\section{Physical processes}

The physical processes in biomass gasification facilities can be used as preliminary cleaning for the separation of solids or organic compounds from the aqueous phase [Lettner et al., 2007]. According to Lettner et al., [2007], the elimination of the organic compounds can be carried out through static processes 
such as sedimentation and flotation and mechanical processes such as centrifugation and filtration. However, when using filtration processes, the tar portion in the waste water often causes problems due to clogging of the filter units [Lettner et al., 2007]. Lettner et al., [2007] further reports that, of the various physical processes the sedimentation process is well suited to separate the major portion of tars from the condensate.

\section{Chemical processes}

Through chemical processes, the organic waste water components can either be converted to ecologically harmless compounds or directly eliminated in consecutive reactions. The chemical processes that can be used include: neutralization, precipitation, oxidation, reduction, adsorption and extraction among others. However, according to Lettner et al. [2007], the oxidation of tars by means of hydrogen peroxide or adsorption of the tars on activated carbon, were investigated in lab-scale units and found out that the two options were associated with high operating costs and therefore the two processes have not yet been accepted.

\section{Biological processes}

Through biological processes, the organic hydrocarbons can be reduced through the metabolic activity of microorganisms in anaerobic and aerobic conditions [Lettner et al., 2007]. During the process of decomposition, the waste water components are transformed into ecologically harmless compounds. However, due to the toxicity of the aromatic hydrocarbons, biological processes are not often used as a waste water treatment technology for biomass gasification facilities [Lettner et al., 2007].

\subsubsection{Primary methods}

The tar concentration in the producer gas can also be reduced through primary methods which involve tar removal in the gasifier through proper selection of gasifier operating conditions. The reduced tar concentration in producer gas results into a less contaminated waste water thus reduced disposal and treatment costs. A cleaner producer gas may also eliminate the need for secondary treatments which create disposal and waste water treatment problems. The main primary measures may include: optimization of the operating conditions such as temperature, equivalence ratio, gasifying medium, use of catalysts, and longer residence time of producer gas in the reactor. Below is a brief discussion on each of the operating parameters. 


\section{Operating temperature}

To achieve a high carbon conversion of the biomass and low tar content in the resultant product gas, a high operating temperature (above $800^{\circ} \mathrm{C}$ ) in the gasifier is preferred [Gill et al., 1999b].. This can be achieved by modifying the gasifier to include both primary and secondary air inlets on the gasifier. Secondary air injection into the gasifier results in a higher temperature which can thermally crack the tar to a considerably lower value. An increase in equivalence ratio also increases the temperature of the fuel bed which results into increase in the gas production rate and reduced tar production. However, an increase in equivalence ratio increases the amount of carbon dioxide in the exit gas. An optimum value of equivalence ratio is reported to be $0.25-0.3$ [Gill et al., 1999b].

\section{Gasifying medium}

Different gasifying medium other than air can also be used for biomass gasification. These may include: oxygen, steam and steam-oxygen. According to Gill et al., [1999b], higher amounts of aromatic hydrocarbons are formed with air gasification of biomass. However, much as oxygen is the most preferred gasifying medium, it has a cost implication. The use of oxygen as a gasifying medium necessitates a nearby source of oxygen, which increases capital and operating costs [Anisa, 2005].

\section{Residence time}

Increase in residence time of the producer gas can result into tar reduction in producer gas. Houben et al., [2002] reported a sharp decrease in amount of tar with an increase in residence time. A higher residence time can be achieved by increasing fuel bed heights which increases the time fuels are available for reactions to occur, thus increasing total producer gas yields and reduced tar production. However, according to Houben et al., [2002], increasing residence time has a significant increase in soot formation.

\section{Use of catalysts during gasification}

The use of catalytically active materials during biomass gasification promotes char gasification, changes the product gas composition and reduces the tar yield. Such materials that can be used include: calcined dolomite, zeolite, Ni-based catalysts, zeoloite and iron catalysts among others. Several studies indicate that dolomite is an efficient catalyst for tar cracking [Devi, 2005, Devi et al., 2002]. 


\subsection{CONCLUSIONS AND RECOMMENDATIONS}

\subsection{Introduction}

This chapter documents both the conclusions and recommendations drawn from the findings of the study.

\subsection{Conclusions}

It should be noted that since the samples were not analyzed immediately and had to be flown to the analytical lab in Mombasa, there was a possibility that some of the aromatic hydrocarbons would have volatilized or exposed to photo-chemical oxidation, thus preventing their accurate measurement.

The LOD for the selected polycyclic aromatic hydrocarbons ranged between 0.06$0.11 \mu \mathrm{g} / \mathrm{ml}$, with naphthalene having the highest and fluorene the lowest. The LOD for the selected light aromatic hydrocarbons ranged between $0.05-0.11 \mu \mathrm{g} / \mathrm{ml}$, with toluene having the highest while benzene, 1,2 dimethylbenzene and 1,3+1,4 dimethylbenzene had the lowest.

The average concentration of naphthalene was $204.25 \mathrm{mg} / \mathrm{m}^{3}$, benzene$16.84 \mathrm{mg} / \mathrm{m}^{3}$, toluene- $105.48 \mathrm{mg} / \mathrm{m}^{3}$, ethylbenzene- $200.88 \mathrm{mg} / \mathrm{m}^{3}$, 1,2-dimethyl benzene-209.51 mg/m $\mathrm{m}^{3}$ and 1,3+1,4-dimethyl benzene- $790.42 \mathrm{mg} / \mathrm{m}^{3}$.

Acenaphthylene, acenaphthene, fluorene phenanthrene and anthracene were not detected in the condensate by the capillary gas chromatography with mass spectrometric detector (CGCMSD). This may be attributed to concentration levels of the organic compounds being below the detection limits of the mass spectrometric detector (MSD) and could therefore not be identified.

The concentrations of naphthalene and xylene were considerably high compared to the recommended permissible exposure limits thus posing risks on both human health and the environment. It is therefore important to treat the condensate before disposal to the environment. On the other hand, the concentrations of benzene, toluene and ethylbenzene were below the recommended permissible exposure limit and therefore for this study, the liquid effluent was considered to meet the regulatory standards. 
The measures that can be taken to reduce pollution levels resulting from biomass gasification may include: waste water treatment and optimization of the operating conditions such as temperature, equivalence ratio, gasifying medium, use of catalyst and bed additives, and ensuring a longer residence time for producer gas in the reactor.

Much as a limited number of experiments were conducted due to the limited resources, the research will serve as a basis for further research in the area of analysis of condensate generated due to producer gas cooling.

\subsection{Recommendations}

The researcher recommends an onsite measurement of the aromatic hydrocarbons in the condensate to avoid possibilities of volatilization and photochemical reactions in water samples and bacterial degradation of the organic compounds that compromise accuracy of the experimental tests.

In addition, more experimental runs should be conducted on the condensate especially for the light aromatic hydrocarbons, heavy aromatics, phenols, BOD, $\mathrm{pH}$ to have conclusive results. Experimental runs should also be conducted on the gasifier using other biomass wastes in both downdraft and updraft gasifiers.

Research should be conducted to ascertain the best treatment option for the contaminated condensate before being discharged to the environment.

In addition, research should be conducted on the gasifier to optimize the gasifier operating conditions such as equivalence ratio, operating temperature, gasifying medium, use of various catalysts and increase of residence time of producer gas in the reactor among others aimed at reducing aromatic compounds in the producer gas. 


\section{REFERENCES}

ACGIH, 1988

Threshold Limit Values (TLVs) and biological exposure indices for 1988-1989

Cincinnati, $\mathrm{OH}$ : American Conference of Governmental Industrial Hygienists.

ACGIH, 1987

TLVs, Threshold Limit Values and Biological Exposure Indices for 1987-1988, Cincinnati

\section{ACGIH, 1986}

Documentation of the threshold limit values and biological exposure indices

5th ed. Cincinnati, $\mathrm{OH}$ : American Conference of Governmental Industrial Hygienists.

\section{Agency for Toxic Substances and Disease Registry (ATSDR), 2007}

Toxicological profile for xylene

Atlanta, GA: U.S. Department of Health and Human Services, Public Health Service.

\section{Amoore J. E and Hautala E, 1983}

Odor as an aid to chemical safety: Odor thresholds compared with threshold limit values and volatiles for 214 industrial chemicals in air and water dilution. J Appl Toxicology 3 (6): 272-290.

\section{Anisa Safitri, 2005}

Biomass gasification using bubbling fluidized-bed gasifier: investigation of the effect of different catalysts on tar reduction

Master Thesis, Technishe Universiteit Eindhoven, Department of Chemical Engineering and Chemistry

\section{Australian and New Zealand Environment and Conservation Council (ANZECC), 1992}

Australian Water Quality Guidelines for Fresh and Marine Waters

Bridgwater, A.V., Evans, G.D.; 1993

An Assessment of Thermochemical Conversion Systems for Processing

Biomass and Refuse Energy Technology Support Unit (ETSU) on behalf of the Department of Trade,ETSU B/T1/00207/REP, 1993. 
CDC, 2005

Fact sheet-benzene,

Department of Health and Human Services

Devi, 2005

Catalytic removal of biomass tars; Olivine as prospective in-bed catalyst for fluidized-bed biomass gasifiers

Technische Universiteit Eindhoven

Proefschrift. - ISBN 90-386-2906-0

Devi L., Ptasinski K.J., Janssen F.J.J.G, van Pasen, S.V.B., Bergman P.C.A., Kiel J.H.A, 2002

A review of the primary measures for tar elimination in biomass gasification processes

Environmental Technology Group, Laboratory of Chemical Reactor Engineering, Eindhoven University of Technology, Den Dolech 2, P.O. Box 513, 5600 MB Eindhoven, Netherlands

Edgerley D. A., 1998

Techniques for improving the accuracy of calibration in the environmental laboratory

Quanterra Environmental Services, 880 Riverside Parkway, West Sacramento, California 95605

WTQA '98 - 14th Annual Waste Testing \& Quality Assurance Symposium

Environment Australia, 2001

Air toxics and indoor air quality in Australia, state of knowledge report ISBN 0642547394

\section{Environment Canada, 1984}

Technical Services Branch, Toluene - Environmental and Technical Information for Problem Spills. Beauregarde Press. 1984.

FAO, 1986

Wood as Gas Engine

Forest Industries Division, FAO Forestry Department

Fürnsinn S., Buhler R., Holfbauer H., 2005

"Health, Safety, and Environment of Biomass Gasification"

Proceedings of the International Workshop, Innsbruck, Austria 
Gill, J., Corella, J., Aznar, M.P., Caballero, M.A., 1999b

Biomass gasification in atmospheric and bubbling fluidized bed: effect of the type of gasifying agent on the product distribution. Biomass and Bioenergy 17, 389-403.

Goorts M.P, 2008,

Applying gas chromatography to analyze the composition and tar content of the product gas of a biomass gasifier Report number WVT 2008.24

Eindhoven University of Technology, Department of Mechanical Engineering

Division Thermofluids Engineering, Section Combustion Technology

Haddon C, Smithers L, Schneidermaunoury S, Coche T, Henrique D and Lewis J, 1998

Multiple Delta genes and lateral inhibition in zebrafish primary neurogenesis

Hariie A.M.K., 2005,

Handbook Biomass Gasification, BTG biomass technology group, Enschede, Netherlands

Hazard Evaluation System and Information Service fact sheet, 1989

Also accessible at http://www.cdph.ca.gov/programs/hesis/Documents/xylene.pdf

Houben, M.P, Verschuur, K., Neeft, J.P.A., de Lange, H.C., Daey Ouwens, C., 2002

An analysis and experimental investigation of the cracking and polymerization of tar. Proceedings of the 12th European Conference and Technology Exhibition on Biomass for Energy, Industry and Climate Protection, Amsterdam. The Netherlands. pp 581-585.

United States Public Health Service, 1990

Toxicological Profile for Naphthalene

Agency for Toxic Substances and Disease Registry

Accessible at http://www.eco-usa.net/toxics/chemicals/naphthalene.shtml

Kasedde, H. 2010;

"Hazard and safety evaluation of gasifier Installations in Uganda"

Masters Thesis, Department of Energy Technology, Division of Heat and Power Technology, Royal Institute of Technology, Stockholm, Sweden (not published) 


\section{Larsen H., Jens Kossmann, Leif Sønderberg Pedersen (2003)}

Risø Energy Report2; New and emerging bioenergy technologies. Risø National Labratory, Denmark.

\section{Lettner .F., Timmerer H., Haselbacher P., 2007}

"Guideline for safe and eco-friendly biomass gasification"

Graz University of Technology - Institute of Thermal Engineering Inffeldgasse 25B, 8010 Graz, Austria

\section{Lubwama M., 2010}

Technical Assessment of the functional and operational performance of a fixed bed biomass gasifier using agricultural residues

Master of Science Thesis Energy Technology EGI-2010-002, KTH School of Industrial Engineering and Management, Division of Heat and Power Technology SE-100 44 STOCKHOLM

Miller, B. ,1983

"State-of-the-Art Survey of Wood Gasification Technology, Final Report," EPRI. AP-3101.

Miller, J.C. and Miller, J.N.,1993

Statistics for Analytical Chemistry, 3rd Edn. Ellis Horwood Ltd, Chichester, UK.

Milne, T.A., R.J. Evans, and N.Abatzoglou. 1998.

Biomass gasification "tars": their nature, formation and conversion. NREL, Golden, CO. Report no. NREL/TP-570-25357.

Neeft, J. 2000

Teren uit pyrolyse en vergassing van biomassa en reststromen, ECN-C-99-102, January 2000

NHMRC-ARMCANZ, 1996

Australian Drinking Water Guidelines. National Water Quality Management Strategy. National Health and Medical Research Council and Agriculture and Resource Management Council of Australia and New Zealand. Commonwealth of Australia

NIOSH, 2005

International Chemical Safety Cards (ICSC-0667), naphthalene Accessible at http://www.cdc.gov/niosh/ipcsneng/neng0667.html 
NIOSH, 1992

Recommendations for occupational safety and health: Compendium of policy documents and statements. Cincinnati, OH: U.S. Department of Health and Human Services, Public Health Service, Centers for Disease Control, National Institute for Occupational Safety and Health, DHHS (NIOSH) Publication No. 92-100.

Podgórska, A., K. Sylwester, B. Wlodzimierz. 2006.

Effect of operating conditions on tar and gas composition in high temperature air/steam gasification (HTAG) of plastic containing waste. Fuel Process Technol (87): 223-33.

\section{Rauch, R., 2005}

Formation, treatment and avoiding of waste water

Vienna, University of Technology, Institute of Chemical Engineering, Getreidemarkt 9/166, 1060, Vienna

IEA Bioenergy, Task 33/ Thermal Gasification of Biomass

Proceedings of the International Workshop on Health, Safety and Environment of Biomass Gasificatoion

Reed T. B., Das, A., 1988

"Handbook of biomass downdraft gasifier engine systems"

Solar Energy Research Insititute, 1617 Cole Boulevard, Golden, Colarado 804013393

Richieri P.R., Buckpitt A.R., 1988

Glutathione depletion by naphthalene in isolated hepatocytes and by naphthalene oside in vivo.

Biochem Pharmacol 1988; 37:2473-2478

Roos, J. C., 2010

Clean Heat and Power Using Biomass Gasification for Industrial and Agricultural Projects

US Department of Energy, Clean Energy Application Center, North West

Sluiter A., B. Hames, R. Ruiz, C. Scarlata, J. Sluiter, and D. Templeton, 2005 Determination of Ash in Biomass Laboratory Analytical Procedure (LAP)

Technical Report , NREL/TP-510-42622, January 2008 
Soniassy. R., Sandra P., Schlett C., 1994

Water Analysis: Organic Micropollutants

Sousa, L.C.R., 2001.

Gasification of wood, urban waste wood (Altholz) and other wastes in a fluidised bed reactor. PhD thesis. Swiss Federal Institute of Technology Zurich.

Stassen H. E.M, 1995

Small-Scale Biomass Gasifiers for Heat and Power, a Global Review

World Bank Technical Paper Number 296 "117 Energys Series

Turare C, 1998;

"Biomass Gasification Technology and Utilization"

ARTES Institute Glucksburg, Germany

Accessible at http://cturare.tripod.com/pdc.htm

\section{United States Department of Labor, 2004}

Occupational Safety and Health Administration. Safety and Health topics: Toluene. Last revised March 17, 2004.

Available at: http://www.osha.gov/dts/chemicalsampling/data/CH_272200.html.

\section{United States Public Health Service, 1995}

Toxicological Profile for Xylene August 1995 Update

Agency for Toxic Substances and Disease Registry

Accessible at http://www.eco-usa.net/toxics/chemicals/xylene.shtml

\section{United States Public Health Service, 1990}

Toxicological Profile for Ethylbenzene December 1990 Update

Agency for Toxic Substances and Disease Registry

Accessible at http://www.eco-usa.net/toxics/chemicals

US Environmental Protection Agency, 1994

Office of Pollution Prevention and Toxics. Chemical Summary for Toluene August 1994. (http://rtk.net/E10290T676. - 01/29/97)

\section{U. S. EPA. 1996a}

EMAP information management plan. Draft, Oct 30, 1996

\section{U.S. Environmental Protection Agency (EPA), 2002a}

Calculating Upper Confidence Limits for Exposure Point Concentrations at Hazardous Waste Sites. OSWER 9285.6-10 December 2002. 


\title{
APPENDICES
}

\section{Appendix A: CGCMSD Conditions for PAH Analysis}

\author{
C: $\backslash$ MSDCHEM $\backslash I \backslash$ METHODS $\backslash$ PAH3 . M \\ Mon Jan 23 08:52:44 2012 \\ Control Information \\ ....... - ........... \\ Sample Inlet : GC \\ Injection Source : GC ALS \\ Mass Spectrometer : Enabled \\ No Sample Prep method has been assigned to this method. \\ Oven \\ Equilibration Time $3 \mathrm{~min}$ \\ Max Temperature \\ Slow Fan \\ Oven Program \\ $50{ }^{\circ} \mathrm{C}$ for $0.4 \mathrm{~min}$ \\ then $25^{\circ} \mathrm{C} / \mathrm{min}$ to $195^{\circ} \mathrm{C}$ for $1.5 \mathrm{~min}$ \\ then $8{ }^{\circ} \mathrm{C} / \mathrm{min}$ to $265^{\circ} \mathrm{C}$ for $0 \mathrm{~min}$ \\ then $20^{\circ} \mathrm{C} / \mathrm{min}$ to $315^{\circ} \mathrm{C}$ for $1.25 \mathrm{~min}$ \\ Run Time

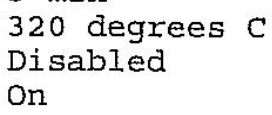

On \\ 20.2 min \\ Front Injector \\ Syringe Size \\ Injection Volume \\ Solvent A Washes (PreInj) \\ Solvent A Washes (PostInj) \\ Solvent A Volume \\ Solvent $B$ washes (PreInj) \\ Solvent B Washes (PostInj) \\ Solvent B Volume \\ Sample Washes \\ Sample Wash Volume \\ Sample Pumps \\ Dwell Time (PreInj) \\ Dwell Time (PostInj) \\ Solvent Wash Draw Speed \\ Solvent Wash Dispense Speed \\ Sample wash Draw speed \\ Sample Wash Dispense Speed \\ Injection Dispense Speed \\ Viscosity Delay \\ Sample Depth \\ Injection Type \\ L1 Airgap

$10 \mu L$
$2 \mu L$
0
5
$8 \mu L$
0
0
$8 \mu L$
2
$8 \mu L$
6
0 min
0 min
$300 \mu L / m i n$
$6000 \mu L / m i n$
$300 \mu L / m i n$
$6000 \mu L / m i n$
$6000 \mu L / m i n$
0 sec
Disabled
Standard
$0.2 \mu L$

PAH3.M Mon Jan 23 08:52:44 2012 


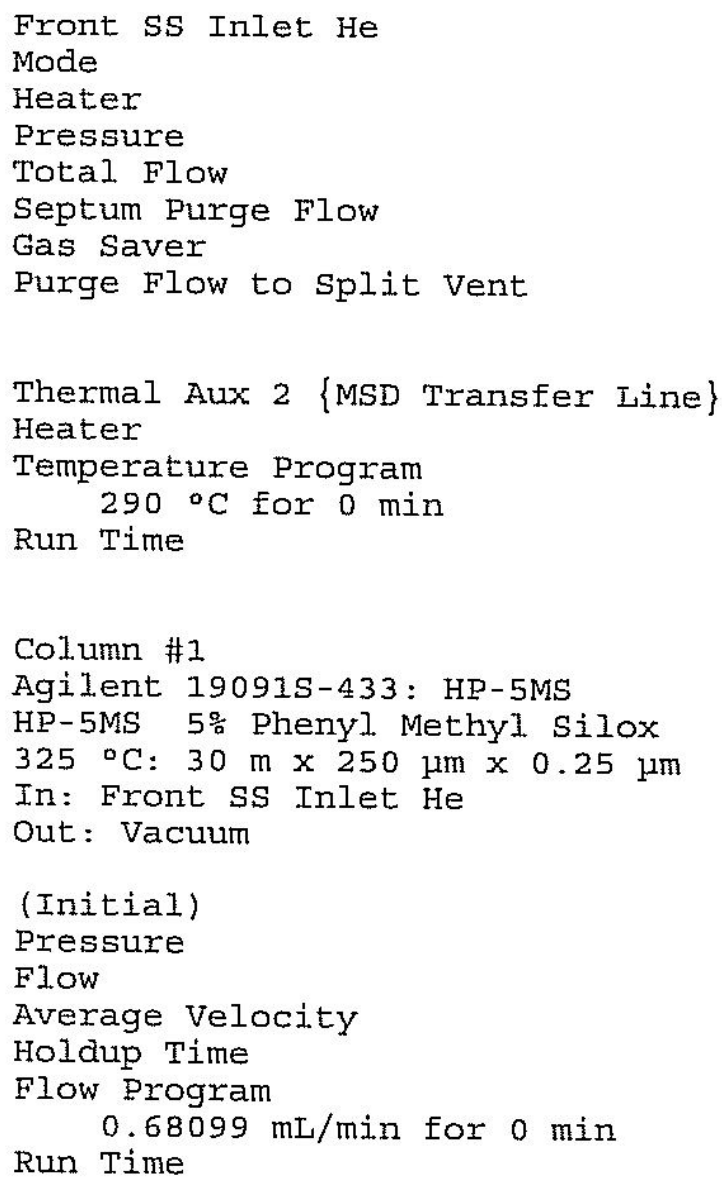

Thermal Aux 2 \{MSD Transfer Line\}

Heater

Temperature Program $290^{\circ} \mathrm{C}$ For $0 \mathrm{~min}$

Run Time

Column \#1

Agilent 19091S-433: HP-5MS

HP-5MS 5음 Phenyl. Methyl Silox

$325^{\circ} \mathrm{C}: 30 \mathrm{~m} \times 250 \mu \mathrm{m} \times 0.25 \mu \mathrm{m}$

In: Front $s$ S Inlet He

Out: Vacuum

(Initial)

Pressure

Flow

Average velocity

Holdup Time

Flow Program

$0.68099 \mathrm{~mL} / \mathrm{min}$ for $0 \mathrm{~min}$

Run Time

on

On

$20.2 \mathrm{~min}$

$50 \circ \mathrm{C}$

$3.7463 \mathrm{psi}$

$0.68099 \mathrm{~mL} / \mathrm{min}$

$30.075 \mathrm{~cm} / \mathrm{sec}$

$1.6625 \mathrm{~min}$

off

$20.2 \mathrm{~min}$

Signals
Test Plot
Test Plot
Test Plot
Test Plot

Save off

$50 \mathrm{~Hz}$

Save off

$50 \mathrm{~Hz}$

Save Off

$50 \mathrm{~Hz}$

Save off

$50 \mathrm{~Hz}$

MS ACQUISTTION PARAMETERS 


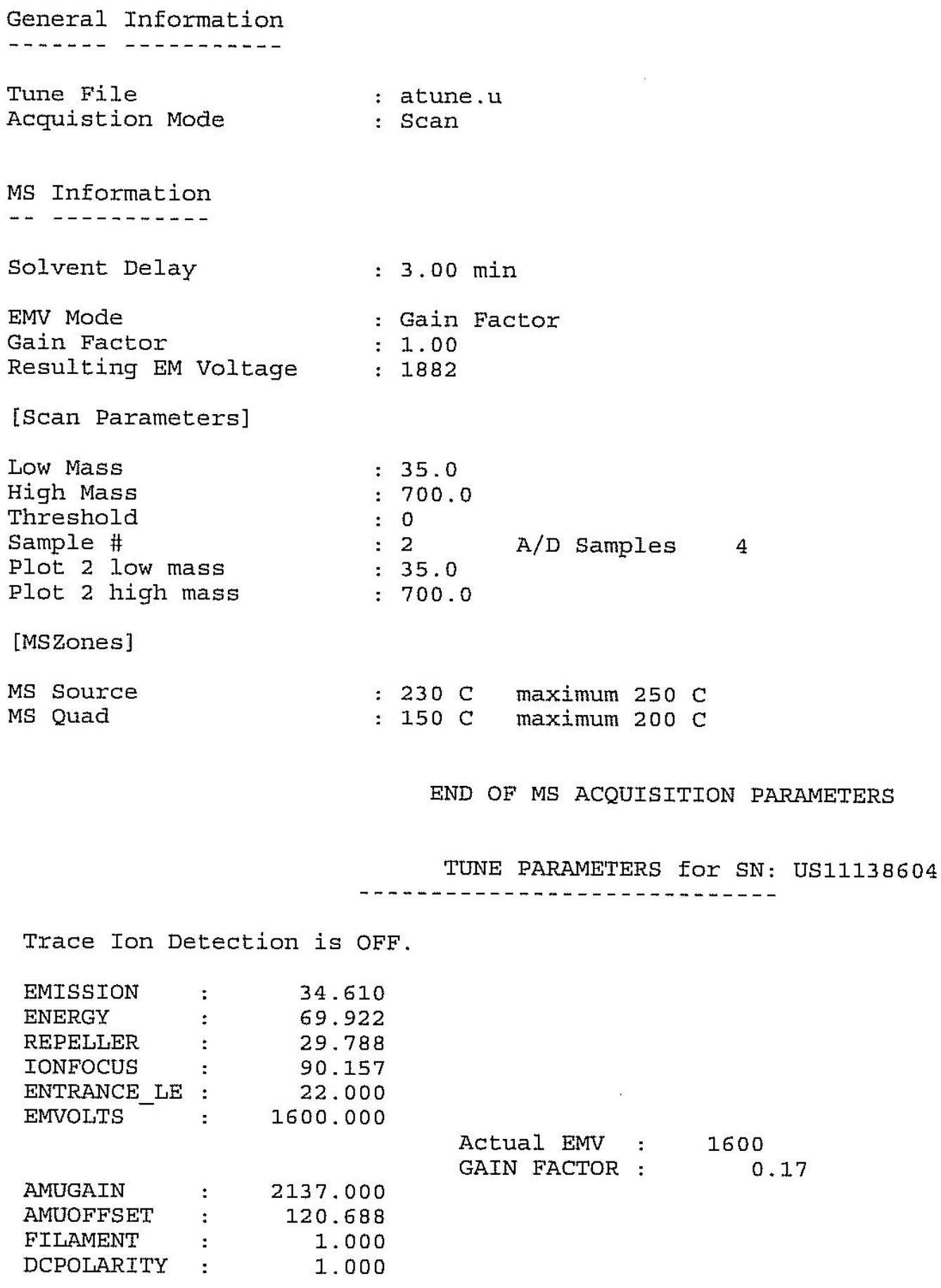

END OF MS ACQUISITION PARAMETERS

TUNE PARAMETERS fOr SN: US11138604

Trace Ion Detection is OFF.

\begin{tabular}{|c|c|c|c|c|}
\hline EMISSION & : & 34.610 & & \\
\hline ENERGY & : & 69.922 & & \\
\hline REPELLER & : & 29.788 & & \\
\hline IONEOCUS & : & 90.157 & & \\
\hline ENTRANCE LE & : & 22.000 & & \\
\hline \multirow[t]{3}{*}{ EMVOI.SS - } & : & 1600.000 & & \\
\hline & & & Actual EMV & 1600 \\
\hline & & & GAIN FACTOR & 0.17 \\
\hline AMUGAIN & : & 2137.000 & & \\
\hline AMUOFFSET & : & 120.688 & & \\
\hline FILAMENT & : & 1.000 & & \\
\hline DCPOLARITY & : & 1.000 & & \\
\hline
\end{tabular}




\title{
Appendix B: CGCMSD Conditions for BTEX Analysis
}

\author{
C: \MSDCHEM \I\METHODS \VOCS2 . M \\ Fri Apr 13 09:49:20 2012 \\ Control Information \\ Sample Inlet : GC \\ Injection Source : GC ALS \\ Mass Spectrometer : Enabled
}

No Sample Prep method has been assigned to this method.

Oven

Equilibration Time

Max Temperature

Slow Fan

Oven Program

$40^{\circ} \mathrm{C}$ for $5 \mathrm{~min}$

then $8{ }^{\circ} \mathrm{C} / \mathrm{min}$ to $180^{\circ} \mathrm{C}$ for $0 \mathrm{~min}$

then $35^{\circ} \mathrm{C} / \mathrm{min}$ to $250^{\circ} \mathrm{C}$ for $0.17 \mathrm{~min}$

Run Time

$3 \mathrm{~min}$ 300 degrees $C$ Disabled

on

$24.67 \mathrm{~min}$

Front Injector

Syringe Size

Injection Volume

Solvent A Washes (PreInj)

Solvent A Washes (PostInj)

Solvent A Volume

Solvent B Washes (PreInj)

Solvent B Washes (PostInj)

Solvent B Volume

Sample Washes

Sample Wash Volume

Sample Pumps

$10 \mu \mathrm{L}$

2 IIL

0

5

$8 \mu \mathrm{L}$

0

0

$8 \mu \mathrm{L}$

2

$8 \mu \mathrm{L}$

6 
Dwell Time (PreInj)

Dwell Time (PostInj)

Solvent Wash Draw Speed

Solvent Wash Dispense Speed

Sample Wash Draw Speed

Sample Wash Dispense Speed

Injection Dispense Speed

Viscosity Delay

Sample Depth

Injection Type

L1 Airgap

Sample Overlap

Sample overlap is not enabled

Front SS Inlet He

Mode

Heater

Pressure

Total Flow

Septum Purge Flow

Gas Saver

Purge Flow to split Vent

Thermal Aux 2 (MSD Transfer Isine\}

VOCS2.M Fri Apr 13 09:49:20 2012
$0 \min$

0 min

$300 \mu \mathrm{L} / \mathrm{min}$

$6000 \mu \mathrm{L} / \mathrm{min}$

$300 \mu \mathrm{L} / \mathrm{min}$

$6000 \mu \mathrm{L} / \mathrm{min}$

$6000 \mu \mathrm{L} / \mathrm{min}$

0 sec

Disabled

Standard

$0.2 \mu \mathrm{L}$

Splitless
On $\quad 100{ }^{\circ} \mathrm{C}$
on $\quad 3.2209 \mathrm{psi}$
on $23.678 \mathrm{~mL} / \mathrm{min}$
on $3 \mathrm{~mL} / \mathrm{min}$
On $20 \mathrm{~mL} / \mathrm{min}$ After $2 \mathrm{~min}$
$20 \mathrm{~mL} / \mathrm{min} \mathrm{at} 0.8 \mathrm{~min}$

Splitless

On $\quad 100^{\circ} \mathrm{C}$

on $3.2209 \mathrm{psi}$

on $23.678 \mathrm{~mL} / \mathrm{min}$

On $3 \mathrm{~mL} / \mathrm{min}$

$20 \mathrm{~mL} / \mathrm{min}$ at $0.8 \mathrm{~min}$ 
General Information

-.-.-............

Tune File

Acquistion Mode

: Restored.U

: Scan

MS Information

-. -...-.-.--

$\begin{array}{ll}\text { Solvent Delay } & : 3.00 \mathrm{~min} \\ \text { EMV Mode } & : \text { Absolute } \\ \text { Resulting EM Voltage } & : 1176\end{array}$

[Scan Parameters]

Low Mass

High Mass

Threshold

Sample \#

plot 2 low mass

plot 2 high mass

$: 35.0$

$: 700.0$

$: 0$

$: 2$

$: 35.0$

A/D Samples 4

$: 700.0$

[MSZones]

MS source

MS Quad

: $230 \mathrm{C}$ maximum $250 \mathrm{C}$

: $150 \mathrm{C}$ maximum $200 \mathrm{C}$

END OF MS ACQUISITION PARAMETERS

TUNE PARAMETERS tOr SN: US11138604

Trace Ion Detection is OFF.

$\begin{array}{llr}\text { EMISSION } & : & 34.610 \\ \text { ENERGY } & : & 69.922 \\ \text { REPELLLR } & : & 26.102 \\ \text { IONFOCUS } & : & 90.157 \\ \text { ENTRANCE_LE } & : & 28.500 \\ \text { EMVOLTS } & : & 1505.882 \\ & & \\ & & \\ \text { AMUGAIN } & : & 2143.000 \\ \text { AMUOFFSET } & : & 120.688 \\ \text { FILAMENT } & : & 1.000 \\ \text { DCPOLARITY } & : & 1.000 \\ \text { ENTLENSOFFS } & : & 18.573 \\ \text { MASSGAIN } & : & -435.000 \\ \text { MASSOFFSET } & : & -38.000\end{array}$

END OF TUNE PARAMETERS 


\title{
Appendix C: Matrix Spike
}

\author{
Data Path : D: |PAY|PAH 3|EMManUEL MENYA| \\ Dáta File : 00501005.D \\ Acq on : 2 Dec $2011 \quad 19: 11$ \\ operator : \\ Sample $: 2 B$ \\ Misc : \\ Ais vial : 5 Sample Multiplier: 1 \\ Quant Time: Feb 01 14:16:59 2012 \\ Quant Method: C:|msdchem|1|methods|PAH3 SIM.M \\ Quant Title : PAH3 SIM \\ QLâst Update : Mon Nov 28 14:43:21 2011 \\ Response via : Initial Calibration
}

Compound R.T. QIon Response Conc Units Dev(Min)

\begin{tabular}{lrlllr} 
Target Compounds & & & & \multicolumn{2}{c}{ Qvalue } \\
1) Naphthalene & 5.608 & 128 & 5696860 & $0.82 \mathrm{ppm}$ & 100 \\
2) Acenaphthylene & 7.287 & 152 & 6516385 & $1.03 \mathrm{ppm}$ & 100 \\
3) Acenaphthene & 7.527 & 153 & 2993572 & $0.93 \mathrm{ppm}$ & 99 \\
4) Fluorene & 8.297 & 166 & 3847634 & $0.87 \mathrm{ppm}$ & 95 \\
5) Anthracene & 10.248 & 178 & 4493564 & $0.79 \mathrm{ppm}$ & 100 \\
6) Phenanthrene & 10.249 & 178 & 4352750 & $0.70 \mathrm{ppm}$ & 100 \\
7) Fluoranthene & 13.142 & 202 & 1094951 & $0.75 \mathrm{ppm}$ & 100 \\
8) Pyrene & 13.720 & 202 & 2843338 & $0.89 \mathrm{ppm}$ & 100 \\
9) Benz (a) anthracene & 17.350 & 228 & 687514 & $0.84 \mathrm{ppm}$ & 100 \\
10) Benzo(a) pyrene & 19.546 & 252 & 557922 & $0.87 \mathrm{ppm}$ & 100
\end{tabular}

$\langle \#\rangle$ = qualifier out of range $(m)=$ manual integration $(t)=$ signals summed 


\section{Appendix E: Total Ion Chromatograms}

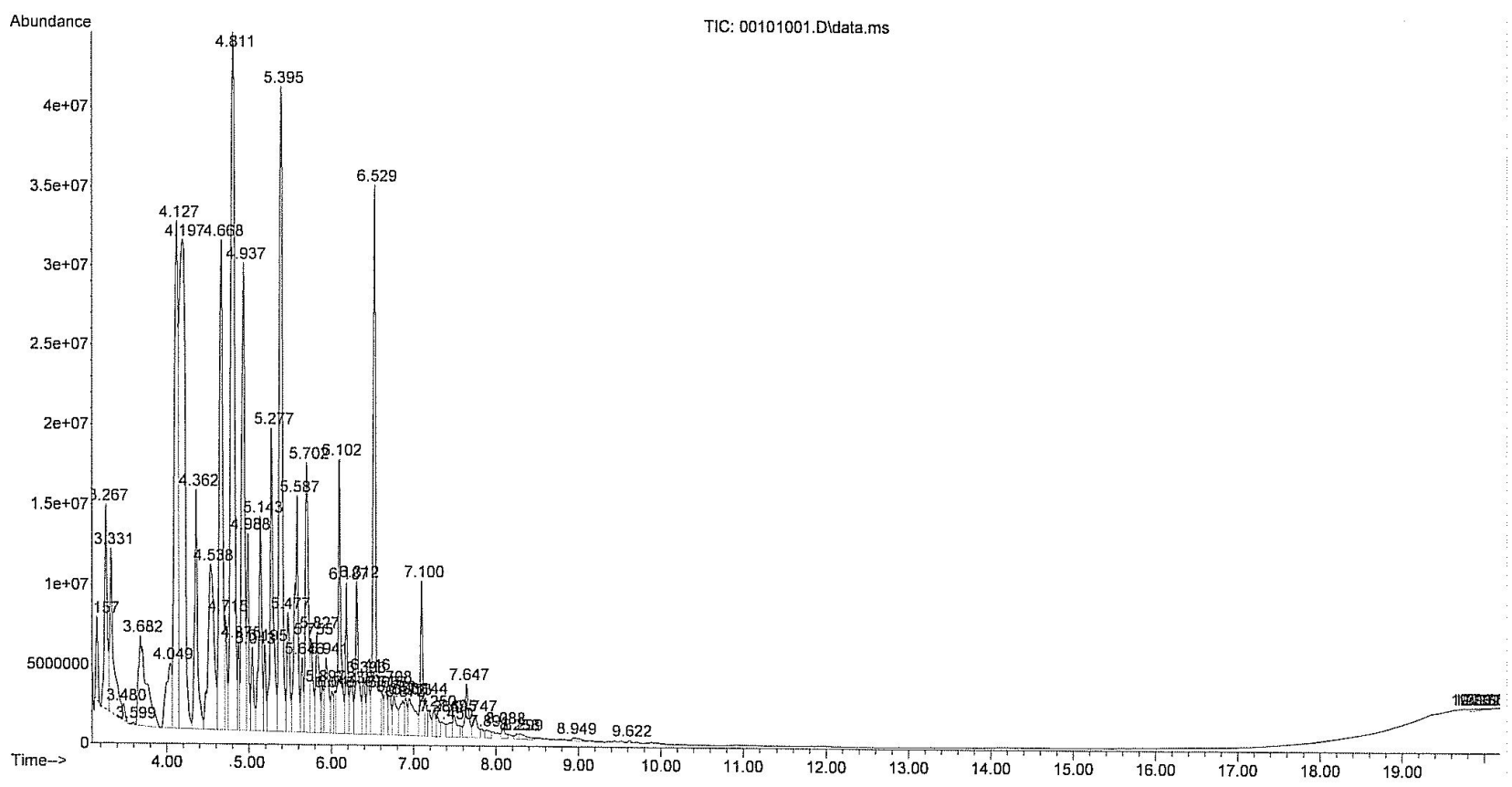

Figure A: Total Ion Chromatogram for experimental Run 1

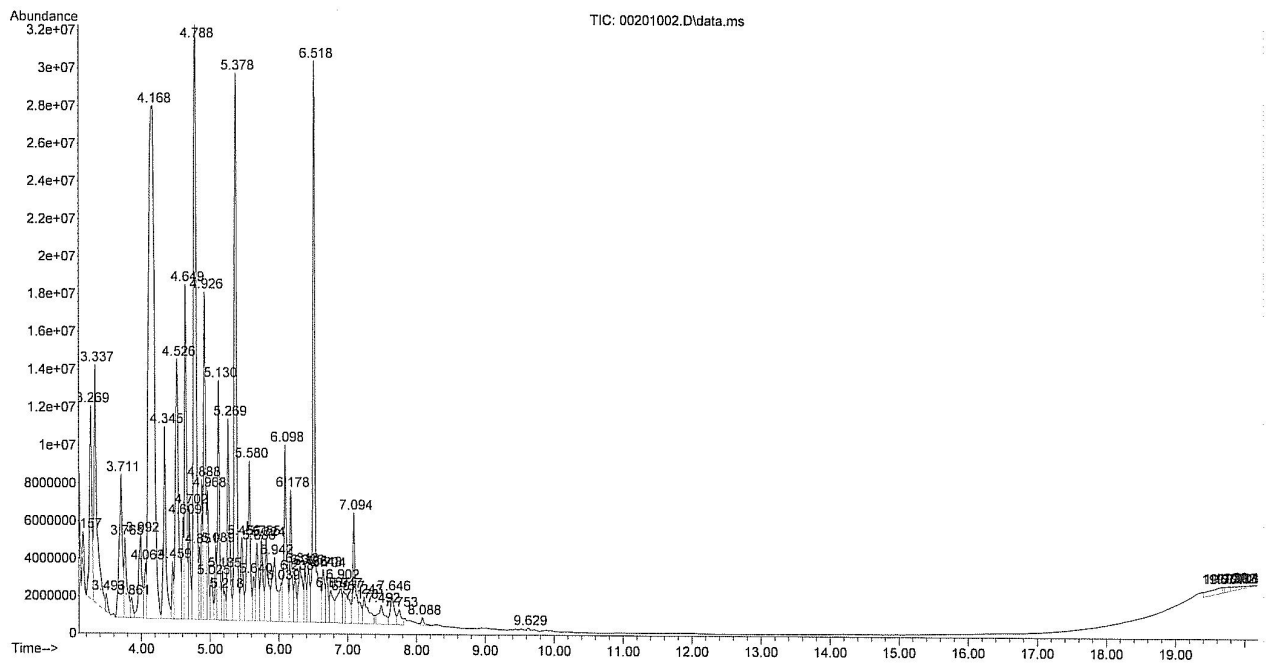

Figure B: Total Ion Chromatogram for experimental Run 2 


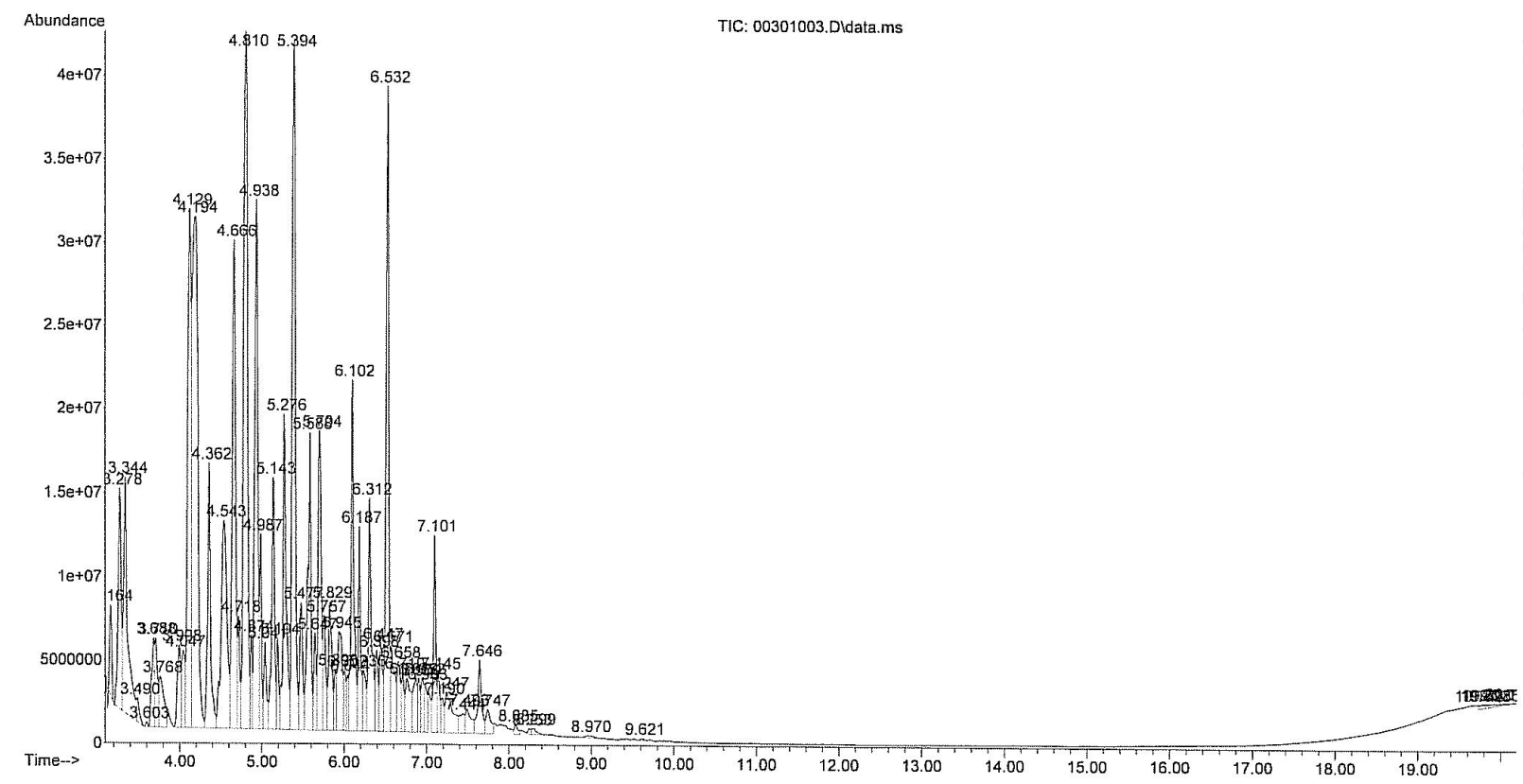

Figure C: Total lon Chromatogram for experimental Run 3 


\section{Appendix F: Calibration curves of selected aromatic hydrocarbons}

Calibration data of Naphthalene

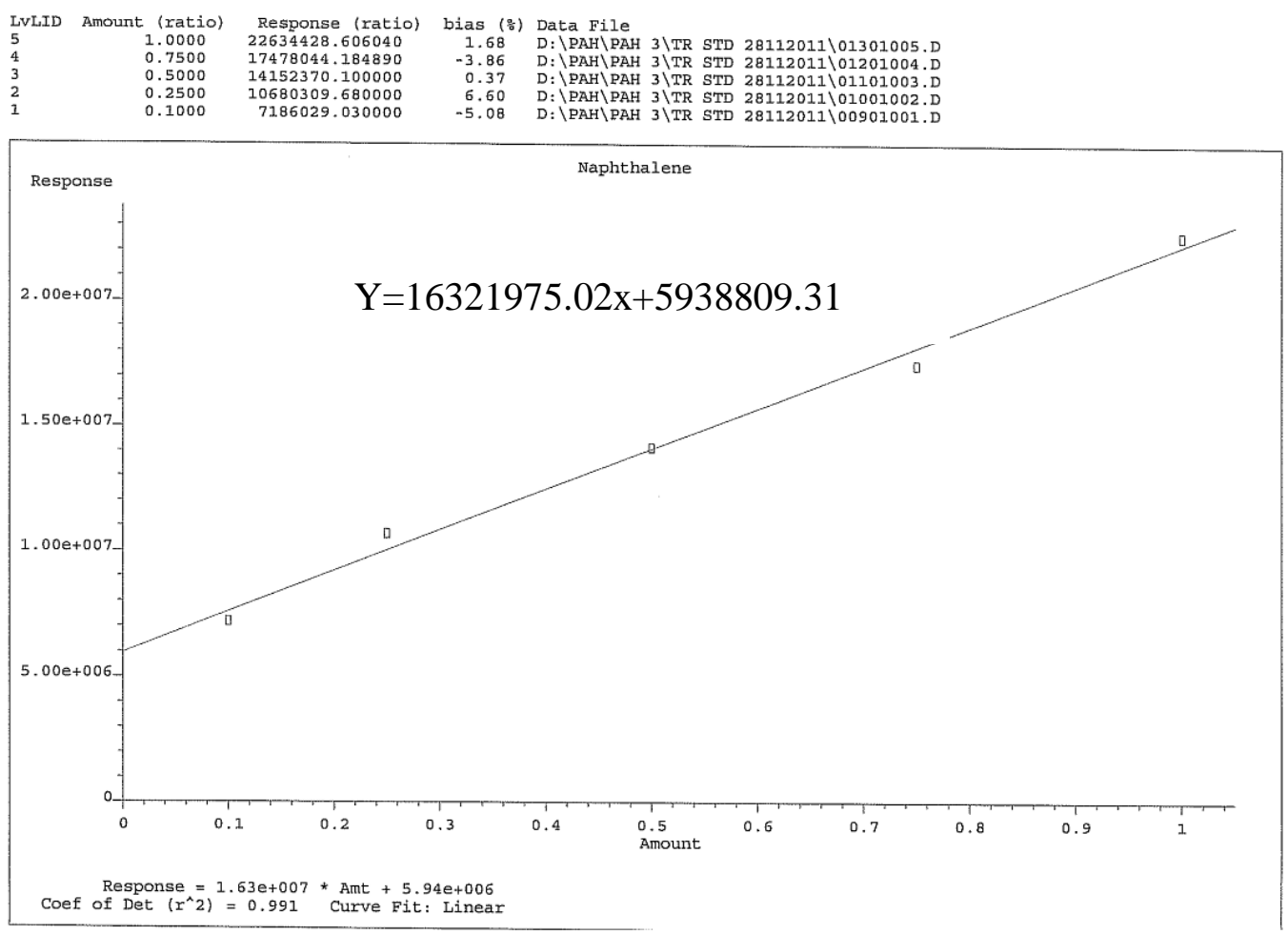


Calibration data of Acenaphthylene

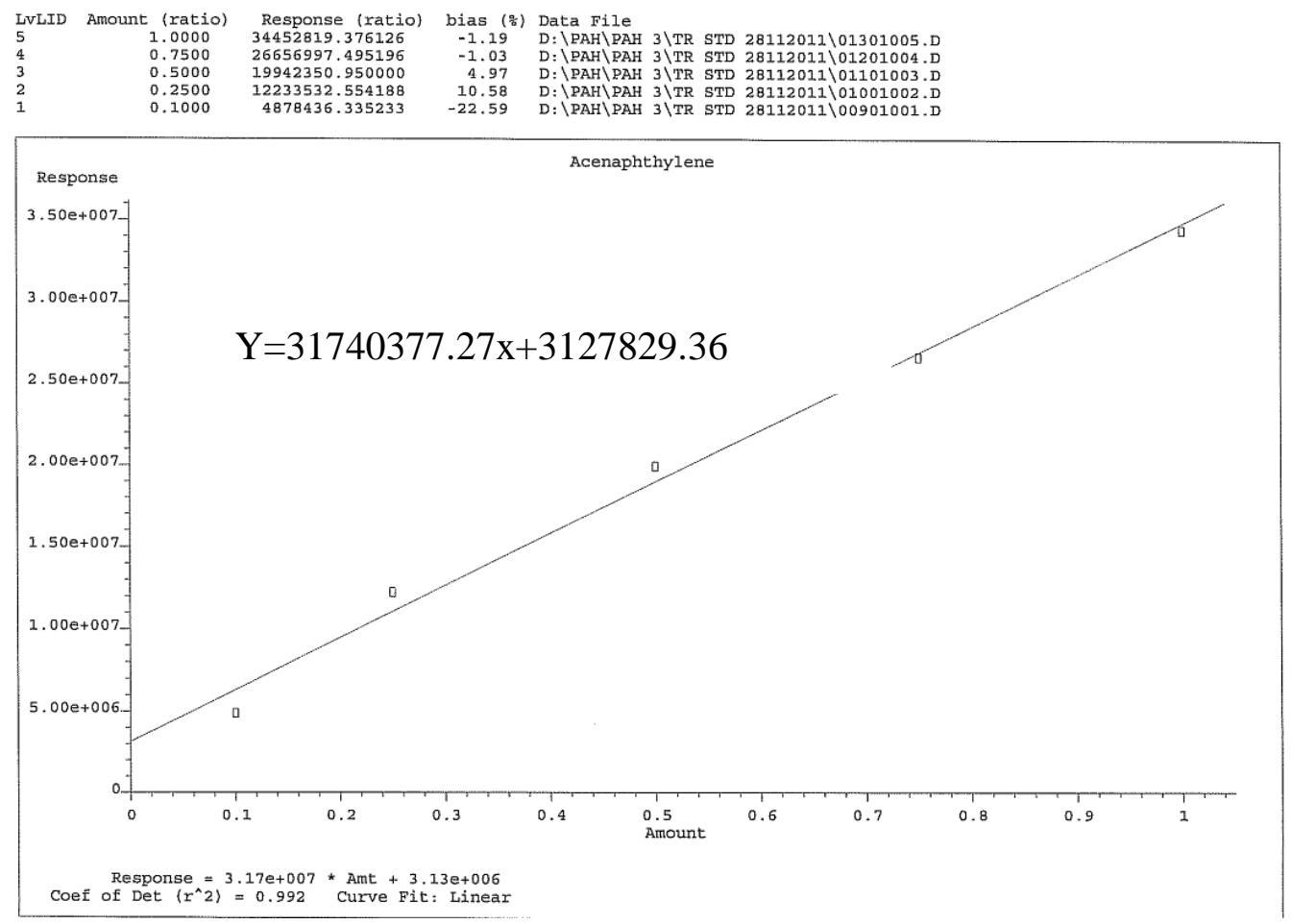


Calibration data of Acenaphthene

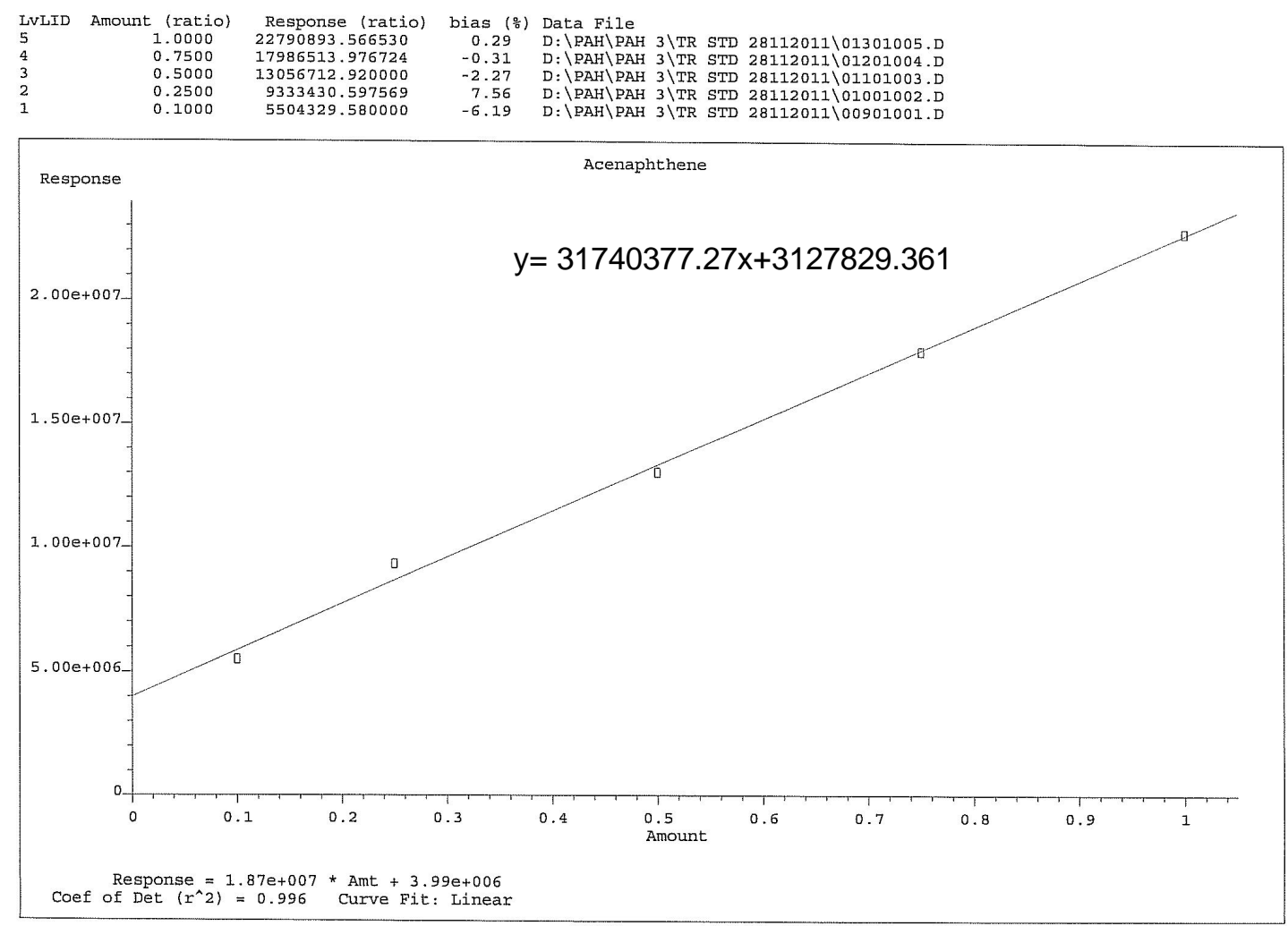

Calibration data of Fluorene
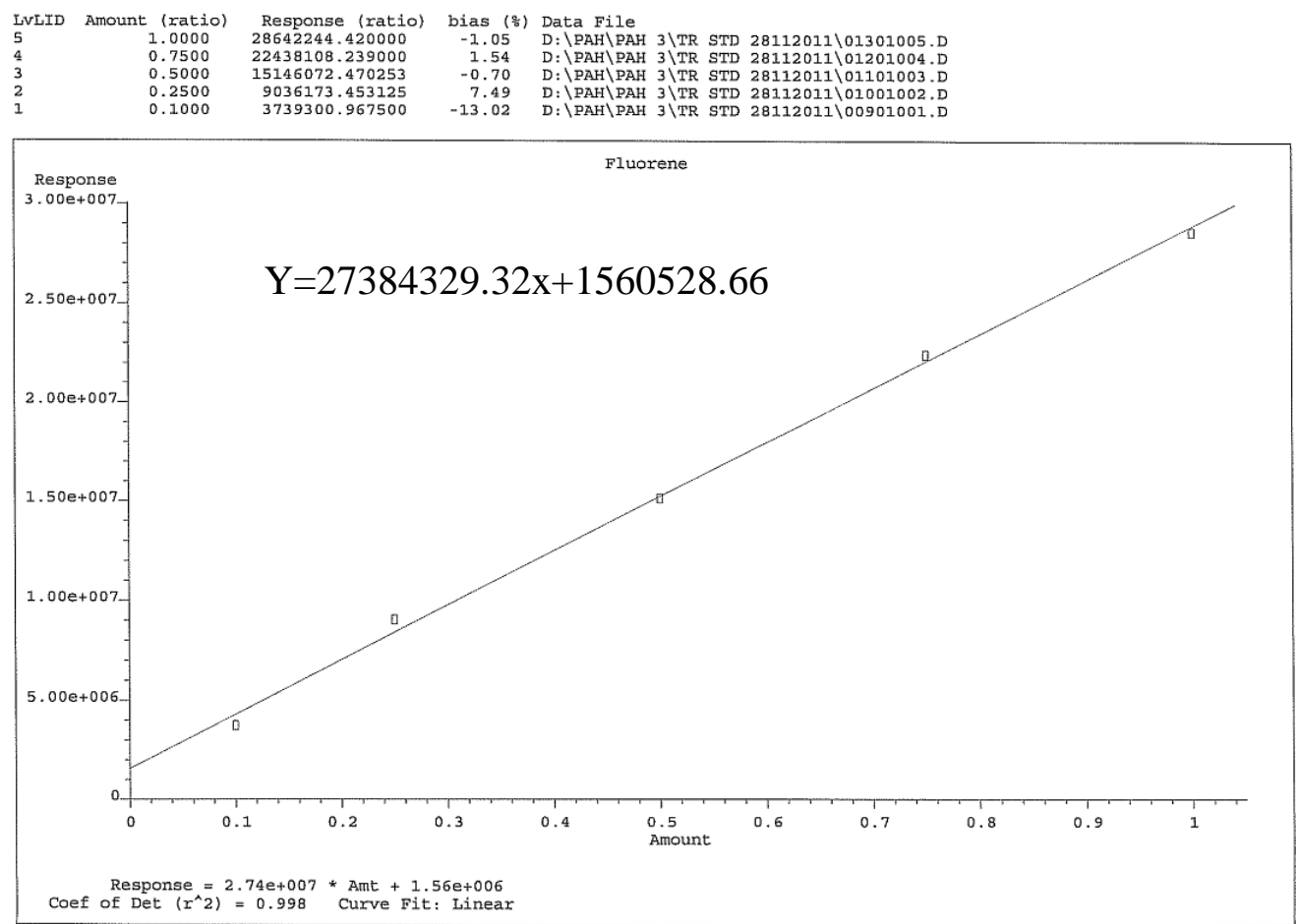
Calibration data of Anthracene

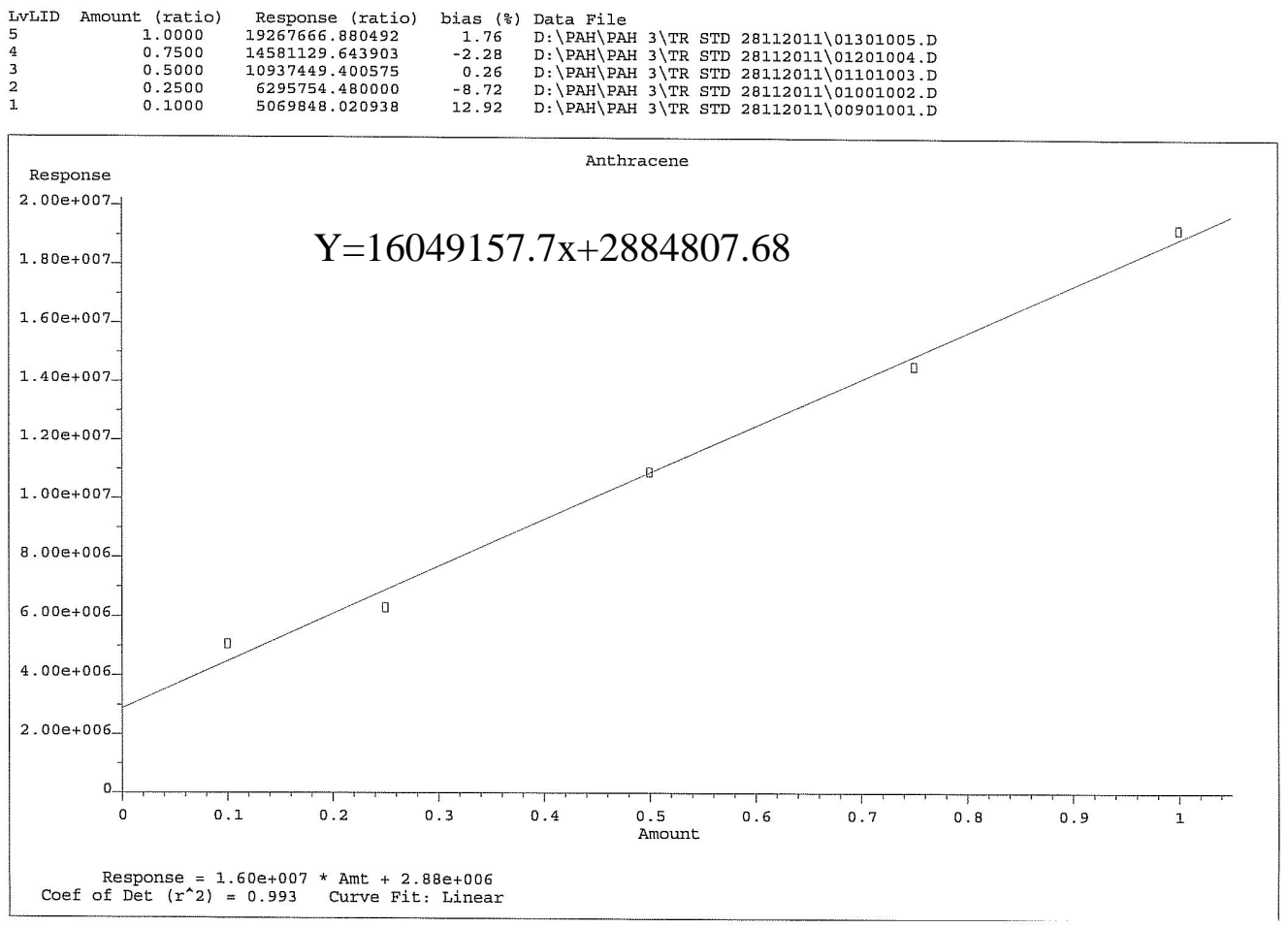

Calibration data of Benzene
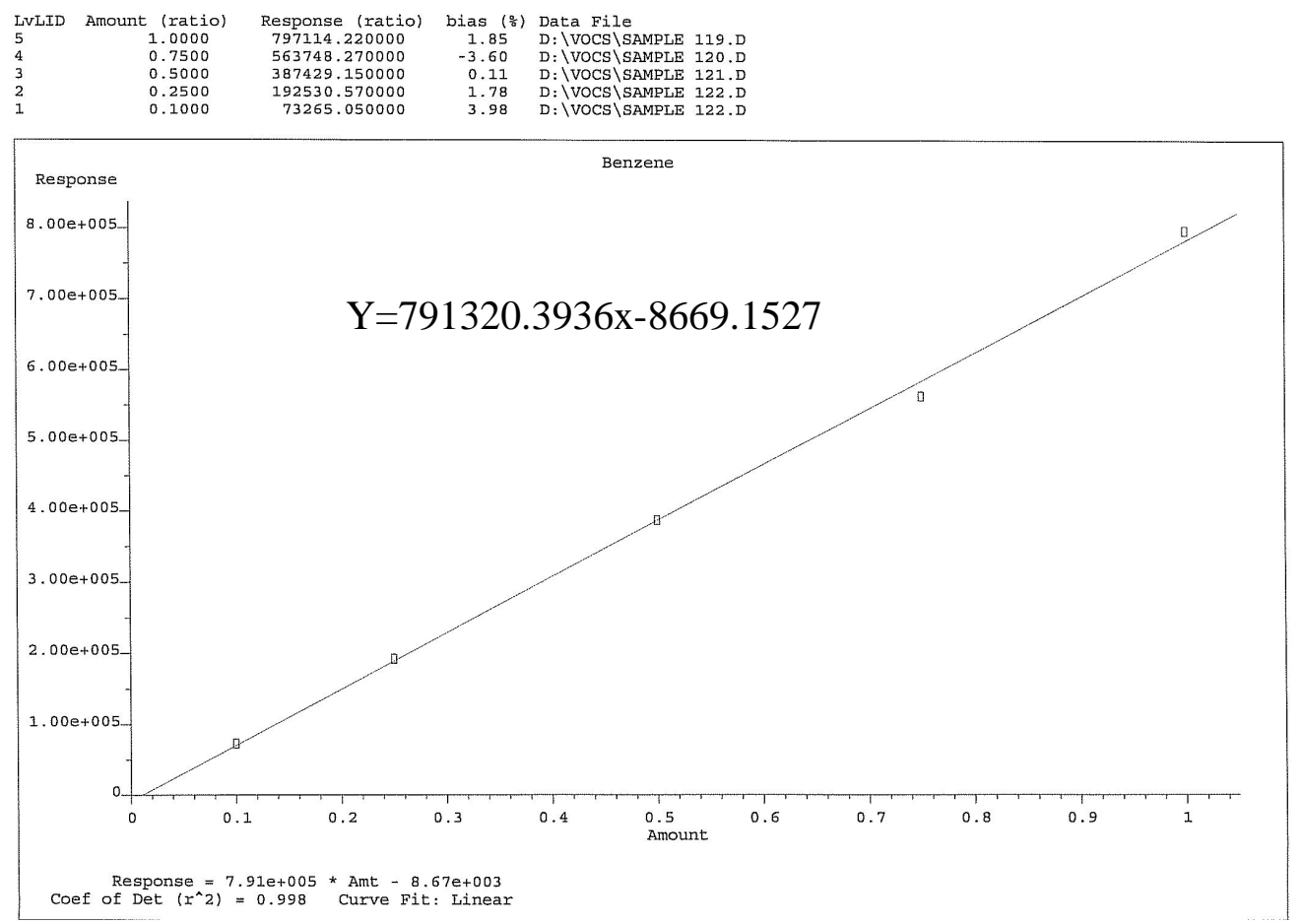
Calibration data of Toluene

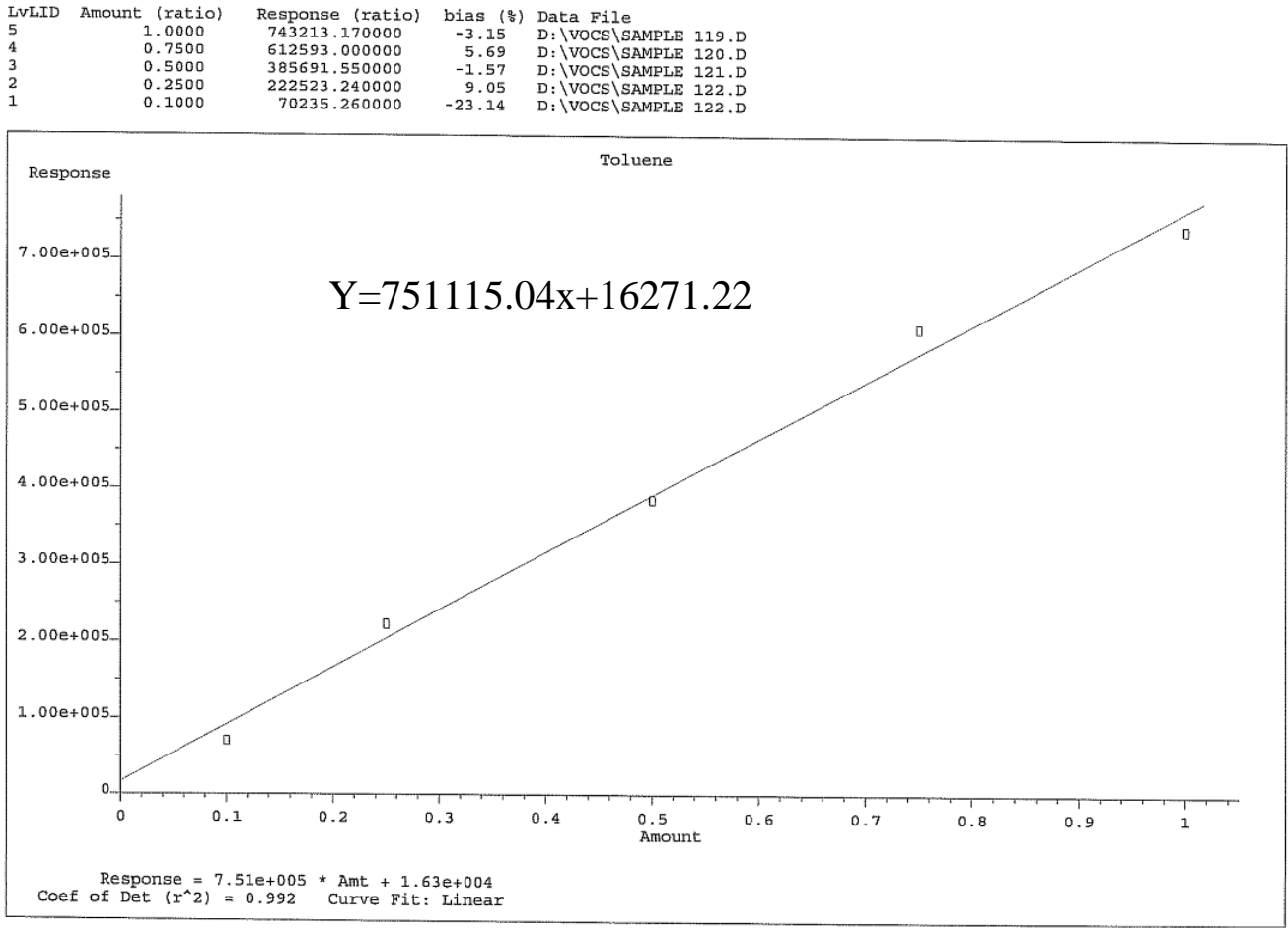

Calibration data of Ethylbenzene
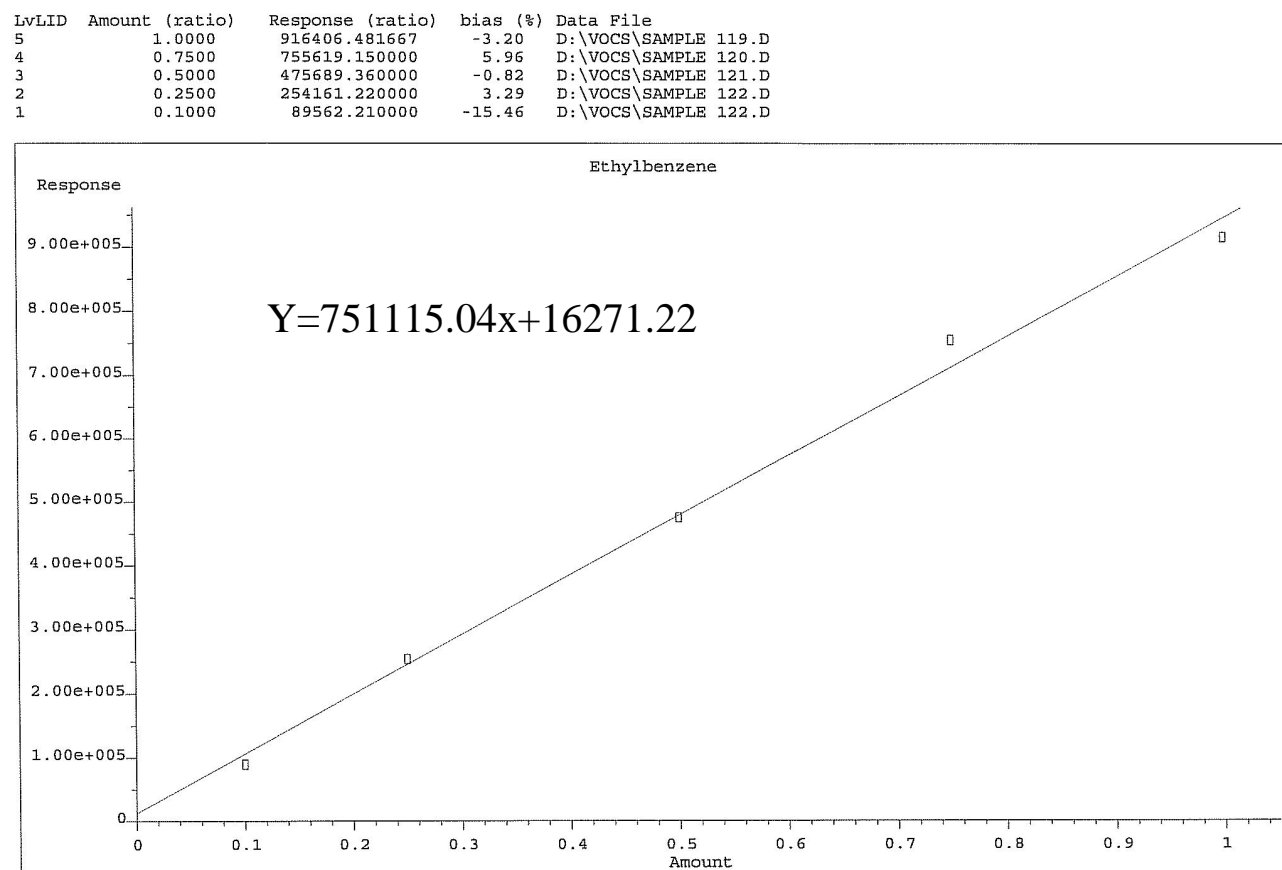

Response $=9.34 \mathrm{e}+005 *$ Amt $+1.25 \mathrm{e}+004$

Coef of Det $\left(r^{\wedge} 2\right)=0.993$ Curve Fit: Linear 
Calibration data of 1,2-Dimethylbenzene

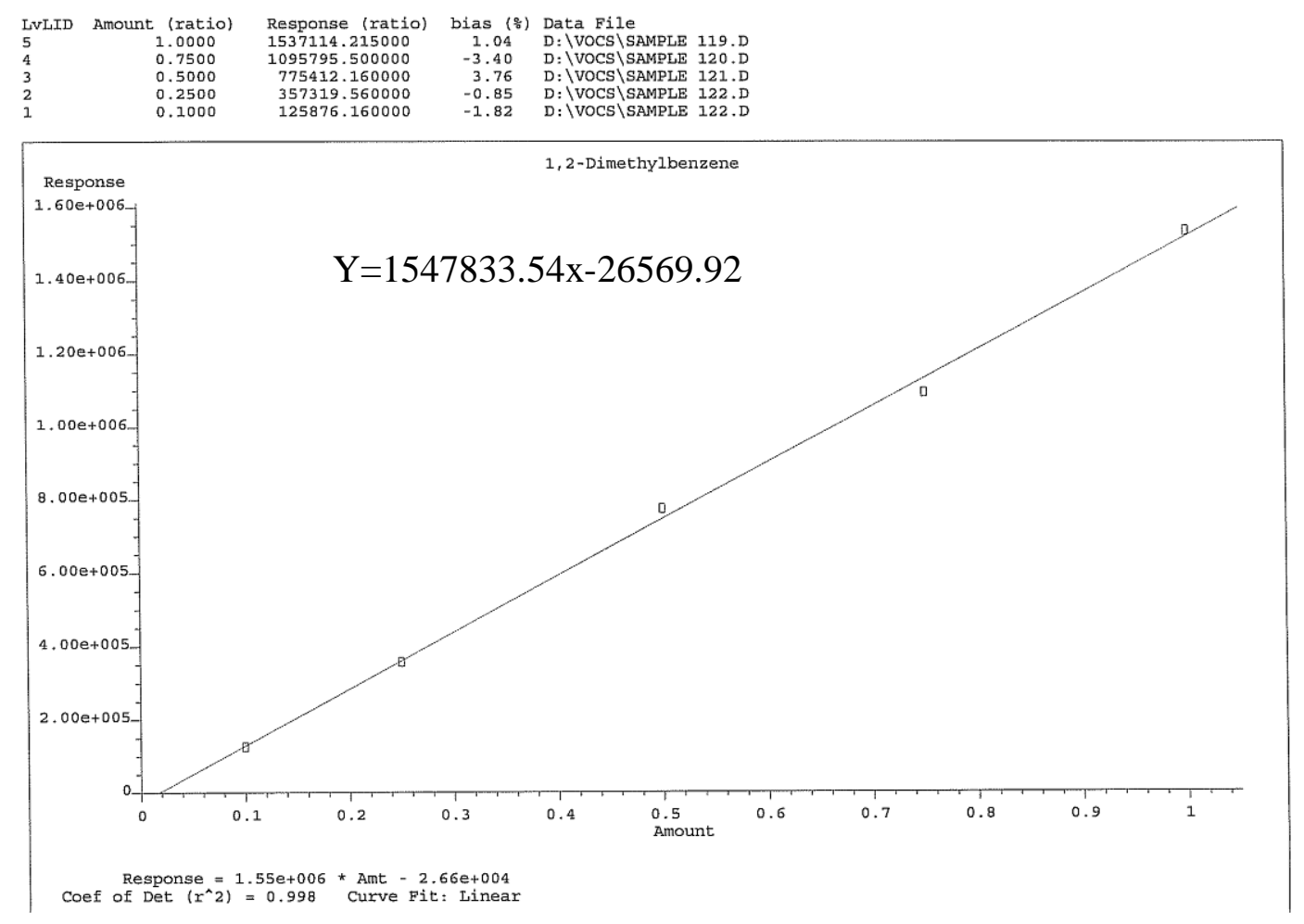

Calibration data of 1,3+1,4-Dimethylbenzene

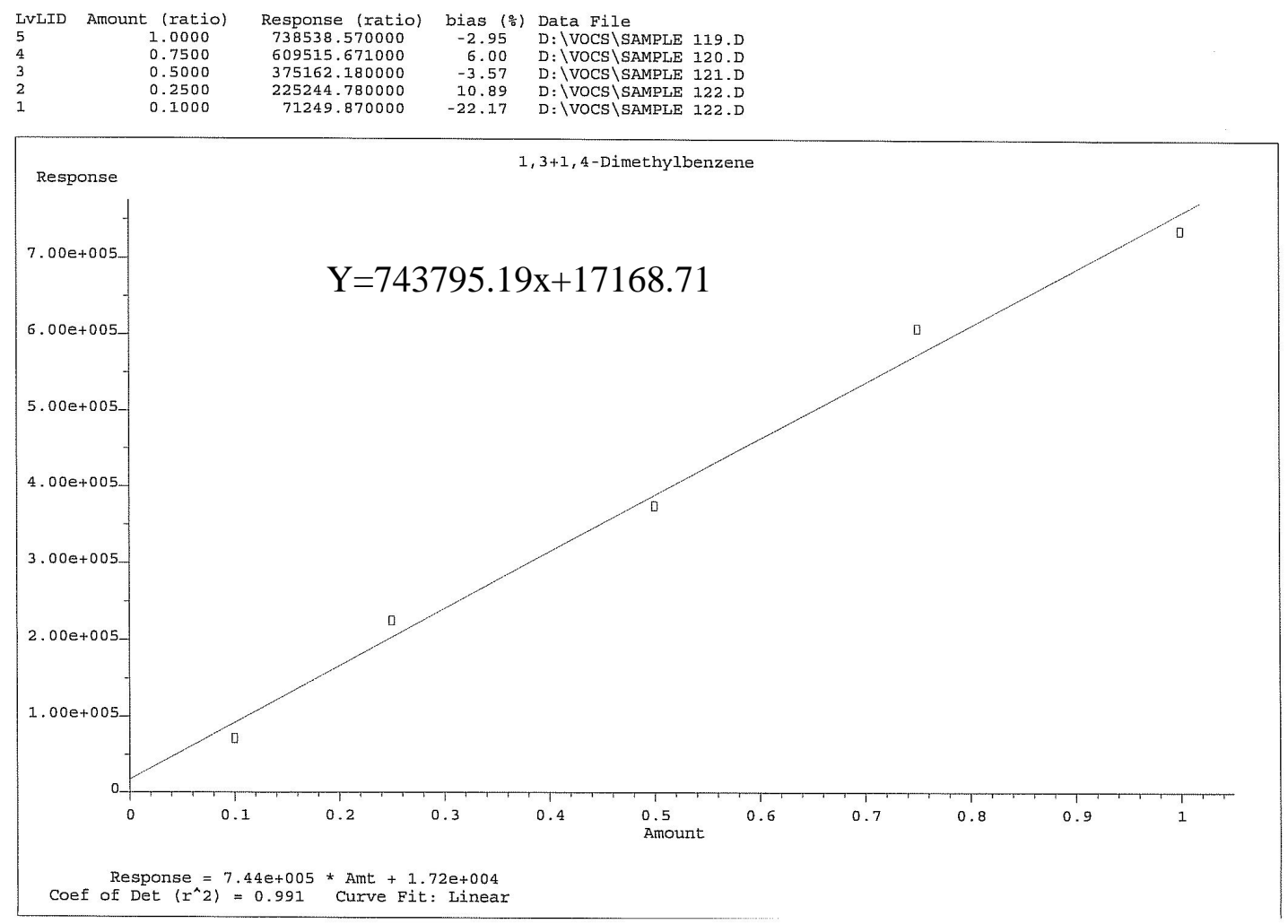

